Universidade de São Paulo

Instituto de Física de São Carlos

Ubaldo Martins das Neves

\title{
Estudo e aplicações do fenômeno de absorção de dois fótons em moléculas azo-aromáticas
}

São Carlos 


\section{Estudo e aplicações do fenômeno de absorção de dois fótons em moléculas azo-aromáticas}

Tese apresentada ao Instituto de Física de São Carlos da Universidade de São Paulo para obtenção do título de Doutor em Ciências: Física Aplicada.

Área de concentração: Óptica não linear Orientador: Cleber Renato Mendonça

São Carlos 2008 

AUTORIZO A REPRODUÇÃO E DIVULGAÇÃO TOTAL OU PARCIAL DESTE

TRABALHO, POR QUALQUER MEIO CONVENCIONAL OU ELETRÔNICO, PARA FINS DE ESTUDO E PESQUISA, DESDE QUE CITADA A FONTE.

Ficha catalográfica elaborada pelo Serviço de Biblioteca e Informação IFSC/USP

Neves, Ubaldo Martins das

Estudo e aplicações do fenômeno de absorção de dois fótons em moléculas azo-aromaticas./Ubaldo Martins das Neves; orientador Cleber Renato Mendonça.- São Carlos, 2008.

p.

Tese (Doutorado em Ciências - Área de concentração: Física Aplicada ) - Instituto de Física de São Carlos da Universidade de São Paulo 1. Armazenamento óptico 2. Absorção de dois fótons 3. Compostos azo-aromáticos. I. Título. 


\section{Dedicatória}

A grandeza de um ser humano pode ser notada pelas suas idéias, sentimentos e ações. Dedico essa tese a dois grandes seres humanos: Ercílio, meu pai e Tereza, minha mãe. Obrigado pelas lições de amor, respeito e dignidade. 


\section{Agradecimentos}

Primeiramente gostaria de agradecer meu amigo e orientdor, Dr. Cleber Renato Mendonça, pelos ensinamentos pessoais e profissionais.

Agradeço também à todos os amigos do Instituto de Física de São Carlos, entre eles Leonardo Castelano, Marcos, Newton Neto, Daniel Silva, Daniel Corrêa, PH, Érick, Jonathas, Pablo, Franzen, Leonardo de Boni, Átila, Jairo, Ilde, Ismael, Renato, Alessandra, Walter, André, Zílio, Samuel e Lino pela amizade e contribuições diversas.

Ao IFSC pelas oportunidades de desenvolvimento e ao CNPQ pela bolsa de doutorado.

Agradeço também aos colegas do grupo de polímeros, principalmente à Débora Balogh pelas contribuições experimentais.

Às minhas queridas irmãs, Cristiana, Rosana, Adriana, Suzana e Juliana companheiras para sempre.

Às tias Cida e Luzia e minha sogra Geni pela amizade, ajuda e carinho nos momentos difíceis.

Ao senhor Menezes pela amizade e grande otimismo.

À Mariana pela amizade e sua disposição constante em ajudar.

À professora Ângela Giampedro pela grande colaboração.

À minha esposa Anne pela compreensão, carinho, amor e força sempre.

Às minhas queridas filhas Ana Carolina e Ana Júlia, por encherem minha vida de alegria, amor e agitação. 


\section{Resumo}

Neste trabalho estudamos o processo de absorção de dois fótons em compostos azoaromáticos, abordando tanto aspectos fundamentais quanto aplicados. Moléculas azo-aromáticos têm recebido especial atenção nos últimos anos devido as suas potencias aplicações em dispositivos para armazenamento óptico de informação, modulação da luz e geração de relevos em superfície, processes estes associados ao mecanismo de foto isomerização. Os trabalhos apresentados nessa tese tiveram como principal foco explorar o fenômeno de absorção de dois fótons, utilizando a propriedade de foto-isomerização das moléculas azoaromáticas. Nosso objetivo foi estudar as vantagens que podem ser obtidas pela utilização de pulsos intensos de luz, que interagem de maneira não linear com a matéria, para desenvolver aplicações utilizando compostos azo-aromáticos. Inicialmente, estudamos o processo de absorção de dois fótons em uma nova família de compostos azo-aromáticos, denominados Salen Dyes. Investigamos a influencia da presença de íons metálicos no processo de absorção de dois fótons dessas moléculas. Nossos resultados mostraram que, devido a ausência de conjugação entre as estruturas azo-aromáticas conectadas pelo metal, este tem pouca influência no processo não linear estudado. Pelo uso de um modelo de soma de estado para a seção de choque de absorção de dois fótons, fomos capazes de determinar os momentos de dipolo de transição destas moléculas. Em seguida, implementamos uma técnica para estudar o processo de armazenamento óptico, induzido através da orientação molecular dos compostos azo-aromáticos, via absorção de dois fótons. Observamos que de fato é possível se observar birrefringência induzida por dois fótons nestas moléculas, a qual esta confinada ao volume focal, conforme demonstrado pela obtenção de armazenamento tri-dimensional. Finalmente, exploramos o processo de controle coerente via formatação de pulsos ultra-curtos para manipular o processo de birrefringência 
induzida por dois fótons em compostos azo-aromáticos. Foi demonstrado que apenas a através da manipulação da fase do pulso ultra-curto, é possível modular a birrefringência induzida em filmes de compostos azo-aromáticos.

Palavras chave: Absorção de dois fótons, armazenamento óptico e compostos azo-aromáticos. 


\section{Abstract}

Here we investigated fundamental and applied aspects of the two-photon absorption process in azoaromatic compounds. Azoaromatic molecules have been studied in the last few years due to their applications in optical storage devices, light modulators and surface relief gratings, processes related to the photo-isomerization mechanism. The main focus of the results presented in this thesis was to explore the two-photon absorption process, taking advantage of the intrinsic photo-isomerization of the azo-aromatic chromophores. Our main goal was to study the advantages of utilizing intense pulses, which promote nonlinear excitation, to develop application with azo-aromatic compounds. Initially, we studied the two-photon absorption process in a new class of azo-aromatic compounds, named Salen Dyes. We investigated the influence of metal ions, presented in the Salen Dyes structure, on the two-photon absorption spectrum. Our results revealed that the metals have practically no influence in the nonlinear optical properties due to the lack of conjugation between the azo-moieties in the Salen Dyes. Through a theoretical model based on a sum-over-states calculation, we were able to determine the transition dipole moment of these molecules. Subsequently, we implemented a technique to study the twophoton induced birefringence, resulting from the molecular re-orientation, in azo-aromatic compounds. We observed that the two-photon induced birefringence is confined to the focal volume, as demonstrated in a three-dimensional optical storage experiment. Finally, we used coherent control processes to manipulate the two-photon induced birefringence in azo-compounds. It was demonstrated that it is possible to modulate the optically induced birefringence by manipulating the phase of the ultra-short pulses, via pulse shaping techniques. 
Keywords: Two-photon absorption, optical storage and azoaromatic compounds. 


\section{Lista de Figuras}

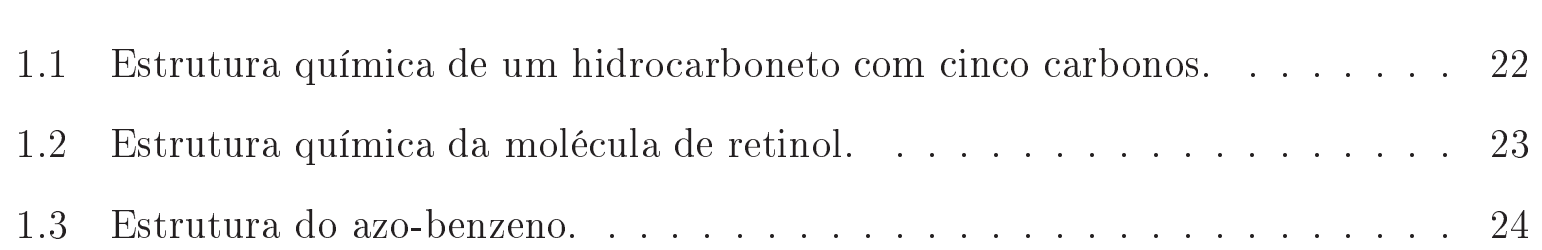

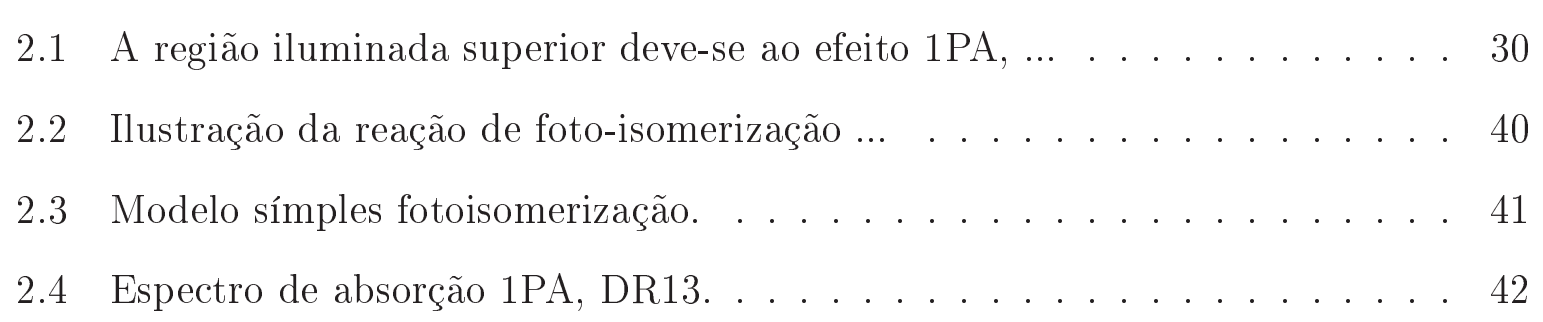

3.1 Fotografia fluorescência 2PA. . . . . . . . . . . . . . . . . . 44

3.2 Estrutura moléculas de Salen Dve. . . . . . . . . . . . . . . . . 44

3.3 Transmitância Normalizada, exemplo de varredura Z . . . . . . . . . . . 46

3.4 Aparato varredura Z. . . . . . . . . . . . . . . . . . . . . 48

3.5 Espectros $1 \mathrm{PA}$ Salen Dve. . . . . . . . . . . . . . . . . . . . . 48

3.6 Resultado do experimento de varredura-Z. Salen Dve. . . . . . . . . . . . . 49

3.7 Curvas varredura Z. Vanádio . . . . . . . . . . . . . . . . 51

$3.82 \mathrm{PA}$ secão de choque . . . . . . . . . . . . . . . . . . . . . . 52

3.9 DR1 no Salen Dve . . . . . . . . . . . . . . . . . . . . . . . 53

3.10 Espectro da TN. . . . . . . . . . . . . . . . . . . 54

3.11 Ajuste da equacão usando SOS. . . . . . . . . . . . . . . . . . . . . . . . . 56

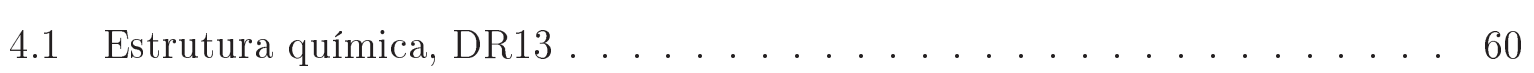

4.2 Ilustracão dipolos moleculares . . . . . . . . . . . . . . . . . . . . . . . . . 61

4.3 Espectro 1PA. filme PMMA-DR13. . . . . . . . . . . . . . . . 62

4.4 Aparato para birrefringência. . . . . . . . . . . . . . . . . . . 64 


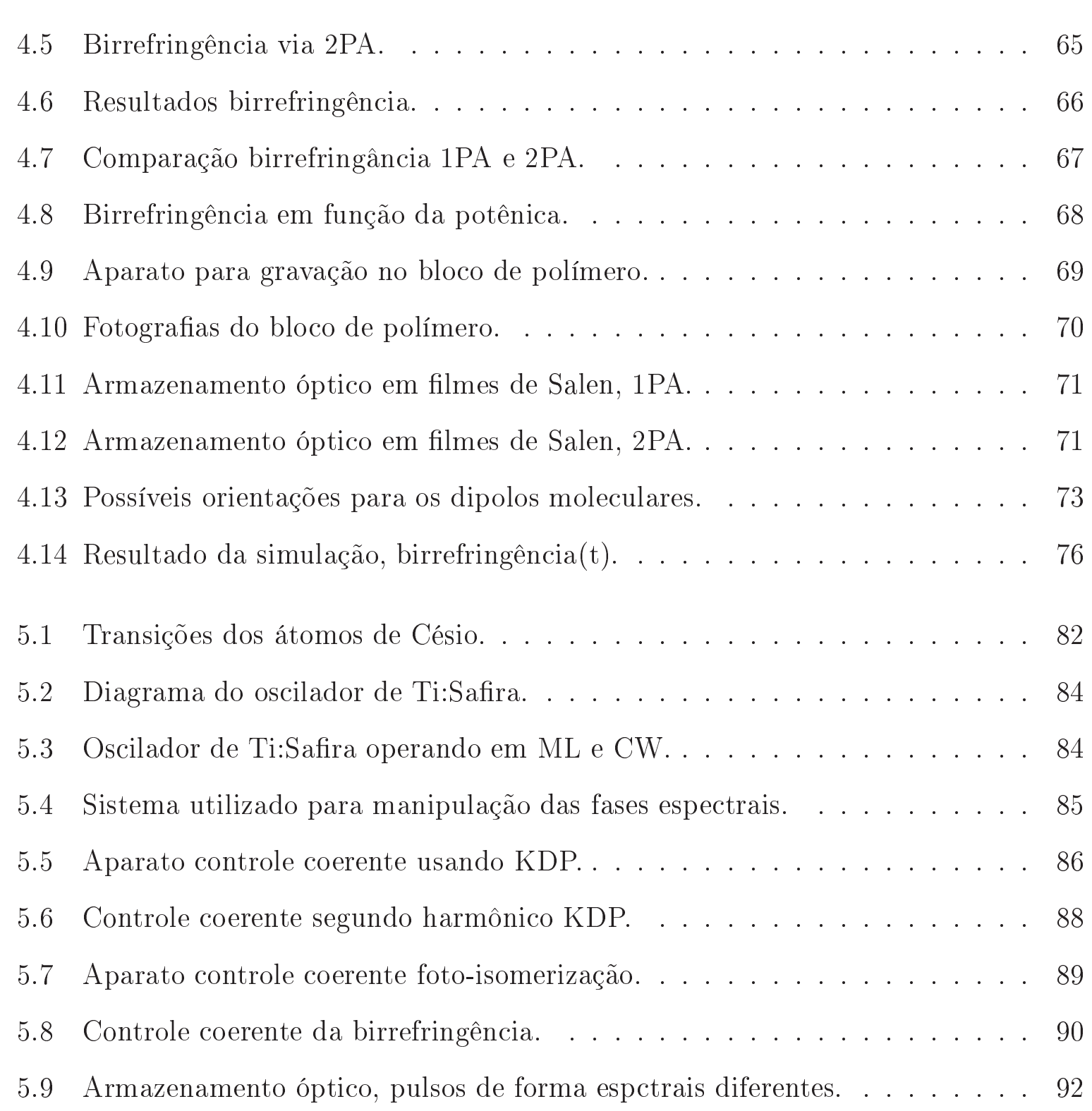




\section{Lista de Tabelas}

3.1 Momentos de dipolo experimentais e calculados Salen . . . . . . . . 57 


\section{Sumário}

Dedicatoria $\quad 5$

$\begin{array}{ll}\text { Agradecimentos } & 7\end{array}$

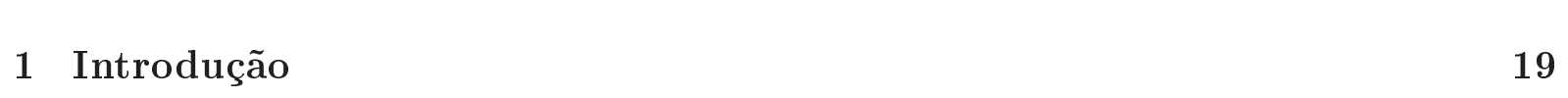

1.1 Óptica não linear e fotônical . . . . . . . . . . . . . . . . . . . . . 19

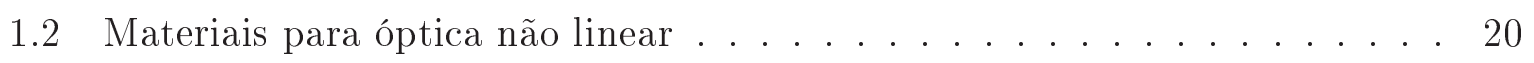

1.3 As ligacões $\pi$ e sua importância nas propriedades ópticas dos materiais . . 21

1.4 As moléculas azo-aromáticas e a estrutura da tese . . . . . . . . . . . . . . 24

2 Óptica não linear. absorcão de dois fótons e foto-isomerizacão 27

2.1 Interpretacão dos fenômenos ópticos não lineares . . . . . . . . . . . . . . . 27

2.2 A absorcão de dois fótons pela matérial . . . . . . . . . . . . . . . . . 29

2.2.1 Sobre a teoria absorcão de dois fótons pela matéria . . . . . . . . . 31

2.2.2 A absorcão de dois fótons como funcão de $d$. . . . . . . . . . . 32

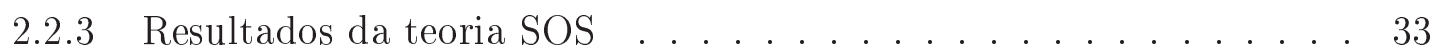

2.3 Sobre a medida experimental da secão de choque de absorção de dois fótons 36

2.4 Isomerização via absorção de um ou dois fótons . . . . . . . . . . . . . . . 40

3 O espectro de absorcão de dois fótons das moléculas de Salen Dve 43

3.1 As moléculas de Salen Dve . . . . . . . . . . . . . . . . . . . 43

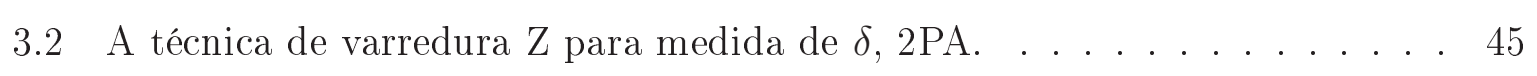

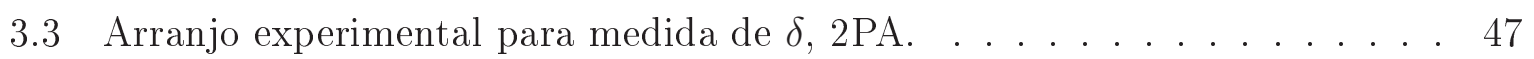

3.4 O espectro de absorcão de dois fótons das moléculas de Salen Dve . . . . . 47

3.4.1 Obtencão da secão de choque a partir da curva de varredura-Z . . . 50 
3.4.2 O espectro de absorcão de dois fótons das moléculas de Salen . . . . 51

3.4.3 Comparacão entre os espectros do Salen Dve e DR1 . . . . . . . . . 53

3.5 Interpretacão dos resultados para $\delta$ segundo o modelo SOS. . . . . . . . . . 54

3.6 Conclusões . . . . . . . . . . . . . . . . . . . . . . . . . . . 58

4 Armazenamento óptico via 2PA em filmes contendo DR13 e Salen Dye 59 4.1 Introducãd . . . . . . . . . . . . . . . . . 59

4.2 Gravacão e leitura de informacões utilizando materiais azo-aromáticos . . . 60

4.3 Producão e medida da birrefringência nos filmes . . . . . . . . . . . . . . . 62

4.3.1 Preparacão do filme. . . . . . . . . . . . . . . . . . 62

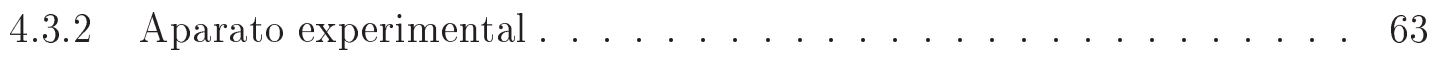

4.3.3 Resultados das medidas de birrefrigêncial. . . . . . . . . . . 65

4.4 Uma aplicacão de armazenamento óptico tridimensional . . . . . . . . . . . 67

4.4.1 A producão do bloco de polímero . . . . . . . . . . . . . 68

4.4.2 Gravacão da informacão no interior do bloco . . . . . . . . . . . . . 69

4.5 Armazenamento óptico em filmes de Salen em PMMA. . . . . . . . . . . . 69

4.6 Modelo simples para a evolucão temporal da birrefringência. . . . . . . . . 72

4.7 Conclusões . . . . . . . . . . . . . . . . . . . . . . . 77

5 Controle coerente da taxa de foto-isomerizacão $\quad 79$

5.1 Introducão ao controle coerente . . . . . . . . . . . . . . . . . . . . . 79

5.2 Controle coerente da absorcão de dois fótons $\quad$. . . . . . . . . . . . . . 81

5.3 O sistema de producão e manipulação dos pulsos de luz . . . . . . . . . . 83

5.4 O experimento de controle . . . . . . . . . . . . . . 86

5.4.1 Controle coerente da producão de segundo harmônico . . . . . . . 86

5.4.2 O experimento de controle coerente da taxa de foto-isomerizacãd . . 89

5.5 Conclusõed . . . . . . . . . . . . . . . . . . . 92

6 Conclusões Gerais e Perspectivas $\quad 95$

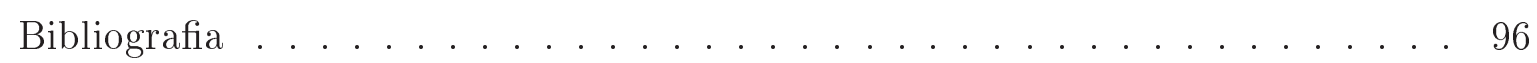




\section{Capítulo 1}

\section{Introdução}

O objetivo desse capítulo inicial é introduzir o leitor aos temas tratados nessa tese de doutorado. Apresentamos a característica principal que possibilita a utilização de materiais moleculares orgânicos em aplicações de óptica linear e não linear: a deslocalização eletrônica. Também é apresentado nesse capítulo o importante fenômeno de foto-isomerização, uma característica importante dos sistemas moleculares estudados com potencial para aplicações em dispositivos ópticos. No final do capítulo são descritos, resumidamente, os estudos realizados e a organização da tese é apresentada.

\section{1 Óptica não linear e fotônica}

Fotônica é uma área multidisciplinar da ciência moderna que está em grande ascensão. Está recebendo muita atenção por parte dos cientistas e engenheiros nos últimos anos devidos, principalmente, à sua aplicação direta na tecnologia da informação. A fotônica usa a luz para adquirir, armazenar, transmitir e processar informações, tarefas realizadas pela eletrônica utilizando os elétrons. Como exemplos de aplicações de efeitos não lineares em fotônica podemos citar a capacidade de se alterar a freqüência ou cor de um feixe luminoso, aumentar a energia de um determinado feixe de luz pela ação de outro feixe, chavear a luz, ou alterar suas características de transmissão da luz através de um meio.

Um tema muito importante para o desenvolvimento da Fotônica é a óptica não linear. O intenso campo elétrico de um laser incidindo na matéria faz com que esta responda de maneira não linear, podendo até mesmo produzir novos campos com diferentes proprie- 
dades. Dessa forma, a área da óptica não linear teve um rápido desenvolvimento após o advento do laser. Entre os processos não lineares estudados, um dos mais fascinantes é a geração de segundo harmônico. Nesse fenômeno, observado por Franken e colaboradores [1], radiação de comprimento de onda de 694,3 nm é convertida em radiação de 347,2 nm, isto é, com o dobro da freqüência, após propagação através de um cristal de quartzo. Esse experimento é considerado por muitos cientistas como o nascimento da óptica não linear.

Para a realização dessas tarefas tem-se a necessidade da pesquisa por novos materiais com propriedades especiais lineares e não lineares para a confecção de dispositivos fotônicos de alto desempenho. Os materiais orgânicos tem sido pesquisados nos últimos anos com grande interesse devido às possibilidades que eles oferecem para a produção de dispositivos fotônicos. Dentre as possibilidades temos a capacidade de se alterar a estrutura química das moléculas de forma a otimizar determinado efeito óptico, área conhecida como engenharia molecular. Além disso, é possível a utilização de diversos métodos de preparação de materiais, principalmente na forma de filmes finos. Deve-se salientar também que o custo para produzir materiais orgânicos é mais baixo que o envolvido na produção de materiais cristalinos. Dentro desse contexto, nosso trabalho tem como objetivo produzir e estudar materiais orgânicos para aplicações em óptica.

\subsection{Materiais para óptica não linear}

Basicamente, todo material apresenta comportamento não linear quando submetido a alta intensidade de luz, não importando se está no estado sólido, líquido ou gasoso. No entanto, a intensidade de luz necessária para a produção desses efeitos varia de muitas ordens de grandeza para diferentes materiais. Esse fato motiva pesquisas com o objetivo de produzir materiais que exibam efeitos não lineares cada vez mais intensos com menor intensidade de luz. Para atingir esse objetivo, é importante estudar detalhes das estruturas que constituem os materiais. Esses estudos indicam que a estrutura eletrônica dos átomos ou moléculas tem um papel muito importante nas manifestações não lineares. Além disso, o comportamento dinâmico, detalhes do arranjo geométrico e propriedades de simetria influenciam a resposta não linear do material a ação da luz intensa.

Os materiais mais utilizados em óptica não linear podem ser divididos basicamente em 
duas classes: os materiais moleculares e os materiais volumétricos. Os materiais moleculares, objetos de estudo desse trabalho, consistem em unidades moleculares quimicamente ligadas que interagem entre si no volume do material por interações fracas de van der Waals. Muitos cristais orgânicos e polímeros pertencem a essa classe de material. Para esses materiais, a não linearidade óptica se deve principalmente a estrutura da molécula [2]. Assim, definem-se coeficientes não lineares que dependem das propriedades da molécula isolada, as chamadas hiperpolarizabilidades moleculares, que são os equivalentes moleculares das susceptibilidades ópticas volumétricas. De fato, para os materiais moleculares, existe uma intima relação entre as susceptibilidades volumétricas e as hiperpolarizabilidades das moléculas que constituem o material. Dessa forma podemos otimizar a resposta não linear do material como um todo através da manipulação de determinadas propriedades das moléculas. Para que essas manipulações tenham o efeito esperado, devemos entender a relação entre a estrutura eletrônica molecular e a polarização não linear que pode ser induzida na molécula.

A segunda classe mencionada trata-se dos materiais volumétricos. As não linearidades nesse tipo de material não estão associadas a elétrons que pertencem a apenas uma molécula, mas sim das características eletrônicas da amostra como um todo. São exemplos desse tipo de material as estruturas de poço quântico derivados do GaAs e semicondutores do tipo II-IV como o CdSe. Cristais inorgânicos como o dihidrogênio fosfato de potássio (KDP) e titânio fosfato de potássio (KTP) são também exemplos desse tipo de material.

Comparado com os tradicionais materiais inorgânicos não lineares, é relativamente nova a aplicação de materiais orgânicos em óptica não linear. Entretanto eles já são reconhecidos como materiais de grande potencial para aplicações em óptica não linear.

\subsection{As ligações $\pi$ e sua importância nas propriedades ópticas dos materiais}

A separação conceitual dos diferentes tipos de ligações químicas em estruturas orgânicas facilita bastante o entendimento das propriedades que esses tipos de materiais exibem. Nesse sentido temos, por exemplo, os elétrons $\pi$ que constituem as ligações $\pi$, e os elétrons 
$\sigma$, que constituem as ligações $\sigma$. Um átomo de carbono pode formar quatro ligações covalentes envolvendo os orbitais $2 s$ e $2 p$. Esses orbitais podem ser misturados para formar quatro orbitais do tipo $s p^{3}$, denominados orbitais híbridos. Essa hibridização permite que um átomo de carbono realize quatro ligações simples com outros átomos. Cada uma dessas ligações envolve uma sobreposição entre um orbital híbrido $s p^{3}$ do átomo de carbono e um orbital do átomo ao qual o carbono se liga, que pode ser outro átomo de carbono. Uma característica importante desse tipo de ligação, denominada $\sigma$, é que são direcionadas ao longo do eixo que une os dois átomos, sendo formadas a partir de orbitais do tipo s. Quando um átomo de carbono realiza quatro ligações $\sigma$ envolvendo quatro orbitais $s p^{3}$, sua valência é dita estar completamente satisfeita. A Fig 1.1 apresenta uma estrutura química desse tipo de composto e uma ilustração da ligação $\sigma$ [2]
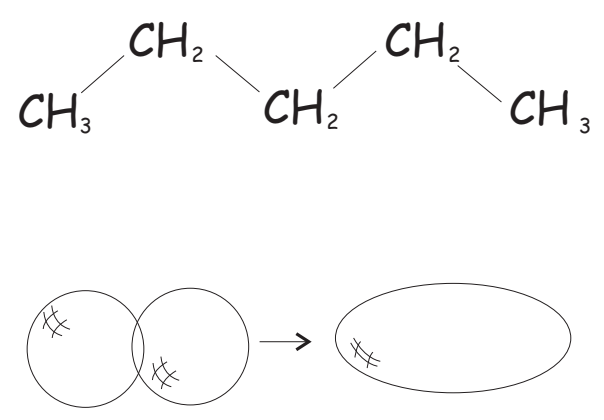

Figura 1.1: Estrutura química de um hidrocarboneto com cinco carbonos e doze átomos de hidrogênio. Todos as ligações entre os átomos são do tipo $\sigma$. A figura na parte inferior ilustra a formação de uma ligação sigma a partir de dois orbitais s.

Estruturas do tipo mostrada na Fig. 1.1]são chamadas de saturadas. O nome saturado refere-se a valência eletrônica do carbono que está completamente satisfeita e não admite mais nenhuma ligação, o carbono está saturado. Como as ligações $\sigma$ são fortes, os elétrons podem ser localizados apenas em regiões próximas aos átomos que estão ligando. Esta pequena mobilidade eletrônica faz com que esse tipo de molécula não apresente uma resposta significativa aos campos luminosos. Dessa forma, seu interesse para a óptica não linear não é muito grande.

Contudo, o carbono pode-se ligar à outros átomos através de outros tipos de misturas de orbitais. Um átomo de carbono pode produzir três orbitais hibridizados do tipo $s p^{2}$, 
que permitem a realização de três orbitais $\sigma$. No entanto, a valência quatro do carbono não é satisfeita com essas três ligações, e o elétron que ocupa o orbital $2 p$ pode ligar-se a outro elétron de outro átomo de carbono $2 p$, produzindo uma ligação denominada $\pi$. Devido a geometria dos orbitais $p$, essa ligação se realiza paralela ao eixo que liga os átomos mas deslocada lateralmente desse eixo lembrando a letra $\pi$, dai o nome da ligação. Essa restrição geométrica faz com que os elétrons $\pi$ não sejam fortemente ligados a um determinado átomo. Dessa forma,oe elétrons $\pi$ possuem relativa liberdade de movimento e podem se distribuir em uma região muito grande da molécula. Esse comportamento deslocalizado das cargas eletrônicas que constituem as ligações $\pi$ faz com que a distribuição de carga nesse tipo de molécula seja bastante susceptível a campos elétricos de luz de diferentes intensidades. Esse fato é que produz os altos valores de susceptibilidades elétricas observadas em moléculas com ligações $\pi$, e leva a efeitos não lineares importantes para muitos tipos de aplicações.
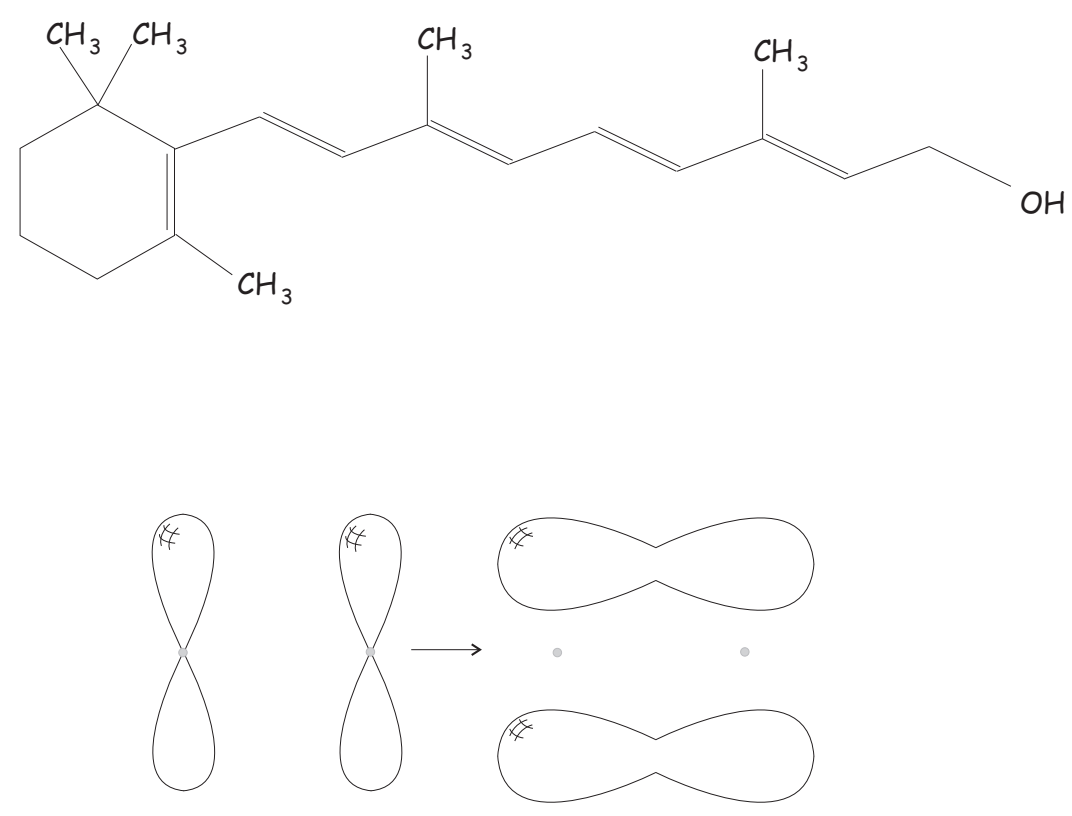

Figura 1.2: Estrutura química da molécula de retinol, mais conhecida como vitamina A, muito importante à saúde do Homem. A molécula possui 10 orbitais $\pi$ conjugados. A conjugação é a causa da molécula absorver energia de fótons no violeta e apresentar coloração amarelada. A figura inferior ilustra a formação da ligação $\pi$. Repare que as ligações $\pi$ se realizam paralelamente a direção que une os dois átomos mas a uma certa distância desta. 
A Fig. 1.2 representa uma molécula com cinco carbonos cujas ligações alternamse entre simples e duplas. Essa tipa de estrutura é denominada conjugada, e apresenta elétrons deslocalizados que levam a polarizabilidades de alta magnitude. Na mesma figura é ilustrada a formação de uma ligação $\pi$ a partir de dois orbitais $p$.

\subsection{As moléculas azo-aromáticas e a estrutura da tese}

As moléculas azo-aromáticas pertencem a uma classe muito importante de substâncias foto-ativas. Essas moléculas foram descobertas em 1858 por Griess, e são muito utilizadas na indústria como pigmentos para tecidos [3]. Elas têm como característica principal à presença de dois radicais aromáticos ligados por dois átomos de nitrogênio, o grupo azo. Esse tipo de molécula, entre outras propriedades interessantes que serão extensamente exploradas nessa tese, possui o caráter de deslocalização eletrônica devido às ligações $\pi$ existentes em sua estrutura. A Fig. 1.3 mostra a estrutura da molécula azo-aromática mais simples, denominada azo-benzeno. Outro a tipo de moléculas azo-aromáticas é formado pela adição de grupos químicos a um ou aos dois anéis aromáticos.

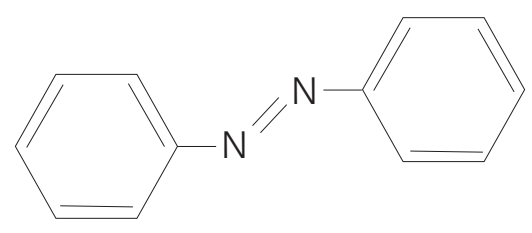

Figura 1.3: Estrutura do azo-benzeno. Os elétrons $\pi$ são deslocalizados em toda extensão da molécula.

As moléculas azo-aromáticas apresentam a propriedade notável de trocar de uma configuração espacial para outra. Essas estruturas são ditas isoméricas e o processo de transformação de uma estrutura para a outra é chamada reação de isomerização. Normalmente a configuração mais estável é a configuração trans e a mais instável é a cis [3, 4]. Essa mudança configuracional espacial pode ser induzida pela luz, o processo é conhecido como foto-isomerização.

Outro fato interessante é que o processo de foto-isomerização é acompanhado de uma 
grande reorientação molecular. Isto é, a molécula após o processo de foto-isomerização apresenta uma orientação espacial diferente da orientação anterior ao processo. Dois mecanismos são aceitos para a foto-isomerização. Um deles, conhecido como mecanismo da rotação propõe que a absorção de luz quebra momentaneamente a ligação $\pi$, permitindo que a molécula gire tendo como eixo a ligação $\sigma$ entre os dois nitrogênios. O segundo mecanismo é conhecido como inversão, e envolve uma re-hibridização do orbital $s p$ provocado pela absorção de luz e conseqüente inversão do anel benzênico [5].

O movimento das moléculas azo-aromáticas provenientes da foto-isomerização permite a aplicação dessas moléculas em dispositivos para armazenamento óptico de informação [6. 7, 8]. Os materiais produzidos para esse tipo de aplicação geralmente usam matrizes poliméricas. Diz-se que o material polimérico é o hospedeiro e as moléculas azo-aromáticas são os hóspedes do material polimérico que é preparado, na maioria das vezes, em forma de filmes finos. A informação é gravada nesses materiais através da orientação das moléculas pela aplicação de luz linearmente polarizada. Essa aplicação é discutida em detalhes no Capítulo 4. Esse fenômeno também permite a criação de relevos em superfícies poliméricas [9]. Outras aplicações de materiais contendo moléculas azo-aromáticas são holografia [10] e chaveamento óptico [1].

A luz utilizada nas aplicações mencionadas acima deve possuir comprimento de onda dentro do espectro de absorção linear da amostra, para ser absorvida e induzir a foto-isomerização. Entretanto, em nossos estudos utilizamos luz de comprimento de onda fora da banda de absorção linear das moléculas azo-aromáticas para produzir o armazenamento óptico. Isto é possível devido à propriedade da matéria de absorver luz de alta intensidade pelo fenômeno de absorção multi-fotônica. Portanto utilizamos lasers com pulsos de femtosegundos e intensidades da ordem de dezenas de $\mathrm{GW} / \mathrm{cm}^{2}$. Nesse sentido, um dos propósitos dessa tese é aplicar o fenômeno de foto-isomerização induzido por luz de comprimento de onda fora da banda de absorção linear das moléculas azo-aromáticas para estudar aplicações de armazenamento óptico de informação. Nesse tipo de aplicação, a luz que induz a foto-isomerização é absorvida pela molécula pelo mecanismo não linear de absorção de dois fótons. Um fator importante nesse tipo de excitação é a possibilidade de localizar o efeito em regiões diminutas de espaço. Essa possibilidade nos permitiu o 
desenvolvimento de um protótipo de dispositivo para armazenamento óptico onde a informação é gravada no interior do material. Essa localização tridimensional aumenta a capacidade de armazenamento óptico em sistemas desse tipo uma vez que até então os estudos envolviam o armazenamento de informação apenas em superfícies (filmes finos). Os resultados desse estudo estão relatados em detalhes no Capítulo 4.

Outro estudo que foi realizado refere-se a um sistema molecular composto de duas unidades azo-aromáticas unidas por um grupo central que pode conter ou não um metal. Esse sistema é denominado Salen. Nossos resultados mostraram que o metal não afeta o processo de absorção de um ou dois fótons do sistema e que esse processo depende apenas dos grupos azo-aromáticos que o constituem. Esse estudo é relatado no Capítulo 3.

O Capítulo 5 refere-se a um estudo sobre o efeito da distribuição espectral dos pulsos de luz no processo de foto-isomerização. Os resultados obtidos indicam que as taxas de foto-isomerização podem ser alteradas apenas alterando as fases das componentes espectrais dos pulsos. O Capítulo final, apresenta as conclusões gerais e perspectivas para desenvolvimentos futuros.

O capítulo seguinte, Capítulo 2, introduz o leitor aos fenômenos ópticos não lineares e, em especial, ao fenômeno de absorção de dois fótons, que é o fenômeno utilizado em todas as aplicações descritas nessa tese. O mecanismo de foto-isomerização das moléculas azo-aromáticas também é tratado nesse capítulo. 


\section{Capítulo 2}

\section{Óptica não linear, absorção de dois fótons e foto-isomerização}

O intuito desse capítulo é apresentar um resumo sobre a teoria dos fenômenos não lineares. Através dessa teoria vamos apresentar a interpretação do fenômeno de absorção de dois fótons, que é o principal fenômeno utilizado nas aplicações que constituem essa tese. O modelo de soma de estados, que será utilizado no Capitulo 4 na interpretação dos resultados de absorção de dois fótons nas moléculas de Salen, é discutido na seção 2.2 .3 Ainda nesse capítulo apresentamos a propriedade de foto-isomerização das moléculas azoaromáticas, extensamente explorada nessa tese em aplicações de memória óptica.

\subsection{Interpretação dos fenômenos ópticos não lineares}

Uma maneira de interpretar os fenômenos ópticos não lineares é utilizando o conceito de polarização. Polarização é uma quantidade vetorial que indica a quantidade líquida de momento de dipolo por unidade de volume. Um material pode possuir uma determinada polarização permanente ou pode adquirir polarização devido a incidência de luz. O campo elétrico oscilante da luz produz uma polarização também oscilante no material. Para baixas intensidades luminosas, a polarização é proporcional a magnitude do campo elétrico. A Eq. 2.1] geralmente é utilizada para expressar esse fato [12].

$$
\vec{P}=\chi^{(1)} \vec{E}
$$


Sob ação de altos campos de luz, como os produzidos por laser, a Eq. 2.1] não concorda com as observações. Termos não lineares para a dependência da polarização com a intensidade do campo elétrico da onda são necessários, conforme mostra a Eq. 2.2] [2].

$$
P=P_{0 i}+\chi_{i j}^{(1)} E^{j}+\chi_{i j k}^{(2)} E^{j} E^{k}+\chi_{i j k l}^{(3)} E^{j} E^{k} E^{l}+\cdots
$$

onde $E^{j}$ é a componente $j$ do campo elétrico aplicado, $\vec{P}_{0 i}$ é a componente $i$ da polarização permanente $\vec{P}_{0}$, e $\chi_{i j}^{(1)}$ é a componente $i j$ do tensor susceptibilidade elétrica linear $\chi^{(1)} \cdot \chi^{(2)}$ é a primeira susceptibilidade não linear ou susceptibilidade de segunda ordem. De um modo geral, $\chi^{(n)}$ é a susceptibilidade elétrica não linear de ordem $n$.

As susceptibilidades lineares e não lineares caracterizam as propriedades ópticas do meio. Se a susceptibilidade $\chi^{(n)}$ de um meio é conhecida, então à princípio, os efeitos ópticos não lineares podem ser preditos. Fisicamente, $\chi^{(n)}$ depende da estrutura microscópica do material e pode ser calculada pela aplicação da mecânica quântica.

Uma representação microscópica dos efeitos da polarização pode ser obtida utilizando o conceito de dipolo elétrico molecular. Um material pode ser polarizado quando submetido a um campo de radiação. Podemos interpretar essa polarização como resultante da ação do campo elétrico oscilante sobre os elétrons que constituem os átomos e as moléculas. Esse campo desloca a nuvem eletrônica da molécula, criando o que podemos chamar momento de dipolo molecular induzido. Esse momento de dipolo, que não é constante no tempo, varia de acordo com a freqüência da radiação incidente e é responsável pela abundância de fenômenos ópticos observados nos materiais.

Se o campo incidente é pequeno em magnitude, a polarização resultante no material também é pequena, e uma relação linear entre o momento de dipolo induzido e o campo elétrico dada por

$$
\overrightarrow{\mu_{i}}(\omega)=\alpha_{i j} \vec{E}_{j}(\omega)
$$

é verificada. A grandeza tensorial $\alpha_{i j}$ é conhecida como a polarizabilidade linear da molécula.

Analogamente ao caso da polarização, podemos expandir o momento de dipolo molecular em termos de potências do campo elétrico. Surgem as chamadas hiperpolarizabilidades 
moleculares [2].

$$
\overrightarrow{\mu_{i}}=\overrightarrow{\mu_{i}^{0}}+\left(\frac{\partial \mu_{i}}{\partial E_{j}}\right) E_{j}+\frac{1}{2 !}\left(\frac{\partial^{2} \mu_{i}}{\partial E_{j} \partial E_{k}}\right) \vec{E}_{j} \vec{E}_{k}+\frac{1}{3 !}\left(\frac{\partial^{3} \mu_{i}}{\partial E_{j} \partial E_{k} \partial E_{l}}\right) \vec{E}_{j} \vec{E}_{k} \vec{E}_{l}+\cdots
$$

ou simplificadamente:

$$
\overrightarrow{\mu_{i}}=\overrightarrow{\mu_{i}^{0}}+\alpha_{i j} \vec{E}_{j}(\omega)+\frac{1}{2 !} \beta_{i j k} \vec{E}_{j}\left(\omega_{1}\right) \vec{E}_{k}\left(\omega_{2}\right)+\frac{1}{3 !} \gamma_{i j k} \vec{E}_{j}\left(\omega_{1}\right) \vec{E}_{k}\left(\omega_{2}\right) \vec{E}_{l}\left(\omega_{3}\right)+
$$

Nessas equações $\overrightarrow{\mu_{i}^{0}}$ representa o momento de dipolo permanente da molécula, $\alpha_{i j}$ é a primeira hiperpolarizabilidade, $\beta_{i j k}$ é a segunda e $\gamma_{i j k}$ é a terceira hiperpolarizabilidade. Essas grandezas são tensores já que relacionam vetores a outros vetores.

Os parâmetros $\beta_{i j k}, \gamma_{i j k}$ e de ordens mais elevadas descrevem os efeitos não lineares, que alteram as características do material e do próprio campo incidente. Os processos ligados a $\beta$ são chamados processos de segunda ordem, e compreendem efeitos como geração de segundo harmônico, soma e diferença de freqüências e geração óptica paramétrica. É interessante mencionar que esses tipos de efeitos, descritos por $\beta$, ocorrem apenas em materiais não centros-simétricos. Além disso, efeitos ligados a potências pares da expansão do momento de dipolo, Eq2.5, não ocorrem em materiais centro-simétricos.

A hiperpolarizabilidade $\gamma$, responsável por efeitos de terceira ordem, tem especial interesse nessa tese pois é interpretada como fonte do processo de absorção de dois fótons, além de outros fenômenos como a geração de terceiro harmônico, mistura de quatro ondas degeneradas e chaveamento Kerr óptico. Na seção 2.2.2 vamos apresentar a conexão ente a probabilidade por tempo de uma molécula absorver dois fótons a hiperpolarizabilidade $\gamma$.

\subsection{A absorção de dois fótons pela matéria}

Em um processo ordinário, a luz pode ser absorvida pela matéria dependendo do seu comprimento de onda. Por exemplo, corantes tem a capacidade de absorver vários comprimentos de onda. Essa propriedade de absorção de luz é quantificada, corriqueiramente, através do espectro de absorção do material. Se a luz tem comprimento de onda dentro 
da banda de absorção do material, a luz é absorvida. No entanto, existe a possibilidade de que luz de comprimento de onda fora da banda de absorção do material também seja absorvida. Uma dessas possibilidades é que o material absorva dois fótons simultaneamente. Ainda que nenhum destes fótons isoladamente tenha energia suficiente para realizar a transição entre os estados, existe a possibilidade de uma associação entre eles de tal modo que esse conjunto de fótons possua a energia necessária para realizar a transição. Uma das condições necessárias para que ocorra essa associação é que os fótons incidam na matéria ao mesmo tempo ou com um intervalo de tempo muito pequeno, da ordem de femtosegundo [13]. A necessidade de altas intensidades para a observação do processo deve-se ao elevado fluxo de fótons necessários para tornar a transição por dois fótons provável.

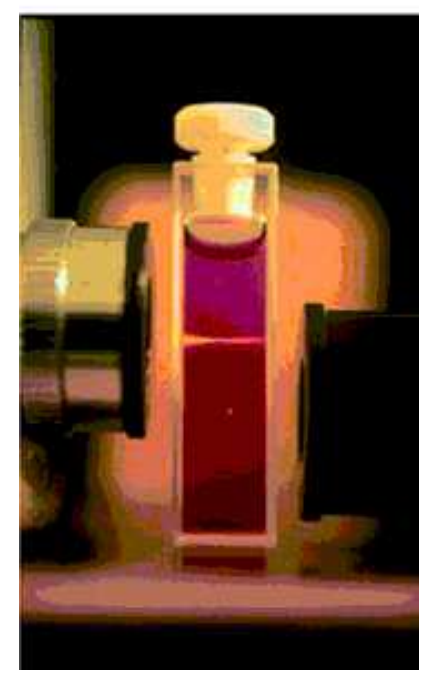

Figura 2.1: A região iluminada superior deve-se ao efeito comum de absorção de um fóton pelas moléculas da solução e a região inferior, diminuta, deve-se ao efeito de absorção de dois fótons.

Uma vantagem que pode ser utilizada em aplicações utilizando a absorção de dois fótons é a capacidade de localizar o efeito não linear em regiões reduzidas do espaço. Essa propriedade deve-se ao fato desse tipo de excitação exigir altas intensidades de radiação, que pode ser confirmada a uma determinada região do espaço pela utilização de lentes. A Fig. 2.1] apresenta uma foto onde se pode observar dois feixes de luz que são focalizados 
por lentes em um ponto no interior de uma amostra contendo um corante orgânico. O feixe superior possui comprimento de onda dentro do espectro de absorção linear das moléculas orgânicas, sendo a luz emitida devido a fluorescência que essa excitação produz. O feixe inferior possui comprimento de onda fora da região de absorção linear da amostra. Assim a fluorescência observada, confinada ao volume focal, deve-se a excitação via absorção de dois fótons. Esse efeito deve-se ao fato de que a irradiância nas vizinhanças do foco cai com o inverso do quadrado da distância axial em relação a posição focal. Isso implica que a absorção de dois fótons cai com o inverso da quarta potência desta distância.

\subsubsection{Sobre a teoria absorção de dois fótons pela matéria}

Processos multi-fotônicos têm sido extensivamente estudados. Um processo multi-fotônico é um processo onde ocorre a absorção dois ou mais fótons pela matéria, num mesmo ato quântico. Em 1931, Maria Goppert-Mayer publica um artigo referente a um estudo sobre uma ação elementar realizado por dois quantum de luz, onde estabelece teoricamente a propriedade que a matéria possui de absorver dois fótons simultaneamente e promover uma transição real entre dois níveis de energia do material [13]. A soma da energia desses dois fótons deve ser igual a diferença de energia entre os níveis envolvidos na transição. Essa interação, no entanto, ocorre apenas para intensidades luminosas muito altas. Dirac já havia demonstrado que a aplicação da teoria da perturbação de primeira ordem para a interação da luz com a matéria produz termos que envolvem a absorção e emissão de um fóton único. Dirac estendeu a aproximação para segunda ordem, e encontrou termos que correspondem ao espalhamento e transmissão da luz. Esse espalhamento corresponde a um tipo de processo onde ocorre à simultânea destruição e criação de dois fótons. Goppert-Mayer chegou a conclusão que essa teoria de Dirac, chamada teoria da dispersão de Dirac, também descreve um novo processo onde a matéria pode absorver dois fótons simultaneamente. Além disso, ela mostrou que as regras de seleção desse processo são diferentes das regras conhecidas para processos envolvendo a absorção de um fóton. Em 1961, Kaiser e Garret confirmaram as previsões teóricas de Mayer observando a fluorescência induzida por absorção de dois fótons degenerados, isto é, de mesma energia, em um cristal de fluoreto de cálcio [14]. Dessa forma, uma nova possibilidade foi criada 
em espectroscopia, a espectroscopia por absorção de dois fótons [15, 16].

\subsubsection{A absorção de dois fótons como função da hiperpolarizabi- lidade de terceira ordem}

Para quantificar a capacidade que uma molécula tem de absorver luz defini-se a seção de choque de absorção de luz. No caso da absorção de dois fótons pela matéria, podemos definir a seção de choque de absorção de dois fótons, $\delta$, pela seguinte equação [?]:

$$
\frac{d n_{p}}{d t}=\delta N F^{2}
$$

onde $d n_{p} / d t$ é o número de fótons absorvidos por unidade de tempo, $N$ é o número de moléculas absorvedoras por unidade de volume, e $F=I / h \nu$, é o fluxo de fótons. Esse fluxo tem magnitude $I / \hbar \omega$, onde $I$ é a intensidade da luz e $\omega$ é a freqüência angular de oscilação do campo luminoso.

A parte imaginária das susceptibilidades ou polarizabilidades estão relacionadas a efeitos dissipativos como a absorção da luz. A relação que pode ser estabelecida entre a seção de choque de absorção de dois fótons idênticos e a hiperpolarizabilidade de terceira ordem $\gamma$ é a dada por [17, 18]:

$$
\delta(\omega)=\frac{3(\hbar \omega)^{2} \Im^{4}}{2 n^{2} c^{2} \epsilon_{0} \hbar} \operatorname{Im}[\gamma(-\omega ; \omega,-\omega, \omega)]
$$

onde $n$ denota o índice de refração e $\Im$ é o fator de campo local. O fator de campo local é incluído para levar em conta que os campos que aparecem nas expressões das hiperpolarizabilidades são campos locais. É importante notar que a hiperpolarizabilidade $\gamma$ que aparece na Eq. 2.7 é uma quantidade escalar, proveniente de uma média orientacional do tensor hiperpolarizabilidade de terceira ordem $\gamma$. Essa aproximação certamente é válida para nosso tipo de material que se apresenta em forma de solução.

De acordo com a Eq. 2.7 para se determinar teoricamente a seção de choque de absorção de dois fótons $\delta$, a polarizabilidade de terceira ordem, $\gamma$, deve ser conhecida. Vários métodos podem ser utilizados para essa finalidade. Existem três tipos de métodos conceitualmente diferentes, são eles: os métodos derivativos, o método dos osciladores não 
harmônicos ou acoplados e o método da soma de estados, ou abreviadamente, SOS (Sum

Over States) [19. A técnica das derivadas consiste em relacionar as derivadas da energia e do momento de dipolo aos vários termos das expansões expressas pelas Eqs. 2.4 e 2.5. Após obter a energia total ou momento de dipolo via métodos da mecânica quântica, as polarizabilidades podem ser deduzidas pelas derivações dos termos da expansão. Nessa técnica, apenas a função de onda do estado fundamental na presença de um campo elétrico externo precisa ser conhecida. No método do oscilador não harmônico, os elétrons são considerados ligados ao núcleo e acoplados entre si. As frequiências de ressonância desses osciladores correspondem as freqüências de transições da molécula [20]. O método da soma de estados envolve cálculos de energia de transições e funções de onda por meio de cálculos de química quântica. As contribuições dos estados excitados são somadas utilizando a teoria de perturbação, de forma a permitir o cálculo das hiperpolarizabilidades.

\subsubsection{Resultados da teoria SOS}

O método da soma de estados permite que as polarizabilidades moleculares sejam avaliadas em função da freqüência. A principal dificuldade desse método está no cálculo preciso das funções de ondas de estados excitados. Essa dificuldade freqüentemente é minimizada pela possibilidade de se utilizar apenas alguns estados excitados, os mais significativos, nos cálculos. Dessa forma, o método permite identificar os estados importantes para o sistema molecular estudado. Como será apresentado em detalhes no Capítulo 4, utilizamos as previsões desse método para interpretar resultados dos experimentos sobre as seções de choque de absorção de dois fótons das moléculas de Salen Dye.

A teoria SOS tem sua base na teoria da perturbação, e foi desenvolvida por Ward em 1965 [21]. Orr e Ward, em um artigo publicado em 1970 [19], deduziram uma equação para a polarização macroscópica em termos dos estados excitados, dos momentos de dipolo e variações deste para as funções de onda estados excitados e fundamental. A expressão deduzida por eles pode ser escrita para a hiperpolarizabilidade $\gamma$ como: 


$$
\begin{aligned}
\gamma\left(-\omega_{\sigma} ; \omega_{1}, \omega_{2}, \omega_{3}\right) & =\wp \sum_{l m n}^{\prime} \frac{\mu_{g l}^{k} \bar{\mu}_{l m}^{j} \bar{\mu}_{m n}^{i} \mu_{n g}^{h}}{\left(\Omega_{l g}-\hbar \omega_{\sigma}\right)\left(\Omega_{m g}-\hbar \omega_{1}-\hbar \omega_{2}\right)\left(\Omega_{n g}-\hbar \omega_{1}\right)} \\
& +\wp \sum_{l m n}^{\prime} \frac{\mu_{g l}^{j} \bar{\mu}_{k}^{j} \bar{\mu}_{m n}^{i} \mu_{n g}^{h}}{\left(\Omega_{l g}^{*}+\hbar \omega_{3}\right)\left(\Omega_{m g}-\hbar \omega_{1}-\hbar \omega_{2}\right)\left(\Omega_{n g}-\hbar \omega_{1}\right)} \\
& +\wp \sum_{l m n}^{\prime} \frac{\mu_{g l}^{h} \bar{\mu}_{i}^{j} \bar{\mu}_{m n}^{k} \mu_{n g}^{j}}{\left(\Omega_{l g}^{*}+\hbar \omega_{1}\right)\left(\Omega_{m g}^{*}-\hbar \omega_{1}+\hbar \omega_{2}\right)\left(\Omega_{n g}-\hbar \omega_{3}\right)} \\
& +\wp \sum_{l m n}^{\prime} \frac{\mu_{g l}^{h} \bar{\mu}_{i}^{j} \bar{\mu}_{m n}^{j} \mu_{n g}^{k}}{\left(\Omega_{l g}^{*}+\hbar \omega_{1}\right)\left(\Omega_{m g}^{*}+\hbar \omega_{1}+\hbar \omega_{2}\right)\left(\Omega_{n g}^{*}-\hbar \omega_{\sigma}\right)} \\
& -\wp \sum_{m n}^{\prime} \frac{\mu_{g m}^{k} \mu_{m g}^{j} \mu_{g n}^{i} \mu_{n g}^{h}}{\left(\Omega_{m g}-\hbar \omega_{\sigma}\right)\left(\Omega_{m g}-\hbar \omega_{3}\right)\left(\Omega_{n g}-\hbar \omega_{1}\right)} \\
& -\wp \sum_{m n}^{\prime} \frac{\mu_{g m}^{j} \mu_{m g}^{k} \mu_{g n}^{i} \mu_{n g}^{h}}{\left(\Omega_{m g}-\hbar \omega_{3}\right)\left(\Omega_{m g}^{*}+\hbar \omega_{2}\right)\left(\Omega_{n g}-\hbar \omega_{1}\right)} \\
& -\wp \sum_{m n}^{\prime} \frac{\mu_{g m}^{h} \mu_{m g}^{i} \mu_{g n}^{k} \mu_{n g}^{j}}{\left(\Omega_{m g}^{*}+\hbar \omega_{\sigma}\right)\left(\Omega_{m g}^{*}+\hbar \omega_{3}\right)\left(\Omega_{n g}^{*}+\hbar \omega_{1}\right)} \\
& -\wp \sum_{m n}^{\prime} \frac{\mu_{g m}^{h} \mu_{m g}^{i} \mu_{g n}^{j} \mu_{n g}^{k}}{\left(\Omega_{m g}^{*}+\hbar \omega_{3}\right)\left(\Omega_{n g}-\hbar \omega_{2}\right)\left(\Omega_{n g}^{*}+\hbar \omega_{1}\right)}
\end{aligned}
$$

A Eq. 2.8, que também leva em conta estados ressonantes, os índices $l, m$ e $n$ denotam estados excitados eletrônicos, enquanto $g$ refere-se ao estado fundamental. O termo $\mu_{l m}^{h}$ é a componente $h$ do momento de dipolo de transição entre os estados $l$ e $m$. A barra sobre o momento $\mu$ indica a mudança no momento de dipolo com relação ao estado fundamental, $\bar{\mu}_{l m}^{h}=\mu_{l m}^{h}-\delta_{l m \mu_{g g}}^{h}$. Os momentos de dipolos devem ser calculados utilizando mecânica quântica. O símbolo $\Omega_{l m}$ é definido como $E_{l m}-i \Gamma_{l m}$, onde $E_{l m}$ é a energia de transição eletrônica entre os estados $l$ e $m$, e $\Gamma_{l m}$ é a constante de amortecimento introduzida fenomenologicamente para levar em conta a largura da linha espectral das transições. $\omega_{1}$, $\omega_{2}$ e $\omega_{3}$ são as freqüências dos campos ópticos incidentes tal que $\omega_{\sigma}=\omega_{1}+\omega_{2}+\omega_{3} . \wp$ é um operador de permutação que atua sobre as frequiências e também as coordenadas do tensor. A somatória é realizada sobre todos os estados eletrônicos exceto o estado fundamental.

A Eq. 2.8 é muito geral e aplica-se a processos lineares e não lineares de absorção de radiação. No entanto, devido a sua complexidade, proveniente da soma de um número 
infinito de estados, ela é inadequada para a interpretação de resultados experimentais. Contudo, é possível considerar apenas os termos mais significativos nessas somas. Dirk [22] e também Birge 223] desenvolveram um modelo simples em que consideram apenas os estados mais significativos no cálculo da hiperpolarizabilidade $\gamma$. Nestas expressões aproximadas, a equação proveniente do modelo SOS é truncada assumindo que existe apenas um estado excitado $|e\rangle$ fortemente permitido por um fóton e vários estados permitidos por dois fótons $\left|e^{\prime}\right\rangle$, que também são fortemente acoplados ao estado $|e\rangle$. Esse modelo simples para absorção de dois fótons degenerados tem sido aplicado com sucesso em vários estudos [18, 24]. A equação utilizada por Birge e colaboradores para interpretar efeitos de absorção de dois fótons é

$$
\delta=\frac{(2 \pi)^{4} \nu_{P}^{2}}{(c h)^{2}} g\left(2 \nu_{P}\right)\left|S_{f 0}\right|^{2}
$$

onde $c$ é a velocidade da luz e $h$ é a constante de Planck. $g\left(2 \nu_{P}\right)$ é um termo referente a forma da linha da absorção de dois fótons, normalmente dada por uma Loretziana do tipo

$$
g\left(2 \nu_{P}\right)=\frac{1}{\pi} \frac{\Gamma_{f 0}}{\left(\nu_{f_{0}}-2 \nu_{P}\right)^{2}+\Gamma_{f 0}^{2}}
$$

O termo $S_{f 0}$ é chamado tensor de dois fótons. Para dois fótons idênticos, chamados degenerados, o termo que aparece na Eq. 2.9] pode ser escrito da seguinte forma [25]:

$$
\begin{aligned}
\left|S_{f 0}\right|^{2}=\frac{1}{30} \sum_{i \neq 0, f}^{M} \sum_{j \neq 0, f}^{M} & \frac{a\left(\vec{\mu}_{i 0} \cdot \vec{\mu}_{f i}\right)\left(\vec{\mu}_{j 0} \cdot \vec{\mu}_{f i}\right)}{\left(\nu_{i 0}-\nu_{P}\right)\left(\nu_{j 0}-\nu_{P}\right)+\Gamma^{2}} \\
+ & \frac{a\left(\vec{\mu}_{i 0} \cdot \vec{\mu}_{f i}\right)\left(\vec{\mu}_{j 0} \cdot \vec{\mu}_{f i}\right)}{\left(\nu_{i 0}-\nu_{P}\right)\left(\nu_{j 0}-\nu_{P}\right)+\Gamma^{2}} \\
+ & \frac{a\left(\vec{\mu}_{i 0} \cdot \vec{\mu}_{f i}\right)\left(\vec{\mu}_{j 0} \cdot \vec{\mu}_{f i}\right)}{\left(\nu_{i 0}-\nu_{P}\right)\left(\nu_{j 0}-\nu_{P}\right)+\Gamma^{2}}
\end{aligned}
$$

onde $\mu_{m n}$ é o momento de dipolo de transição, e $\nu_{m n}$ a freqüência das transições $n$ para $m(m, n=0, i, j, f)$. O índice 0 denota o estado fundamental, enquanto $f$ indica o estado final. Os índices $i$ e $j$ denotam os estados intermediários. O modelo admite $M$ estados $i$ e $j$. $\Gamma$ é a constante de amortecimento, a qual está relacionada aos estados intermediários. Os parâmetros $a$ e $b$ variam dependendo da polarização dos dois fótons. 
Caso os dois fótons possuam a mesma polarização linear, $a=b=8$, que é o caso do nosso experimento.

Equações desse tipo serão utilizadas no Capítulo 3 para interpretar os resultados das seções de choque de absorção de dois fótons das moléculas de Salen Dye.

\subsection{Sobre a medida experimental da seção de choque de absorção de dois fótons}

Sistemas moleculares podem interagir com campos de radiação por processos paramétricos ou processos dissipativos. Num processo paramétrico ocorre troca de momento e energia entre os diferentes modos dos campos, não havendo dissipação de energia. Nos processos dissipativos, ocorre troca de energia e momento entre o campo e a matéria. Podem ocorrer absorção e emissão de energia. Dessa forma, o processo de absorção de dois fótons é um processo dissipativo. A molécula absorve a energia da radiação e a transforma em outra forma de energia como, por exemplo, energia térmica ou até mesmo novamente em radiação, como ocorre em compostos fluorescentes [26].

A taxa de energia média trocada entre a radiação e a matéria por unidade de volume é dado por [17, 27]:

$$
\frac{d W}{d t}=\langle\vec{E} \cdot \overrightarrow{\dot{P}}\rangle
$$

onde $\vec{E}$ é o campo elétrico da radiação e $\vec{P}$ é a polarização do meio. A polarização pode ser descrita pela seguinte expansão proveniente da Eq. 2.2.

$$
P=\chi^{(1)} E+\chi^{(2)} E^{2}+\chi^{(3)} E^{3}+\cdots
$$

A absorção de dois fótons está relacionada a parte imaginária do termo de terceira ordem $\chi^{(3)}$. A parte imaginária de $\chi^{(5)}$ refere-se à absorção de três fótons. Para ondas monocromáticas com campos elétricos de amplitude $E$, a Eq. 2.12 pode escrita como:

$$
\frac{d W}{d t}=\frac{1}{2} \omega \operatorname{Im}\{E \cdot P\}
$$


Considerando dois fótons de mesma energia, a polarização é dada por:

$$
\left.\frac{1}{2} P e^{i \omega t}=\frac{1}{8} \chi^{(3)}(-\omega t,-\omega, \omega, \omega)\right) \vdots E E E^{*} e^{i \omega t}
$$

Usando 2.14 2.15, a taxa com que a energia é absorvida num processo de dois fótons é dado por:

$$
\frac{d W}{d t}=\frac{8 \pi^{2} \omega}{n^{2} c^{2}} I^{2} \operatorname{Im} \chi^{(3)}
$$

onde a intensidade é dada por $I=E E^{*} n c / 8 \pi$.

É importante notar que a taxa de absorção de dois fótons varia com o quadrado da intensidade da radiação enquanto que, para efeitos lineares, essa dependência é linear.

Em geral, a capacidade apresentada pela molécula para absorver dois fótons é verificada pelo conceito de seção de choque de absorção de dois fótons, $\delta$. Está quantidade pode ser definida pela Eq. 2.17, reescrita abaixo:

$$
\frac{d n_{p}}{d t}=\delta N F^{2}
$$

Se usarmos $d W / d t=\left(d n_{p} / d t\right) h \nu$ em conjunto com a Eq. 2.16] e $P_{\text {ind }}=-N e r$, teremos:

$$
\delta=\frac{8 \pi^{2} h \nu^{2}}{n^{2} c^{2} N} \operatorname{Im} \chi^{(3)}
$$

Para efeitos de medida no laboratório é conveniente expressar a Eq. 2.18 em termos de variação de intensidade de um feixe. À diminuição da intensidade de um feixe de luz que se propaga através de um meio que absorve fótons de maneira linear é dado pela lei de Beer. Se além do processo de absorção linear o material também absorve dois fótons, a lei que expressa a atenuação da intensidade da luz em função da distância $x$ na amostra é dada por:

$$
\frac{d I}{d x}=-\left(\alpha I+\beta I^{2}\right)
$$

onde $\alpha$ é o coeficiente de absorção linear e $\beta$ é o coeficiente de absorção de dois fótons, cuja unidade física é $m / W$. Para um feixe laser Gaussiano incidindo num meio 
de espessura $L$ sem atenuação linear, mas que apresente absorção de dois fótons, a luz transmitida é dada por:

$$
I(L)=\frac{1}{L \beta}\left[\ln \left(1+I_{0} L \beta\right)\right]
$$

onde $I_{0}$ é a intensidade da luz incidente. O valor do coeficiente de absorção de dois fótons $\beta$ é obtido pela medida da intensidade de luz transmitida pela através da aplicação da Eq. 2.20] A utilização da seguinte equação permite a determinação da seção de choque de absorção de dois fótons.

$$
h \nu \beta=\delta N_{0}=\delta N_{A} C_{0} \cdot 10^{-3}
$$

nessa igualdade $h \nu$ é a energia de cada fóton incidente, $N_{0}$ é a densidade molecular $\left(\mathrm{cm}^{-3}\right), N_{A}$ é o número de Avogadro , e $C_{0}$ é a concentração em $\mathrm{mol} / \mathrm{l}$.

Assim como a absorção de dois fótons é proporcional à parte imaginária de $\chi^{(3)}$, a seção de choque de absorção de três fótons é proporcional à parte imaginária de $\chi^{(5)}$. A análise da absorção de três fótons é uma simples extensão do que foi exposto sobre a absorção de dois fótons, bastando substituir a Eq. 2.19 por:

$$
\frac{d I}{d x}=-\left(\alpha I+\beta I^{2}+\gamma_{3} I^{3}\right)
$$

$\gamma$ é o coeficiente de absorção de três fótons $\left(m^{3} / W^{2}\right)$, o qual está relacionado à parte imaginária de $\chi^{(5)}$. Se a absorção linear puder ser desprezada, a solução da Eq. 2.21] implica na seguinte dependência com a posição $x$ dentro da amostra:

$$
I(x)=\frac{I_{0}}{\sqrt{\left(1+2 \gamma x I_{0}^{2}\right)}}
$$

Várias técnicas podem ser utilizadas para medir os processos de absorção multi-fotônicos. Entre elas, destacamos a técnica de varredura-Z que consiste, basicamente, na focalização de um feixe de luz e translação da amostra ao redor da posição focal. A medida da transmissão da luz em função da posição da amostra permite que as seções de choque de absorção de dois ou mais fótons sejam obtidas. Essa foi à técnica utilizada para obtermos o espectro de absorção de dois fótons das moléculas de Salen Dye, e será 
descrita em detalhes no Capítulo 3. Em alguns tipos de sistemas observa-se fluorescência após a excitação multi-fotônica. Nesses casos a fluorescência pode ser utilizada para estudar o processo de absorção multi-fotônica. O tipo de dependência da intensidade da fluorescência com a intensidade da excitação pode revelar, por exemplo, se a absorção de luz deve-se via absorção de dois ou três fótons [26].

A parte imaginária de $\chi^{(3)}$ pode ser avaliada também por absorção transiente, que é uma ferramenta muito importante principalmente para estudos de efeitos de absorção de estados excitados. Essa técnica usa pulsos ultra-curtos para excitar o sistema para estados superiores, e pulsos de baixa intensidade para provar o sistema excitado. Além disso, o pulso de prova pode ser atrasado em relação ao pulso de excitação, permitindo o estudo da resposta dinâmica do sistema.

Outro método bastante importante no estudo de processos de terceira ordem é a da mistura de quatro ondas [28]. Diferentemente dos processos de segunda ordem, os processos de terceira ordem ocorrem independentemente da simetria da molécula, isto é, ocorrem para moléculas que possuam ou não simetrias de inversão. Isso fato faz com que esse método seja muito útil para a análise de determinados tipos de materiais. O efeito pode ocorrer quando, no mínimo, duas componentes de ondas de freqüências diferentes se propagam juntas no interior de um material não linear como, por exemplo, uma fibra óptica. Assumindo, por exemplo, que as componentes incidentes sejam $\nu_{1}$ e $\nu_{2}$, com $\nu_{1}>\nu_{2}$, obtém-se modulação do índice de refração numa freqüência diferente das ondas incidentes, que novamente interage com cada onda incidente. Com efeito, duas novas freqüências são geradas. É importante saber que esse efeito é sensível às fases das ondas. A mistura de quatro ondas é utilizada como ferramenta espectroscópica na técnica conhecida como espectroscopia Raman anti-Stokes, onde se detecta um sinal de alta freqüência produzido pela incidência de dois campos de freqüências bastante próximas. Pela introdução de um atraso entre as ondas incidentes, é possível medir os tempos de vida de estados excitados e taxas de defasagens. 


\subsection{Isomerização via absorção de um ou dois fótons}

Como mencionamos anteriormente, compostos azo-aromáticos existem em duas configurações geométricas, denominados isômeros. Estas configurações são conhecidas como trans e cis. Como explicado no Capítulo 2, a conversão de uma configuração para outra é chamada reação de isomerização, e pode ser induzida por luz. Dependendo do tipo de molécula, uma das configurações é mais estável que a outra. Geralmente, a configuração trans é mais estável que a configuração cis, em condições normais de temperatura e pressão. A Fig. 2.2 ilustra a transformação da molécula de azo-benzeno de uma configuração isomérica para outra [3, 29]. A molécula é levada, pela absorção de luz, da configuração trans para a configuarção cis, retornando para a configuração trans (mais estável), após algum tempo. Esse retorno pode ser também induzido por luz ou pode ocorrer naturalmente envolvendo troca de calor.

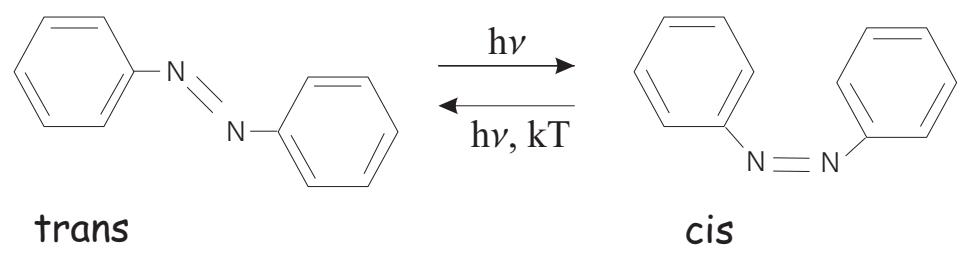

Figura 2.2: Ilustração da reação química de foto-isomerização da molécula de azo-benzeno. É importante notar que a foto-isomerização envolve um grande movimeto da molécula. A diferença de energia entre os isômeros é da ordem de $50 \mathrm{KJ} / \mathrm{mol}$.

Um modelo simples para as energias envolvidas no processo, muito utilizado por Sekkat [30, 4], pode ser observado na Fig. 2.3. Nesse modelo simplificado, os estados da molécula são representados por apenas dois estados excitados, mas cada estado é na realidade constituído de um conjunto de níveis energéticos. Partindo da configuração de menor energia, a reação de foto-isomerização leva o sistema para estados eletrônicos excitados de maior energia. As taxas com que as configurações trans e cis absorvem a luz são representadas no esquema pelas respectivas seções de choque de absorção $\sigma_{t}$ e $\sigma c$, cabe ressaltar que estas absorções podem devidos a absorção de um ou dois fótons. O sistema então troca de forma isomérica com as seguintes eficiências quãnticas, $\phi_{c t}$ do estado trans excitado 
para o cis fundamental e $\phi_{t c}$ do estado cis excitado para o estado trans fundamental. A molécula na forma cis pode reverter para a forma trans por dois mecanismos: relaxação térmica espontânea ou por uma nova foto isomerização. Na Fig. 2.3, a taxa de relaxação térmica é igual ao inverso do tempo de vida da configuração cis, $1 / \gamma_{0}$. As eficiências quânticas de foto-isomerização entre as duas configurações são representadas por $\Phi_{c t}$ e $\Phi_{t c}$.

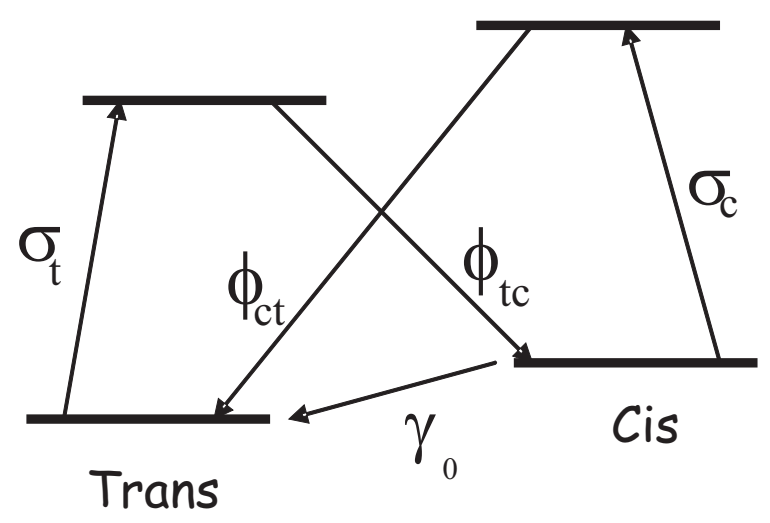

Figura 2.3: Modelo símples para os estados moleculares durante o ciclo de foto-isomerização. Na realidade cada estado representado pelo traço horizontal constitui-se de um conjunto de niveis de energia.

Para induzir as reações de foto-isomerização basta incidir luz cujo comprimento de onda esteja situado dentro da banda de absorção da molécula azo-aromática. Desse modo, como se pode observar na Fig. 2.4 [31], que apresenta o espectro de absorção linear de um filme polimérico contendo moléculas azo aromáticas de DR13, luz de comprimento de onda entre 450 e $550 \mathrm{~nm}$ é bastante absorvida e produzem altas taxas de foto-isomerização. Nesse tipo de excitação, que ocorre até mesmo para intensidades muito baixas, um único fóton é absorvido pela molécula do corante que é levada para outra configuração isomérica.

No entanto, como explicado em seções anteriores, para altas intensidades luminosas, as moléculas podem absorver radiação de comprimento de onda fora da região de absorção linear pelo mecanismo não linear de absorção de dois fótons. Em nosso trabalho, comprovamos experimentalmente a possibilidade de se induzir foto-isomerizações em moléculas azo-aromáticas utilizando radiação de comprimento de onda em torno de 700 e $900 \mathrm{~nm}$. Portanto, fora do espectro de absorção mostrado na Fig. 2.4. Os Capítulos 4 e 5 descrevem como utilizamos esse processo no desenvolvimento de aplicações em armazenamento 


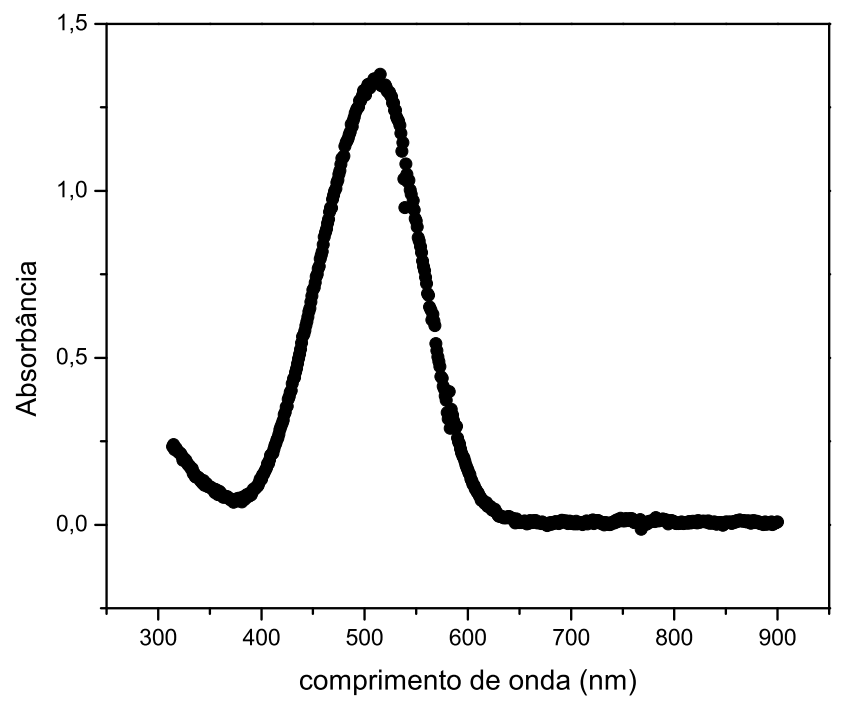

Figura 2.4: Espectro de absorção linear de um filme de PMMA contendo o cromóforo azo-aromático DR13.

óptico de informação (Capítulo 4) e controle coerente (Capítulo 5). 


\section{Capítulo 3}

\section{O espectro de absorção de dois fótons das moléculas de Salen Dye}

A busca por moléculas de alta seção de choque de absorção de dois fótons é de grande interesse prático, pois além de garantir altas magnitudes de interação possibilita que a intensidade da luz necessária para determinado efeito seja reduzida. Como exemplo de aplicação onde moléculas de alta seção de choque de absorção de dois fótons são importantes, podemos citar a microscopia por absorção de dois fótons. As moléculas absorvedoras são levadas ao interior das células e se espalham pelas organelas segundo afinidades químicas e biológicas. Minúsculas organelas podem ser observadas devido à fluorescência produzida pela absorção de dois fótons [32. A Fig. 3.1 apresenta uma imagem de uma célula obtida por microscopia por fluorescência via absorção de dois

fótons. A iluminação da célula por luz de alta intensidade e comprimento de onda dentro da região de absorção de dois fótons da molécula faz com que estas fluoresçam, permitindo que sejam produzidas imagens de altíssima resolução. O campo da terapia foto dinâmica por absorção de dois fótons também têm grande interesse em moléculas com seções de choque de alta magnitude para absorção de dois fótons [33].

\subsection{As moléculas de Salen Dye}

A introdução de metais na estrutura química de moléculas é uma opção na tentativa de se obter moléculas de alta seção de choque de absorção de dois fótons [34, 35, 36, 37, 38, 39] 


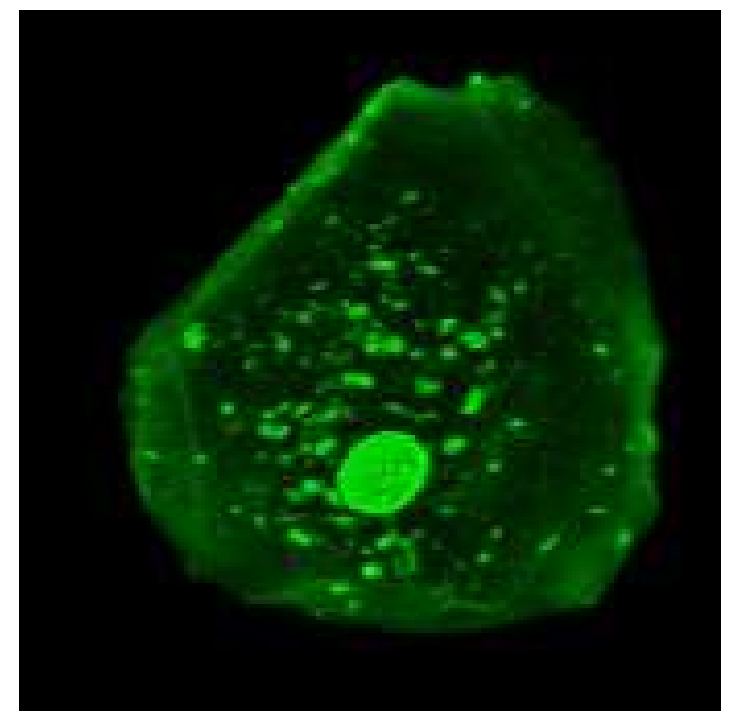

Figura 3.1: Fotografia obtida por fluorescência induzida por absorção de dois fótons (Laboratory for Optics and BiosciencesEcole Polytechnique).

e alta estabilidade. Com esse objetivo, o grupo do Prof. Xiu R. Bu, (Clark Atlanta University-EUA) sintetizou um grupo de moléculas denominadas Salen Dye, contendo os seguintes metais de transição: Cobre, Níquel e Vanádio. Os detalhes sobre a síntese dessas moléculas podem ser encontradas nas referências [40]. A Fig. 3.2 mostra a estrutura química das moléculas de Salen. À esquerda temos a molécula de Salen Dye sem metal, e a direita a estrutura química da molécula de Salen Dye com os metais que ocupam a posição indicada pela letra $\mathrm{M}$.

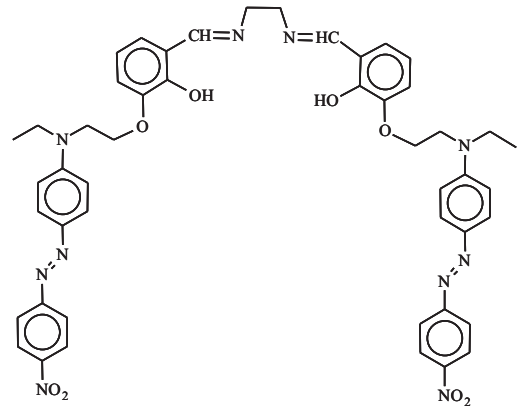

S-Dye

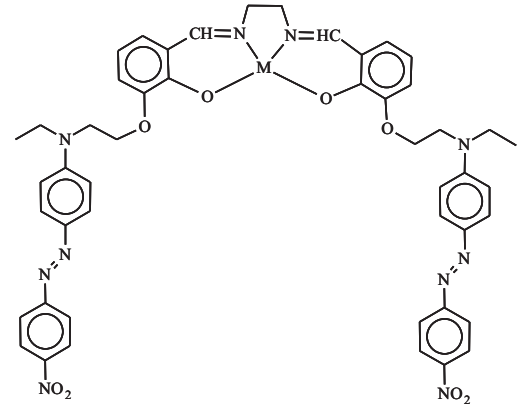

$\mathrm{S}-\mathrm{Cu} \quad \mathrm{M}=\mathrm{Cu}$

$\mathrm{S}-\mathrm{Ni} \quad \mathrm{M}=\mathrm{Ni}$

$\mathrm{S}-\mathrm{VO} \quad \mathrm{M}=\mathrm{VO}$

Figura 3.2: A esquerda mostramos a estrutura química da molécula de salen Dye, e à direita as moléculas de Salen Dye contendo metais à sua estrutura. 
As moléculas de Salen Dye constituem-se de dois grupos azos-aromáticos unidos por um grupo central constituído de átomos de nitrogênio, oxigênio e carbono. Os átomos de metal ocupam a posição central nas moléculas em que estão presentes, e estão ligados a dois átomos de oxigênio e nitrogênio, como pode ser observado na Fig. 3.2

\subsection{A técnica de varredura $\mathrm{Z}$ para medida da seção de choque de absorção de dois fótons}

A técnica de varredura-Z se tornou muito popular na investigação de não linearidades ópticas, particularmente refração e absorção não linear de luz. Está técnica tem sido usada para medir não linearidades em semicondutores [41, 42], dielétricos [43, 44] e moléculas orgânicas 45, 46], com pulsos laser operando em regimes temporais de femtosegundos até milisegundos. A técnica de varredura $\mathrm{Z}$ tem como vantagem em relação a outras técnicas permitir a determinação do sinal e o tipo de não linearidade (refrativa ou absorciva).

A técnica de varredura-Z foi desenvolvida por Sheik-Bahae e colaboradores em 1989 [47, 48] sendo relativamente simples do ponto de vista experimental, requerendo a focalização de um feixe de luz laser, com o auxílio de uma lente, em uma determinada região do espaço. A direção do feixe de luz é denominada direção Z. A amostra que se deseja estudar é transladada em torno da posição focal varrendo essa região sempre na direção Z. Dessa forma, quando a amostra está longe do foco, a intensidade da luz é baixa e portanto efeitos não lineares são desprezíveis, de tal forma que a luz interage apenas linearmente com a amostra. Nas proximidades do foco, a intensidade da luz é alta e efeitos não lineares refrativos e absorcivos se manifestam. A razão entre a intensidade da luz transmitida pela amostra em qualquer posição pela intensidade transmitida quando a amostra se encontra distante do foco é denominada transmitância normalizada, e é a grandeza obtida em um experimento de varredura-Z. A Fig. 3.3 mostra uma curva de varredura Z obtida para uma determinada intensidade de luz incidente para uma não linearidade absorciva positiva devido à absorção de dois fótons, quando a amostra está longe do foco a transmitância normalizada tem valor 1 . Conforme a amostra vai se deslocando para direita, se aproximando do foco, a transmitância normalizada diminui pois a amostra absorve luz 
devido ao efeito não linear. O menor valor da transmitância normalizada é obtida no foco, $Z=0$. Após o foco, a absorção de luz diminui e a transmitância normalizada aumenta gradualmente até chegar novamente ao valor 1, quando a amostra está longe do foco.

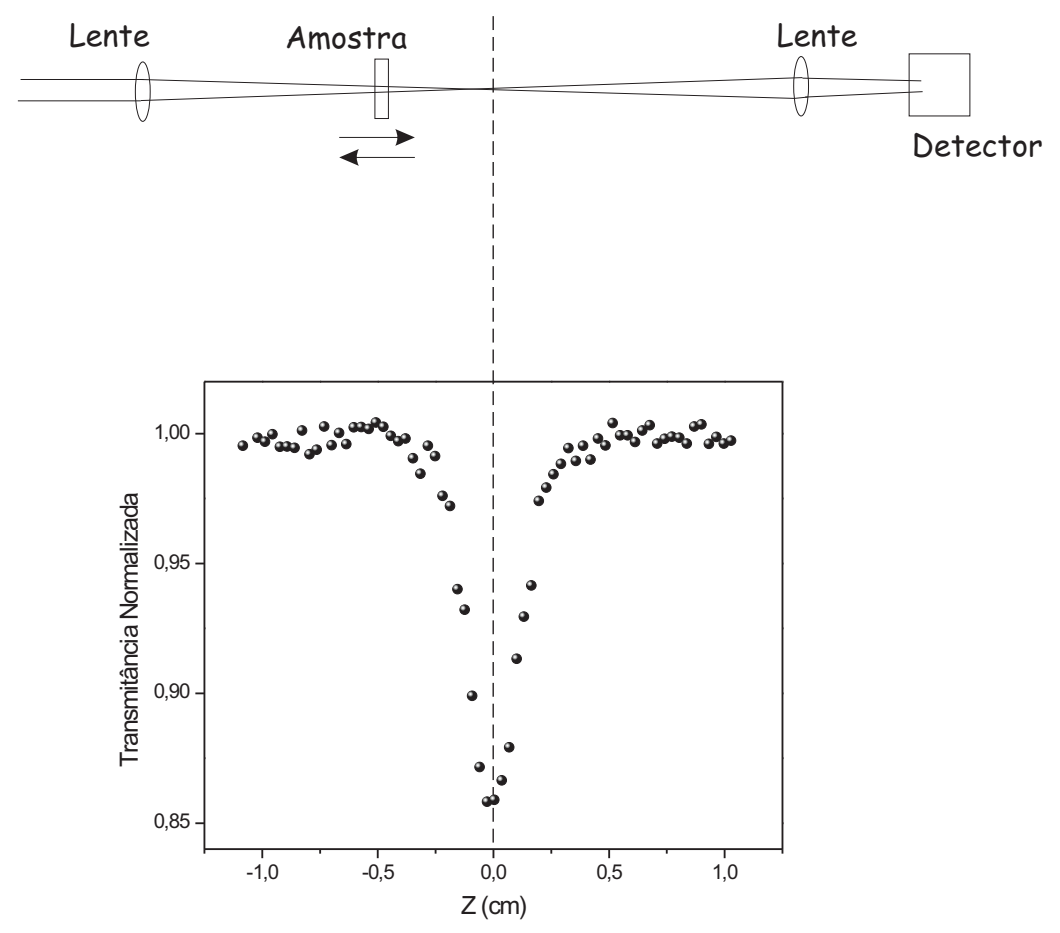

Figura 3.3: Exemplo de um resultado de transmitância normalizada obtida em um experimento de varredura $Z$, para uma amostra que apresenta absorção de dois fótons. Note que a lente após a amostra tem a função de fazer com que toda luz transmitida pela amostra seja captada pelo detector.

A técnica de varredura $\mathrm{Z}$ pode ser utilizada também para estudar efeitos refrativos. Nesse caso, a refração induzida na amostra modifica a distribuição espacial da luz que é transmitida através da mesma. Esse efeito é captado utilizando uma abertura de pequena dimensão na frente do detector. Essa técnica é capaz de mostrar claramente o sinal do efeito refrativo produzido pela amostra, além de permitir a determinação da magnitude do processo não linear com precisão. 


\subsection{Arranjo experimental para medida de absorção de dois fótons em regime de femtosegundo}

O aparato experimental montado para a realização das medidas das seções de choque de absorção de dois fótons nas moléculas de Salen Dye está ilustrado na Fig. 3.4. Como fonte de luz utilizamos um laser Ti:Safira (Clark-MXR) que fornece pulsos de $775 \mathrm{~nm}$, com largura temporal de $150 \mathrm{fs}$ a uma taxa de $1 \mathrm{KHz}$. Com a finalidade de obter pulsos com outros comprimentos de onda, utilizamos um amplificador paramétrico (TOPASQuantronix). Esse amplificador paramétrico é capaz produzir pulsos com comprimento de onda de $460 \mathrm{~nm}$ até $2000 \mathrm{~nm}$, sem alterar significativamente a largura temporal dos pulsos. O feixe proveniente do amplificador paramétrico atravessa um conjunto de espelhos dielétricos que tem a finalidade de filtrar o comprimento de onda desejado. Com a finalidade de melhorar o modo transversal dos pulsos utilizamos um filtro espacial composto de duas lentes (foco $=50 \mathrm{~cm}$ ) e uma íris, conforme ilustrado na Fig. 3.4. A luz que atravessa o filtro espacial segue em direção a lente de distância focal $11 \mathrm{~cm}$, que focaliza a luz na posição $Z=0$. A luz atravessa a amostra e é direcionada para o foto-detector. Um programa de computador controla o motor de passo, que tem a função de transladar a amostra na direção $Z$ em torno do foco, e capta o sinal fornecido pelo amplificador Lock-in. Com o objetivo de obter maior precisão nas medidas, a amostra é transladada várias vezes de um extremo ao outro do percurso, e o programa calcula a média dessas diversas varreduras.

\subsection{O espectro de absorção de dois fótons das moléculas de Salen Dye}

As amostras de Salen Dye utilizadas no experimento de varredura $\mathrm{Z}$ foram preparadas através da dissolução em N-metil pirrolidona (NMP). As soluções apresentaram ótima qualidade óptica para a realização da medida quanto a transparência e dissolução. As con-

centrações das quatro soluções preparadas são de aproximadamente $5.10^{17}$ moléculas $/ \mathrm{cm}^{3}$. As soluções foram inseridas em cubetas de $1 \mathrm{~mm}$ de espessura, e os espectros lineares, me- 


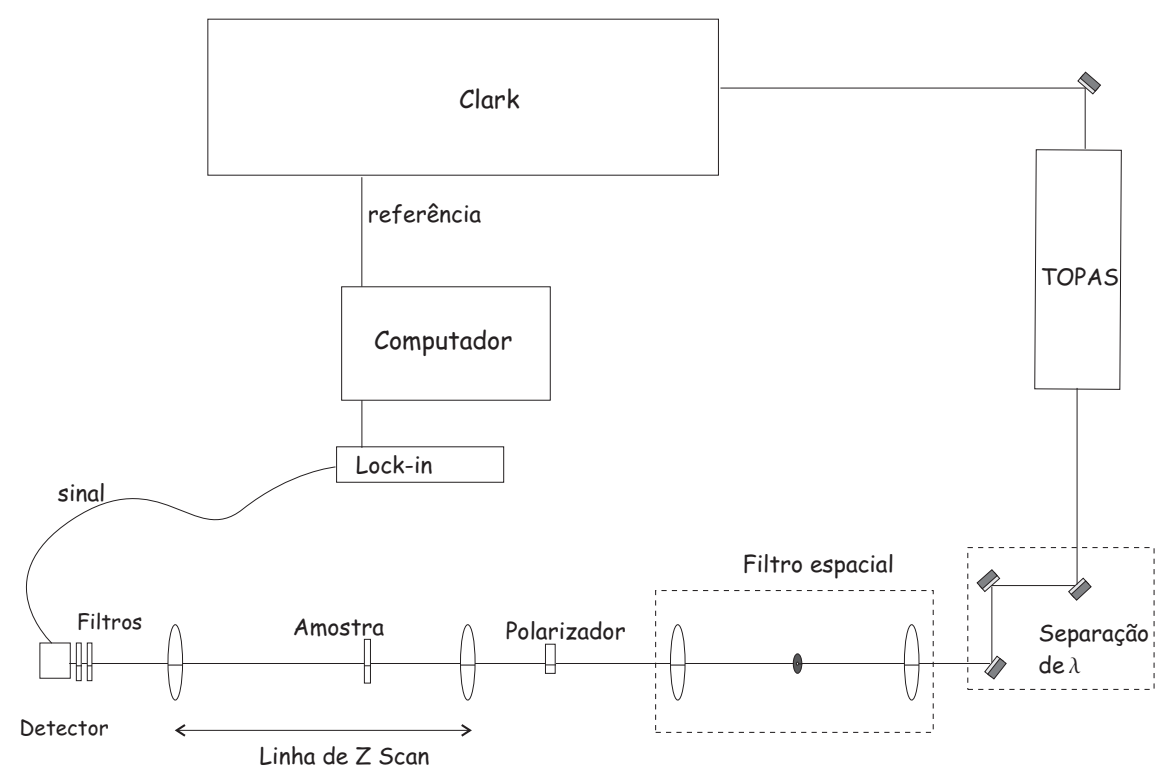

Figura 3.4: Aparato experimental montado para obtenção das curvas de varredura $Z$ para medida de absorção de dois fótons. Os pulsos de luz que saem do sistema Clark tem duração temporal de aproximadamente $150 \mathrm{fs}$ e taxa de repetição de $1 \mathrm{KHz}$.

didos utilizando um espectrofotômetro Cary 17, estão mostrados na Fig. 3.5.

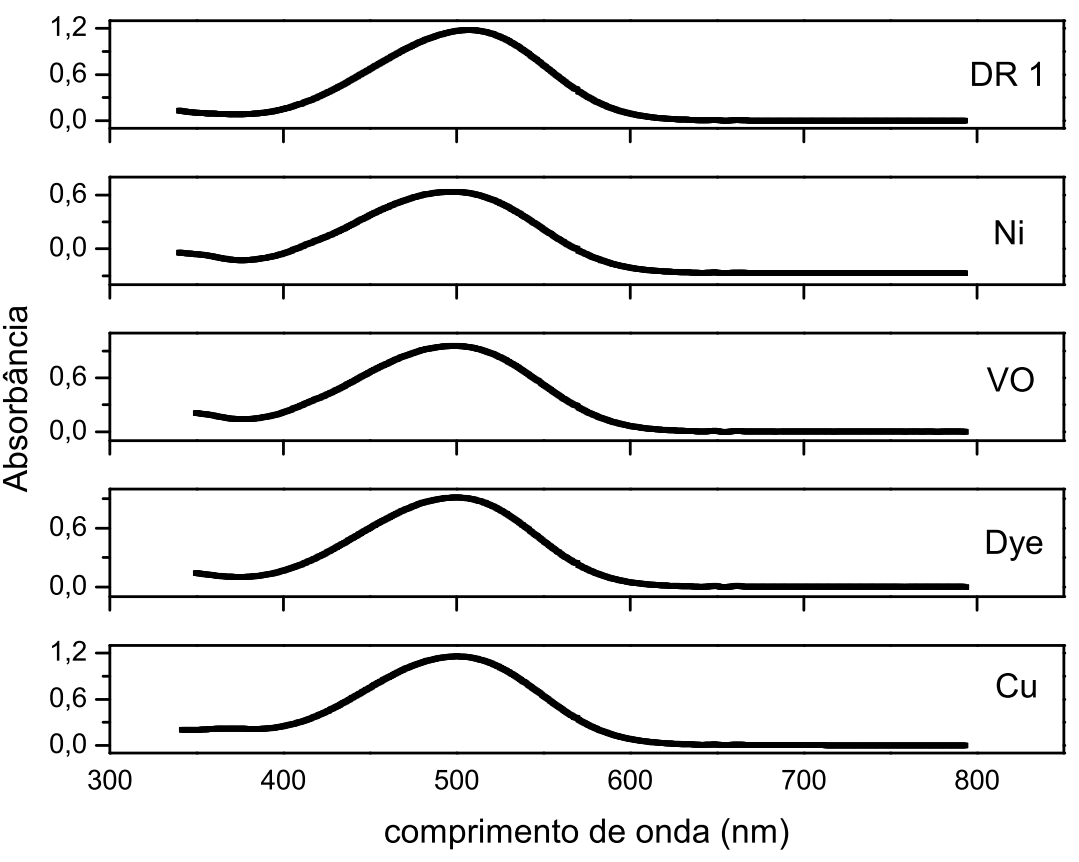

Figura 3.5: Espectros de absorção linear para as diferentes amostras de Salen Dye. O espectro do cromóforo vermelho disperso 1 (DR1) também é mostrado para ser utilizado na seção 3.4 .3 . 
Os espectros lineares das moléculas de Salen apresentam um pico em 500 nm, que corresponde, principalmente, a transição eletrônica $\pi \mapsto \pi^{*}$, característica do grupo azoaromático [3]. Os espectros mostram que os metais não influenciam fortemente na banda de absorção linear das moléculas, mostram também que além de 650 nm a absorção linear das amostras é nula. Essa informação é importante, pois nos diz que devemos trabalhar com comprimentos de onda maiores de $650 \mathrm{~nm}$ para estudar processos de absorções multifotônicas 2 .

A Fig. [3.6 apresenta, como exemplo o resultado de um experimento de varredura Z para a solução de Salen Dye sem metal. O comprimento de onda utilizado nessa medida foi de $700 \mathrm{~nm}$.

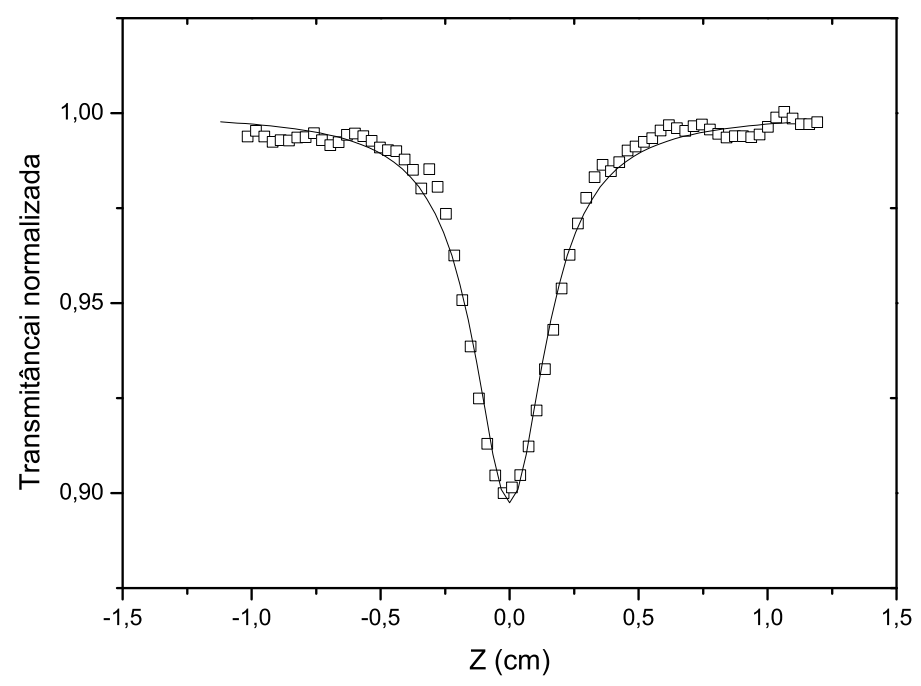

Figura 3.6: Resultado do experimento de varredura-Z para solução de Salen Dye. A intensidade da excitação usada nessa medida é de aproximadamente $108 \mathrm{GW} / \mathrm{cm}^{2}$. A linha contínua representa o ajuste teórico obtido da Eq. 3.1.

\footnotetext{
${ }^{1}$ transições $n \mapsto \pi^{*}$, fracas, geralmente estão presentes e sobrepostas às transições $\pi \mapsto \pi^{*}$.

${ }^{2}$ As concentrações das soluções para a medida do espectro de absorção linear não foram determinadas por estarmos interessados apenas no aspecto qualitativo do espectro.
} 


\subsubsection{Obtenção da seção de choque a partir da curva de varredura- $\mathrm{Z}$}

Uma medida como a da Fig. 3.6 permite a obtenção da seção de choque de absorção de dois fótons para as moléculas da solução num determinado comprimento de onda, através do ajuste dos dados experimentais com a seguinte equação [48, 49, 50, 51]:

$$
T_{N}(z)=\frac{1}{\sqrt{\pi} q_{0}(z, 0)} \int_{-\infty}^{\infty} \ln \left[1+q_{0}(z, 0) e^{\left(-x^{2}\right)}\right] d x
$$

$T_{N}(z)$ é a transmitância normalizada em função na posição $z$,

$q_{0}(z, t)=\beta I_{0}(t) L /\left(1+z^{2} / z_{0}^{2}\right)$ e a seção de choque, $\delta$, relaciona-se com o coeficiente de absorção de dois fótons $\beta$ da seguinte maneira:

$$
\delta=\frac{h \nu \beta}{C}
$$

onde $C$ é a concentração das moléculas absorvedoras na solução. $I_{0}$, a intensidade de pico, é calculada segundo a seguinte relação que vale para pulsos Gaussianos [51]:

$$
I_{0}=\frac{4 \sqrt{\ln 2} E_{p}}{\pi^{3 / 2} \mathrm{w}_{0}^{2} t_{p}}
$$

nessa equação $E_{p}$ é a energia do pulso, wo é o raio da cintura do feixe e $t_{p}$ é a largura temporal do pulso.

Com o objetivo de verificar o intervalo de intensidades conveniente para a realização das medidas e confirmar a dependência do processo com a intensidade, foram realizados experimentos de varredura $\mathrm{Z}$ com as amostras para diferentes intensidades luminosas. $\mathrm{O}$ resultado desse experimento para a amostra contendo Vanádio, e para luz de comprimento de onda de 700 nm, é apresentado na Fig. 3.7 A dependência linear da variação absoluta máxima da transmitância normalizada com a irradiância, mostrada na mesma figura, indica um valor constante de $\beta$ para intensidades de até $120 \mathrm{GW} / \mathrm{cm}^{2}$. Dessa forma, temos certeza que utilizando $50 \mathrm{GW} / \mathrm{cm}^{2}$ estamos observando absorção de dois fótons 48. 


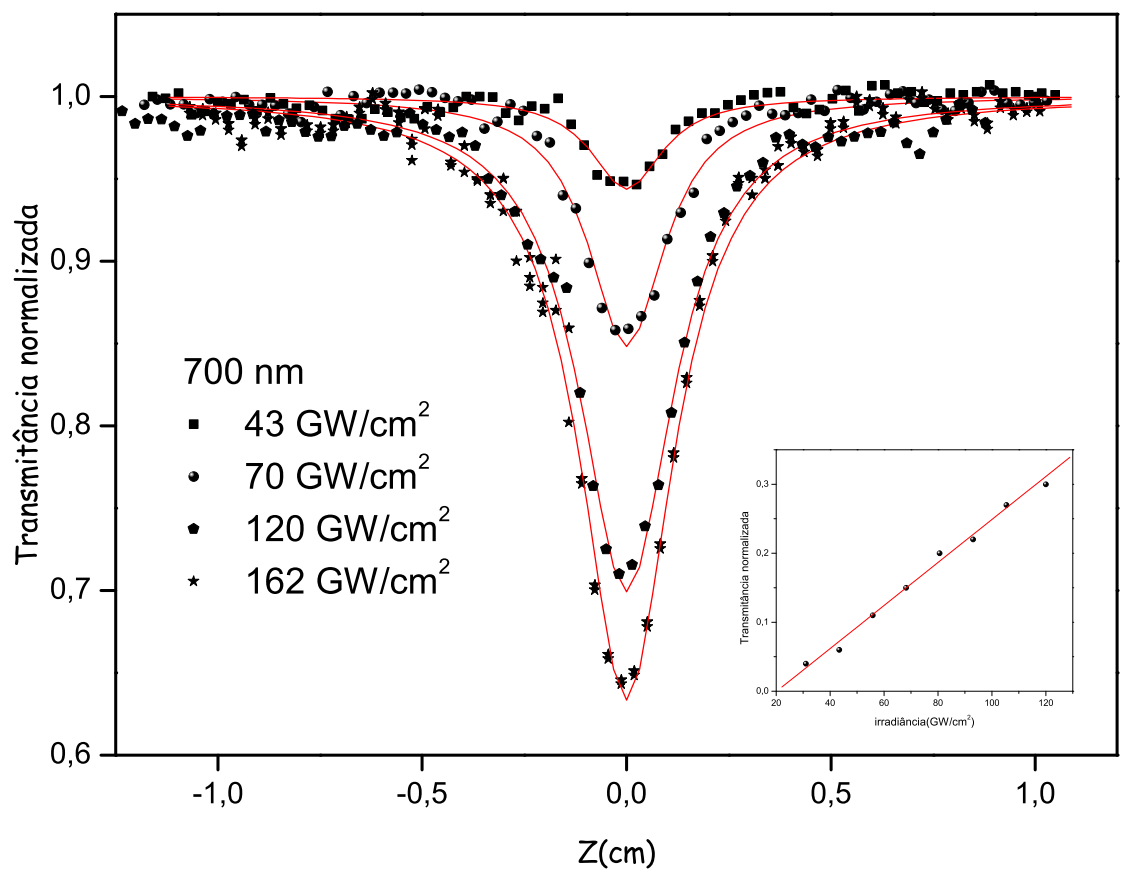

Figura 3.7: Curvas de varredura-Z obtidas com a solução com Vanádio para pulsos com diferentes intensidades. As linhas contínuas são obtidas através do ajuste utilizando a Eq. 3.1.

\subsubsection{O espectro de absorção de dois fótons das moléculas de Salen}

Para obter o espectro de absorção de dois fótons de cada molécula, ou seja, $\delta$ em função de $\lambda$, várias curvas de varredura-Z foram tomadas para luz de vários comprimentos de onda, para todas as amostras. A intensidade da luz utilizada nessas medidas variou de aproximadamente $50 \mathrm{GW} / \mathrm{cm}^{2}$. Os valores das seções de choque foram extraídas seguindo o procedimento descrito anteriormente e são apresentados na Fig. 3.8

Os espectros de dois fótons das moléculas de Salen, 3.8, mostram um único pico em torno de $1000 \mathrm{~nm}$ para todas as molécula. A magnitude da seção de choque de absorção de dois fótons decresce monotonicamente após $1000 \mathrm{~nm}$ e vai a zero. Um fato interessante ocorre para comprimentos de onda abaixo de $1000 \mathrm{~nm}$, para valores decrescentes do comprimento de onda a seção de choque cai até aproximadamente $840 \mathrm{~nm}$, voltando a crescer à medida que os comprimentos de onda se aproximam da banda de absorção 


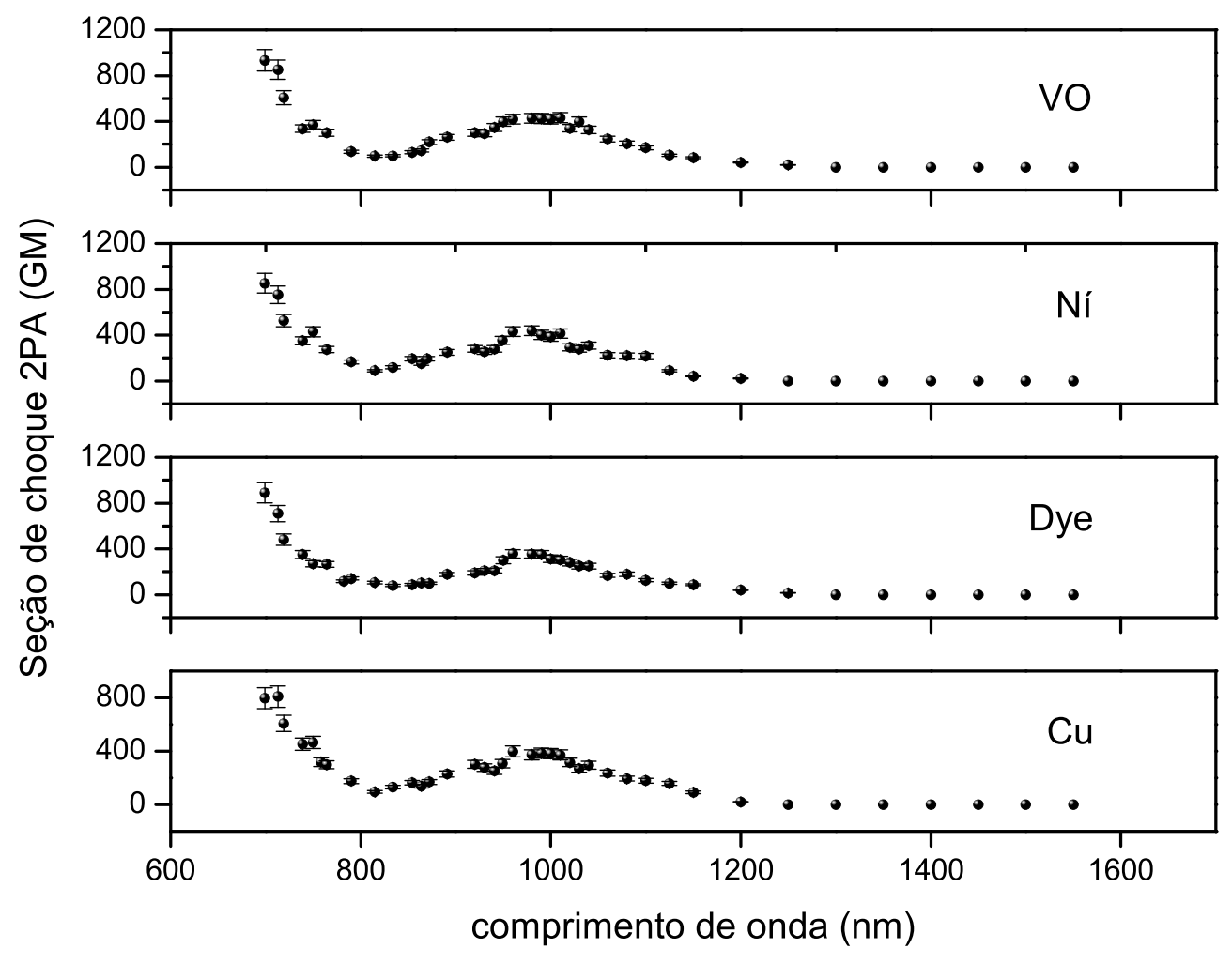

Figura 3.8: Seções de choque de absorção de dois fótons em função do comprimento de onda para as moléculas de Salen Dye. Cada ponto experimental foi obtido de um experimento de varredura $Z$ para o determinado comprimento de onda.

linear. Esse fato é atribuído a um efeito denominado engrandecimento por ressonância, e será discutido com mais detalhe posteriormente.

Um fato importante revelado pelos resultados na Fig. 3.8 é que, assim como para o comportamento linear, o espectro de absorção de dois fótons não notamos diferenças devido à presença dos metais. Tanto a magnitude quanto a posição dos espectros são os mesmos para todos os tipo de moléculas. Esse fato foi por nós interpretado como resultado da ausência de ligações que permitam a transferência de cargas entre os metais e as áreas conjugadas da molécula. Os metais estão ligados ao restante da molécula por ligações simples, que não permitem essa transferência de carga. 


\subsubsection{Comparação entre os espectros do Salen Dye e do azo- cromóforo vermelho disperso 1 (DR1)}

Para reforçar a hipótese que o efeito de absorção de dois fótons deve-se apenas ao grupo azo-aromático, comparamos o espectro de absorção de dois fótons das moléculas de Salen com o espectro da molécula de DR1. O DR1 foi tomado devido à sua estrutura que é idêntica às estruturas laterais das moléculas de Salen, como pode ser observado na Fig. 3.9 .

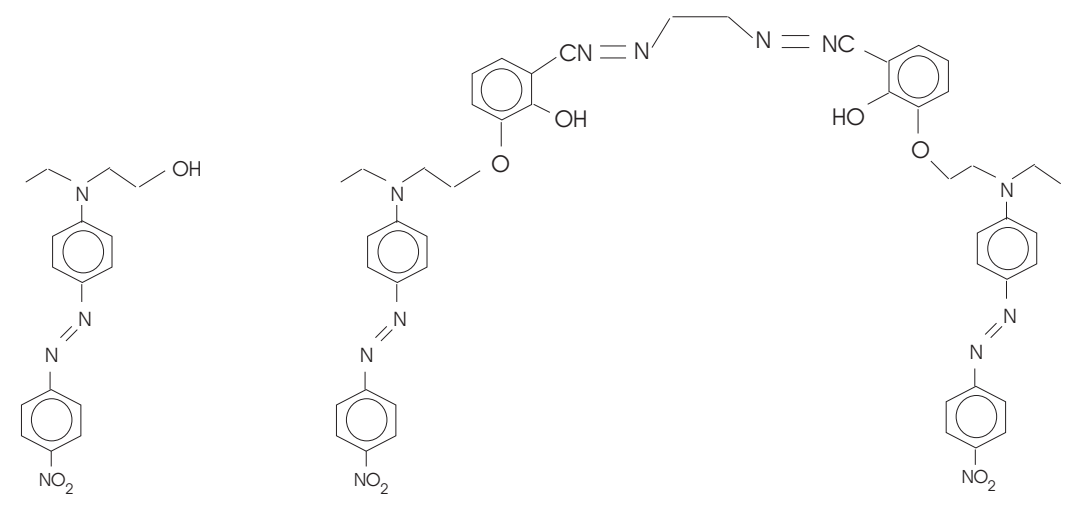

Figura 3.9: Molécula do corante DR1 à esquerda e a molécula de Salen Dye sem metal à direita. Note que os ramos da molécula de Salen são idênticos a molécula de DR1.

Preparamos uma solução de DR1 em NMP com o dobro da concentração de azocromóforos DR1 $\left(2.10^{17}\right.$ moléculas $\left./ \mathrm{cm}^{3}\right)$ em relação à concentração de moléculas de Salen Dye, $\left(1.10^{17}\right.$ moléculas $\left./ \mathrm{cm}^{3}\right)$ e procedemos da forma anteriormente descrita para a obtenção do espectro de absorção de dois fótons. Os resultados para os traços da varredura-Z foram aproximadamente iguais, em magnitude. A Fig. 3.10 apresenta as valores obtidos para a variação da transmitância normalizada $(\Delta \mathrm{T})$ para as soluções de DR1 (círculos) e para a solução de Salen Dye (cruzes).

A Fig. 3.10 mostra que as soluções de DR1 e de Salen apresentam o mesmo espectro para a variação da transmitância. Esse fato era esperado uma vez que a concentração dos cromóforos é a mesma nas duas soluções. Esse fato indica que apenas os grupos azo-aromático das moléculas de Salen são responsáveis pela absorção dos dois fótons. 


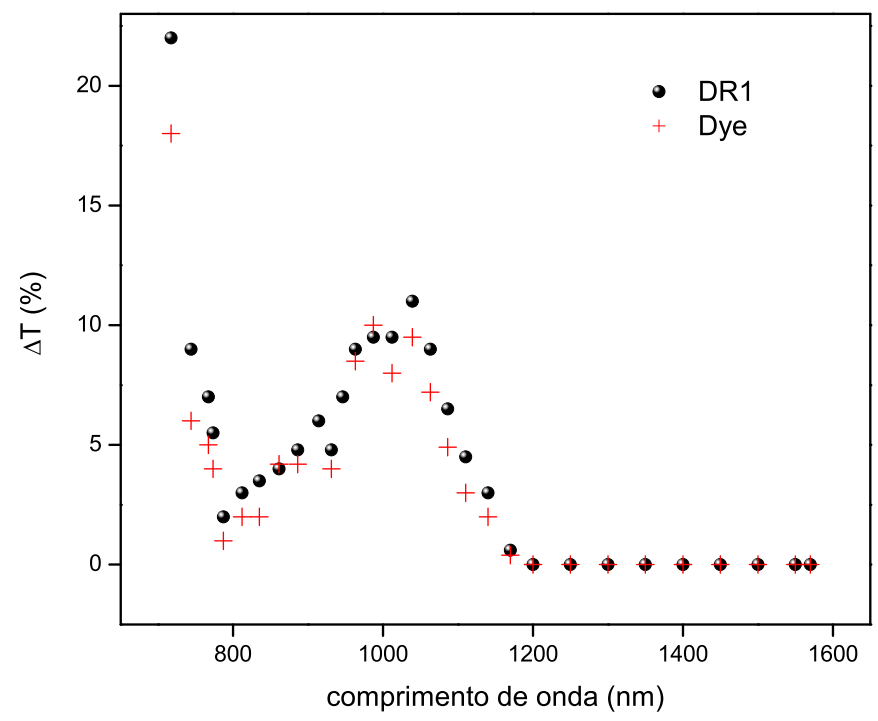

Figura 3.10: Variação da transmitância normalizada $\Delta T$ para diferentes comprimentos de onda para as soluções de Salen e DR1.

\subsection{Interpretação dos resultados das seções de choque segundo o modelo da soma de estados}

Nessa seção vamos utilizar os resultados da teoria de soma de estados descrita no Capítulo 2 para interpretar os resultados das seções de choque de absorção de dois fótons das moléculas de Salen. A seguinte equação foi apresentada no Capítulo 2 para a seção de choque de absorção de dois fótons $\delta$ :

$$
\delta=\frac{(2 \pi)^{4} \nu_{P}^{2}}{(c h)^{2}} g\left(2 \nu_{P}\right)\left|S_{f 0}\right|^{2}
$$

onde $g\left(2 \nu_{p}\right)$ é dada pela Eq. 2.10 e representa a forma da linha da transição de dois fótons. $\left|S_{f 0}\right|^{2}$ é o tensor de dois fótons e é dado pela Eq. 2.11 Utilizaremos o modelo proposto por Kamada et al [25], que é uma simples extensão do modelo de três níveis. Nesse modelo é proposta a existência de dois estados finais, $|1\rangle$ e $|2\rangle$ e um estado intermediário $|j\rangle$. Dessa forma, a equação para a seção de choque $\delta$ é dada por [25]:

$$
\delta\left(\nu_{p}\right)=\frac{4}{5 \pi} \frac{(2 \pi)^{2}}{(c h)^{2}} \frac{\nu^{2}}{\left[\left(\nu_{0 j}-\nu\right)^{2}+\Gamma_{01}^{2}\right]}\left[\frac{\left|\mu_{01}\right|^{2} \Delta \mu_{01}^{2} \Gamma_{01}}{\left(\nu_{01}-2 \nu\right)^{2}+\Gamma_{01}^{2}}+\frac{\left|\mu_{12}\right|^{2}\left|\mu_{01}\right|^{2} \Gamma_{02}}{\left(\nu_{02}-2 \nu\right)^{2}+\Gamma_{02}^{2}}\right]
$$


$\nu_{m n}, \Gamma_{m n}$ e $\mu_{m n}$ representam, respectivamente, a energia de transição, constante de amortecimento e momento de dipolo de transição entre os estados $n$ e $m$. Nessa expressão, $\Delta \mu_{01}=\mu_{11}-\mu_{00}$, onde $\mu_{11}$ é o momento de dipolo da molécula excitada e $\mu_{00}$ é o momento de dipolo da molécula no estado fundamental. Na Eq. 3.5, o termo entre os colchetes referem-se a forma da linha de transição de dois fótons e pode ser separado em uma contribuição do tipo dipolar, correspondente a transição por dois fótons para o estado $|1\rangle$ (transição $\pi \mapsto \pi^{*}$ ), fortemente permitida por um fóton, e um segundo estado final $|2\rangle$ na região do ultra-violeta. Assumimos por simplicidade que somente um estado intermediário contribui significativamente para o processo. Esse estado intermediário corresponde ao termo fora dos colchetes na Eq 3.5 .

A curva sólida na Fig. 3.11 representa a curva ajustada pela Eq. 3.5. A frequência $\nu_{01}$ foi obtida do pico de absorção de dois fótons correspondente a transição $\pi \mapsto \pi^{*}$. $\mu_{01}$ foi obtido através do espectro de absorção linear. Para as constantes de amortecimento usamos $\Gamma_{01} \approx 4000 \mathrm{~cm}^{-1}$, correspondente à largura da linha observada no espectro linear e $\Gamma_{02} \approx 10000 \mathrm{~cm}^{-1}$ [40].

De acordo com o modelo, o pico de dois fótons em 1000 nm deve-se ao primeiro termo entre parênteses da Eq. 3.5. Para freqüências cujo dobro localiza-se em torno de $\nu_{01}$, temos um máximo associada a este termo, produzindo o pico observado. Partindo desse pico, que corresponde à ressonância por dois fótons, e examinando valores decrescentes do comprimento de onda observa-se um grande aumento da magnitude da seção de choque de absorção de dois fótons. Esse efeito é denominado engrandecimento por ressonância e é caudado pela aproximação do comprimento de onda de excitação da região de ressonância do espectro de absorção linear. Podemos interpretar o engrandecimento por ressonância com base na Eq. 3.5. Nessa equação, o termo correspondente ao tensor de dois fótons, termo fora dos colchetes, cresce devido a diminuição da magnitude do denominador desse termo. Outra causa para o engrandecimento refere-se ao segundo termo entre os colchetes, que cresce devido à proximidade de $2 \nu$ da freqüência do segundo estado final, $|2\rangle$.

Os numeradores dos termos da Eq. 3.5 entre os colchetes foram tratados com parâmetros ajustáveis para a obtenção das curvas provenientes do modelo. O ajuste desses parâmetros e o conhecimento do momento de dipolo da transição, $\mu_{01}$, obtido do espectro 


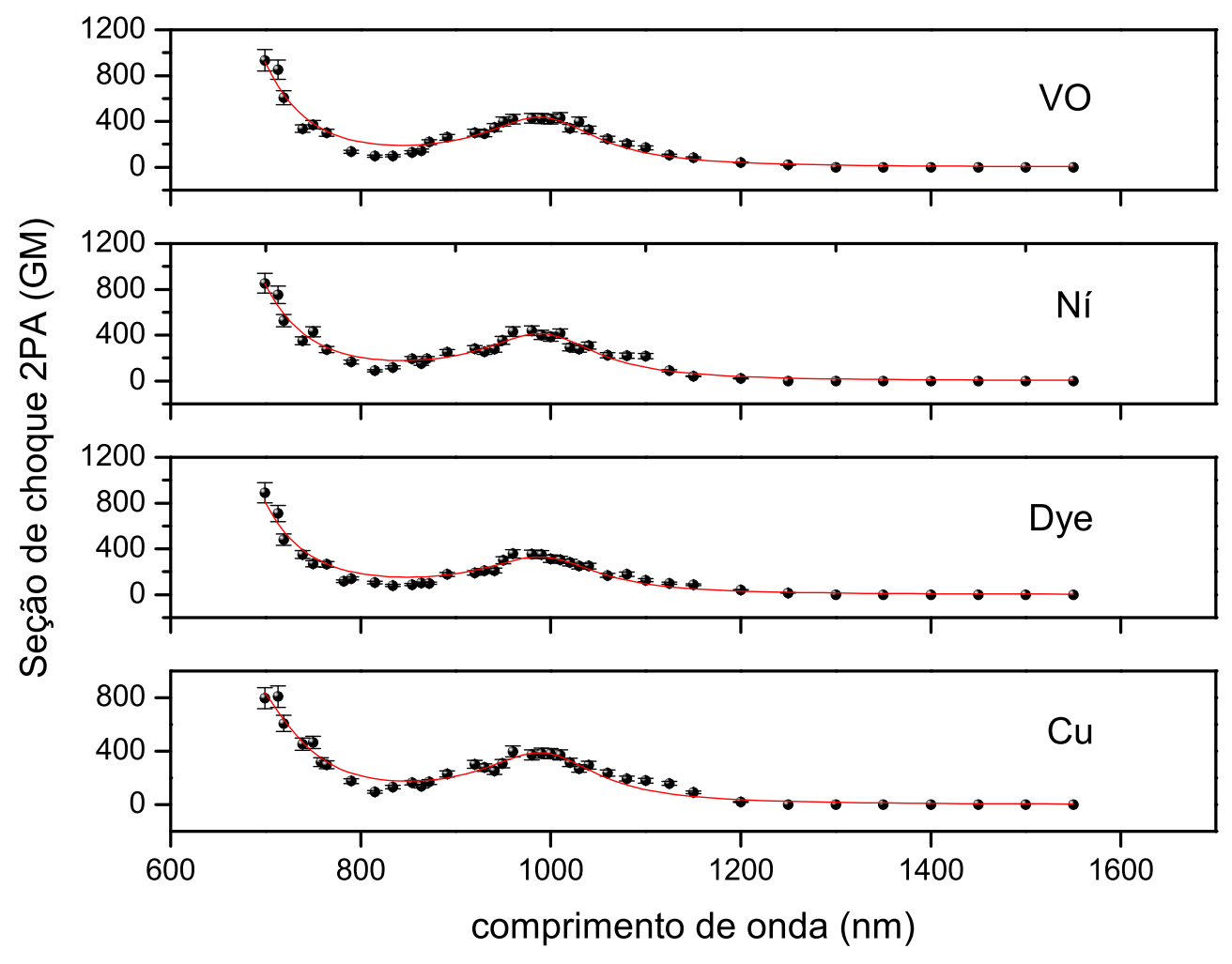

Figura 3.11: Ajuste da equação proveniente do modelo SOS.

linear, nos possibilitou determinar o momento de dipolo da transição $\mu_{12}$ e a variação do momento de dipolo entre os estados fundamental e primeiro final, $\Delta \mu_{01}$.

A força de oscilador da absorção de um fóton, da transição eletrônica do estado fundamental $|0\rangle$ para o estado final $|1\rangle$ pode ser obtido por [52]

$$
f_{01}=\frac{8 \pi^{2}}{3} \frac{m}{e^{2} h} \nu_{01}\left|\mu_{01}\right|^{2}
$$

onde $m$ é a massa do elétron, $e$ é a carga do elétron e $\nu_{01}$ é a freqüência da transição entre os dois estados.

A força de oscilador calculada é relacionada à intensidade integrada experimental pela equação

$$
f_{01}=\frac{m c}{\pi e^{2} C} \int \alpha(\nu) d \nu
$$

onde $\alpha$ é o coeficiente de absorção linear medido em $\mathrm{cm}^{-1}, \nu$ é a frequência em $\mathrm{Hz}$ e $C$ 
é a concentração da amostra em moléculas por $\mathrm{cm}^{3}$. Para integrar a Eq. 3.7 utilizamos uma função Gaussiana para representar a banda espectral experimental. Dessa forma,

$$
f_{01}=\frac{m c}{\pi e^{2} C} \sqrt{\pi} \alpha_{\max } \theta
$$

onde $\theta$ é um parâmetro de largura [52]. Assim, através das Eqs. 3.6 e 3.7 pode-se determinar o momento de dipolo $\mu_{01}$, desde que a largura de banda e $\alpha_{\max }$ sejam conhecidos. A tabela 3.1 mostra os valores de $\mu_{01}$ determinados utilizando esse procedimento para todas as amostras estudadas como $\mu_{01}^{e x p}$. Como $\mu_{01}$ é conhecido do epectro linear, podemos determinar $\mu_{12}$ e $\Delta \mu_{01}$. Estes valores são listados na Tabela [3.1] respectivamente como $\mu_{12}^{e x p}$ e $\Delta \mu_{01}^{e x p}$.

Tabela 3.1: Momentos de dipolo experimentais e calculados para as moléculas de Salen. Todos os valores estão expressos em Debyes (D).

\begin{tabular}{|l|l|l|l|l|}
\hline Molécula & $\mu_{01}^{\exp }$ & $\mu_{12}^{\exp }$ & $\Delta \mu_{01}^{\exp }$ & $\Delta \mu_{01}^{\text {teorico }}$ \\
\hline Salen Dye & 15,6 & 14,1 & 11,4 & 9,7 \\
\hline Salen Níquel & 15,6 & 13,3 & 11,7 & 12,1 \\
\hline Salen Cobre & 15,6 & 14,8 & 11,5 & 10,1 \\
\hline Salen Vanádio & 15,6 & 15,9 & 12,6 & 11,7 \\
\hline
\end{tabular}

Para dar suporte aos nossos resultados experimentais sobre os momentos de dipolo, utilizamos outra informação obtida através de cálculos de mecânica quântica molecular utilizando o programa Hyper-Chem [53]. O programa nos forneceu os valores do momento de dipolo permanentes do estado fundamental, $\mu_{00}^{\text {teorico }}$, e do primeiro estado excitado, $\mu_{11}^{\text {teorico }}$. A partir desses valores, foi possível de se calcular a variação entre esses momentos de dipolo permanentes

$$
\Delta \mu_{01}^{\text {teorico }}=\mu_{11}^{\text {teorico }}-\mu_{00}^{\text {teorico }}
$$

A Tabela 3.1. em sua última coluna, mostra os resultados desses cálculos. Observa-se que os valores calculados pelo programa concordam com os valores obtidos do experimento. Além disso, esses valores concordam também com os obtidos por Day et al. em seus 
estudos sobre moléculas azo-aromáticas isoladas [52].

Os cálculos foram realizados através do método semi-empírico Zindo1 (Zerner's Intermediate Neglect of Differential Overlap) [54]. O ZINDO é um método semi-empírico de mecânica quântica molecular que negligencia a sobreposição entre orbitais. Ignorar essa sobreposição acarreta em uma grande simplificação pois integrais complicadas, referentes à interação entre elétrons, são ignoradas.

\subsection{Conclusões}

Nesse capítulo determinamos, através da técnica de varredura-Z, o espectro de absorção de dois fótons degenerado das moléculas de Salen Dye. A partir desses resultados fomos capazes de determinar as variações dos momentos de dipolos entre os estados fundamentais e os primeiros estados excitados dessas moléculas. Os valores dessas variações de momento de dipolo concordam com cálculos provenientes do programa de química quântica HyperChem. Concluímos que os picos observados nesse espectro devem-se às mudanças de momento de dipolos do grupo azo-aromático, que ocorre quando as moléculas são excitadas pela luz e que os efeitos absorcivos estão ligados apenas à parte azo-aromática da molécula. A hipótese de que os metais não influenciam na absorção de luz devido à quebra na conjugação das ligações $\pi$ foi confirmada pela comparação do espectro das moléculas Salen com o espectro do azo-cromóforo DR1. Verificamos que as moléculas de DR1 possuem comportamento análogo às moléculas de Salen Dye com respeito à absorção de luz, por 1 ou 2 fótons. O importante efeito de engrandecimento da seção de choque da absorção de dois fótons, que ocorre quando o comprimentos de onda se aproxima da ressonância linear das moléculas, foi explicada pelo modelo de 4 níveis [25], um modelo simplificado proveniente da teoria geral da soma de estados [21, 19, seção 2.2.3. 


\section{Capítulo 4}

\section{Armazenamento óptico via absorção de dois fótons em amostras de polímero contendo DR13 e Salen Dye}

As propriedades ópticas dos azo-cromóforos, particularmente em estruturas poliméricas, tem sido intensivamente estudadas nos últimos anos devido ao grande potencial que esses compostos apresentam para aplicações em dispositivos ópticos [2, 55, 56, 30]. A possibilidade da produção de birrefringência através da luz é uma das aplicações mais importantes. Além dessa aplicação, podemos citar estudos sobre deslocamento de massa em superfícies poliméricas e aplicações de óptica não linear como, por exemplo, a produção de dispositivos moduladores de luz 57.

\subsection{Introdução}

O método utilizado para armazenar informações utilizando as moléculas azo-aromáticas é baseado no efeito Weigert [58]. Esse efeito utiliza radiação polarizada para criar anisotropia em determinados materiais. O fenômeno chave que permite esse tipo de aplicação é o movimento das moléculas do cromóforo que resulta da reação de foto-isomerização. O movimento deve-se ao fato de que os isômeros possuem configurações espaciais bastante diferentes, como pode ser visto na Fig. 2.2. Desse modo, na interconversão entre 
as configurações isoméricas ocorre movimento molecular significativo. Esse movimento depende de alguns fatores como o volume livre que a molécula possui para a realização do movimento [59], que depende do método e condições escolhidas para confeccionar o dispositivo, e do comprimento de onda da excitação.

Recentemente, a propriedade de absorção de dois fótons em compostos conjugados tem chamado bastante atenção de pesquisadores [52, 60, e estudos teóricos e experimentais tem sido realizados sobre a foto-isomerização induzido pela absorção de dois fótons [61, 62]. Motivados por esses resultados iniciamos nossos estudos de indução de birrefringência via absorção de dois fótons em um sistema constituído do cromóforo vermelho disperso 13 (DR13) em matriz de poli-metacrilato de metila (PMMA). A estrutura química do cromóforo DR13 está apresentada na Fig. 4.1.

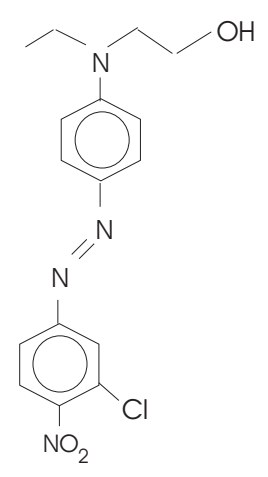

Figura 4.1: Estrutura do cromóforo vermelho disperso 13 (DR13).

\subsection{Gravação e leitura de informações utilizando mate- riais azo-aromáticos}

Nessa seção descrevemos o método de armazenamento de informação utilizando as moléculas azo-aromáticas imersas em material polimérico. O método baseia-se na utilização de luz linearmente polarizada para induzir as foto-isomerizações. Inicialmente as moléculas do cromóforo, no nosso caso o DR13, estão orientados ao acaso no interior do filme de polímero. É importante saber que as moléculas que possuem orientações próximas da orientação da polarização da luz laser possuem maior probabilidade de absorver essa luz. 
Como já mencionamos, uma molécula azo-aromáticas que absorve luz é levada a uma outra orientação espacial. Nessa nova orientação espacial, a probabilidade da molécula absorver novamente luz e realizar outro processo de foto-isomerização é diferente da probabilidade anterior. As moléculas que se orientam próximas à direção perpendicular à polarização da luz apresentam baixa probabilidade de serem submetidas novamente ao processo de foto-isomerização. Dessa forma, a incidência de luz polarizada aumenta a população das moléculas que se orientam em torno da direção perpendicular à polarização da luz. Essa anisotropia produzida pela diferença de orientações populacionais torna a amostra birrefringente. O índice de refração na direção da polarização da luz é diferente do índice de refração na direção perpendicular a essa polarização. Essa diferença é devida a forte dependência da constante dielétrica, por conseqüência do índice de refração, com as orientações dos dipolos elétricos, ou polarização do meio. A Fig. 4.2 apresenta uma ilustração desse processo de orientação molecular.
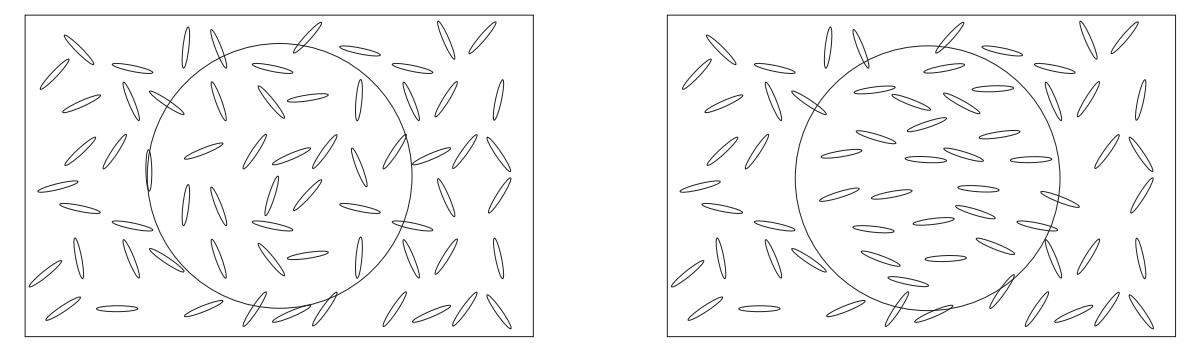

Figura 4.2: Ilustração bidimensional da orientação dos dipolos moleculares das moléculas azo-aromáticas em um filme polimérico. Na figura da esquerda, os dipolos estão orientados ao acaso. Porém na figura da direita os dipolos apresentam uma orientação preferencial provocado pela absorção de luz com polarização vertical.

O laser que produz a excitação das moléculas e a conseqüente foto-isomerização é chamado laser de excitação (escrita). Para excitações lineares, luz de comprimento de onda na região do verde é fortemente absorvida pelas moléculas azo-aromáticas, que possuem uma banda de absorção em torno de $500 \mathrm{~nm}[3]$ devido a transição entre os estados $\pi \mapsto \pi^{*}$. Para excitações por absorção de dois fótons o laser deve ter comprimento de onda no infravermelho, em torno de $1000 \mathrm{~nm}$, por exemplo. Nesse caso, a soma das energias de dois fótons é suficiente para promover a transição eletrônica. Em nosso trabalho, devido 
a facilidades operacionais, utilizamos pulsos de radiação infravermelha de comprimento de onda de $775 \mathrm{~nm}$. Deve ser observado que a seção de choque de absorção de dois fótons para $775 \mathrm{~nm}$ é aproximadamente o mesmo que para $1000 \mathrm{~nm}$ [31]. Esse fato deve-se ao efeito de engrandecimento por ressonância explicado no Capítulo 3. O espectro de absorção de dois fótons das moléculas de DR13 mostrando esse efeito pode ser encontrado na referência [31. A Fig. 4.3 mostra o espectro de absorção linear do filme.

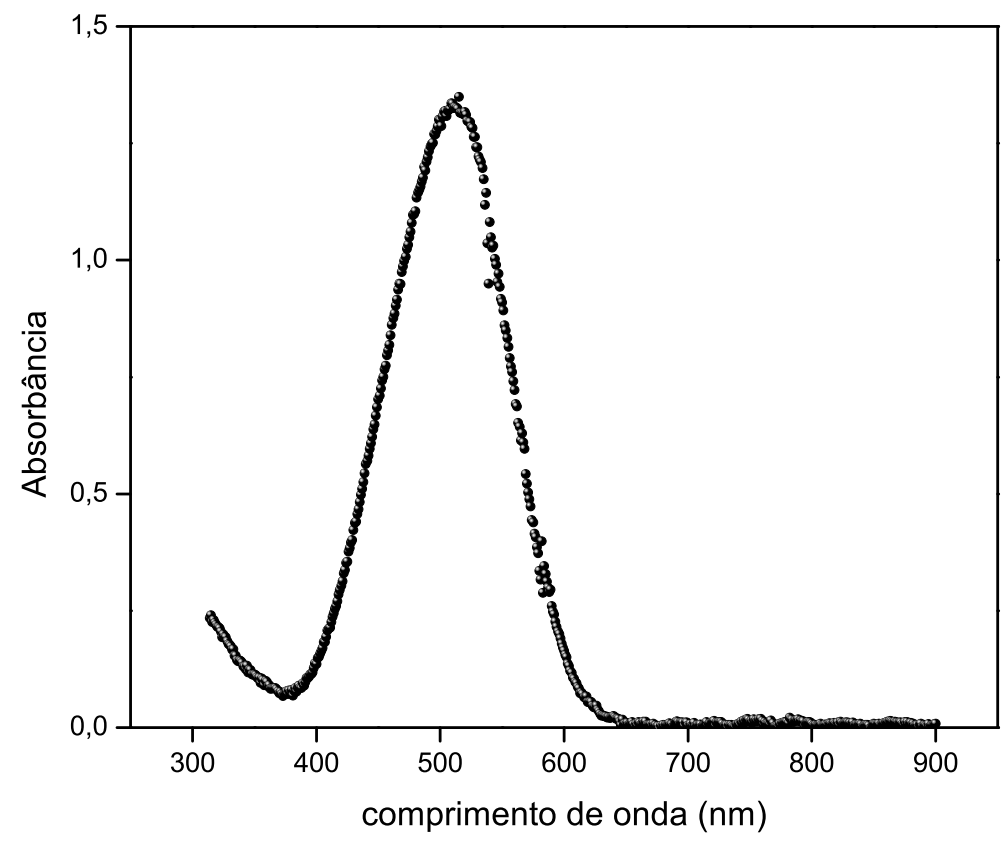

Figura 4.3: Espectro de absorção linear do filme de PMMA contendo o cromóforo DR13. A banda de absorção observada em torno de $500 \mathrm{~nm}$ refere-se, orincipalmente, a tranição eletrônica $\pi \mapsto \pi^{*}$ das moléculas de DR13.

\subsection{Produção e medida da birrefringência nos filmes}

\subsubsection{Preparação do filme}

O método do derramamento, mais conhecido como método casting, foi escolhido para a produção do filme. Esse método é muito simples e permite a produção de filmes espessos, que são mais convenientes para as medidas realizadas por produzir um maior sinal devido a maior transmissão de luz. 
Uma solução foi preparada dissolvendo 0,0089 gramas de DR13 (Aldric) mais 0,3838g de PMMA em $4 \mathrm{ml}$ de clorofórmio. Essas quantidades produzem filmes contendo 2,3 \% de DR13 em PMMA. É importante salientar que o ambiente deve ser refrigerado para que a evaporação do solvente não seja muito rápida, a temperatura do ambiente foi de $20^{\circ} \mathrm{C}$. A evaporação rápida do solvente pode fazer com que os filmes fiquem turvos, sem qualidade óptica para as medidas. Utilizamos uma lâmina de vidro para suportar o filme. Essa lâmina depois de lavada com detergente foi banhada em álcool etílico e secada com nitrogênio. Com auxílio de uma pipeta de Pasteur, a solução foi gotejada sobre o substrato. Visando diminuir a taxa de evaporação do solvente, o sistema foi coberto com um vidro de relógio. Após a evaporação do solvente no ambiente refrigerado, o sistema substrato mais filme é levado para estufa e submetido a uma temperatura de $100^{\circ} \mathrm{C}$ por 12 horas. Após esse procedimento, o filme é retirado do substrato através de imersão em água. Este filme é então novamente levado à estufa e secado por duas horas a $100^{\circ} \mathrm{C}$. Ao final de todo esse procedimento, o filme apresentou espessura de $150 \mu \mathrm{m}$. Além disso, o filme mostrou-se auto-sustentável e de excelente qualidade óptica.

\subsubsection{Aparato experimental}

Para a produção da birrefringência foram utilizados pulsos de luz laser com largura temporal de aproximadamente de $150 \mathrm{fs}$, provenientes de um amplificador de Ti:Safira que emite pulsos numa taxa de repetição de $1 \mathrm{KHz}$. Para detectar a birrefringência induzida no filme, utilizamos um feixe laser de baixa intensidade (He-Ne) de comprimento de onda de $632,8 \mathrm{~nm}$, conforme ilustra a Fig. 4.4

A luz do laser de He-Ne atravessa dois polarizadores cruzados, com eixos de polarização fazendo $45^{\circ} \mathrm{com}$ a vertical e $90^{\circ}$ entre si, representado na Fig. 4.4. Dessa forma, a luz desse laser não chega ao detector. Quando os pulsos de luz de escrita, verticalmente polarizados, provenientes do laser de Ti: Safira incidem na amostra, ocorrem rearranjos nas orientações das moléculas azo-aromáticas, como já foi descrito, levando à produção de birrefringência no filme polimérico. Essa birrefringência produz uma mudança na polarização da luz do feixe de He-Ne de linear para elíptica, permitindo que uma fração desta chegue ao detector. A Fig. 4.5ilustra um resultado típico obtido desse experimento. 


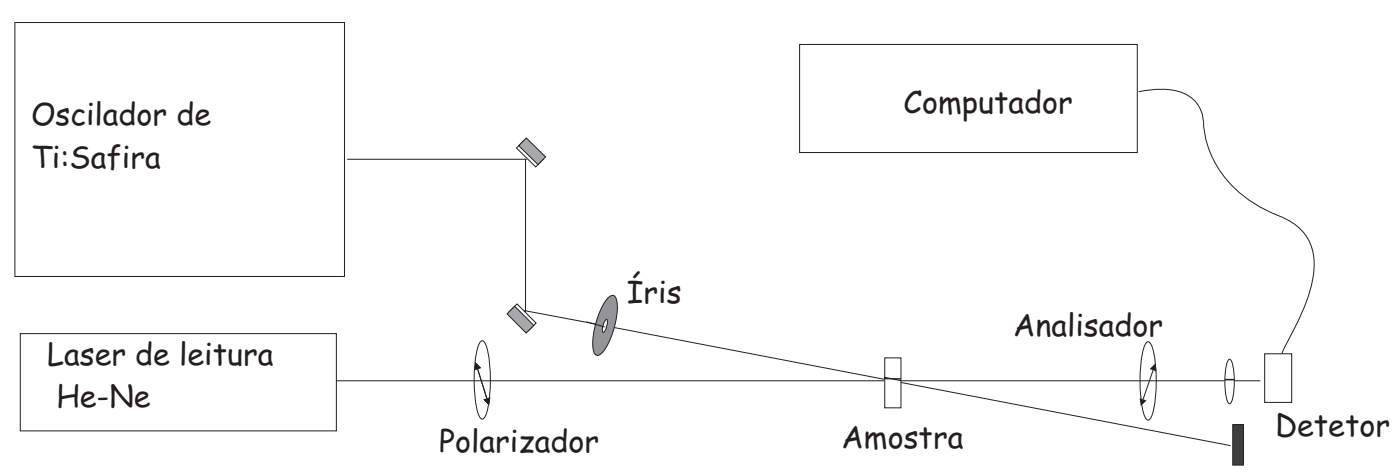

Figura 4.4: Ilustração do aparato experimental utilizado para indução e medida da birrefringência. É importante notar que o feixe não foi focalizado na amostra. A íris limitou o diâmetro da seção tranversal do feixe para $2 \mathrm{~mm}$.

No ponto A, o laser que cria a birrefringência, chamado laser de escrita, é aberto e incide na amostra. O crescimento do sinal detectado deve-se a birrefringência induzida na amostra. A birrefringência cresce até o instante em que o laser de escrita é desligado, ponto B na figura. A partir desse ponto ocorre uma queda do sinal devido à relaxação da orientação molecular induzida. Para aplicações de armazenamento óptico de informação, é interessante que esse sinal não desapareça para que a informação não se perca. É possível obter altos valores de birrefringência residual através da manipulação da estrutura química do material como, por exemplo, ligando o cromóforo quimicamente à matriz polimérica [63, 64, 8]. Outra possibilidade está no método utilizado para produzir o material [65, 7, 66]. No entanto, pode ser que se queira apagar a informação. Isso pode ser feito facilmente nesse tipo de memória de duas maneiras: aumentando a temperatura do filme para próxima da temperatura de transição vítrea do material, ou através da incidência de luz circularmente polarizada [8]. 


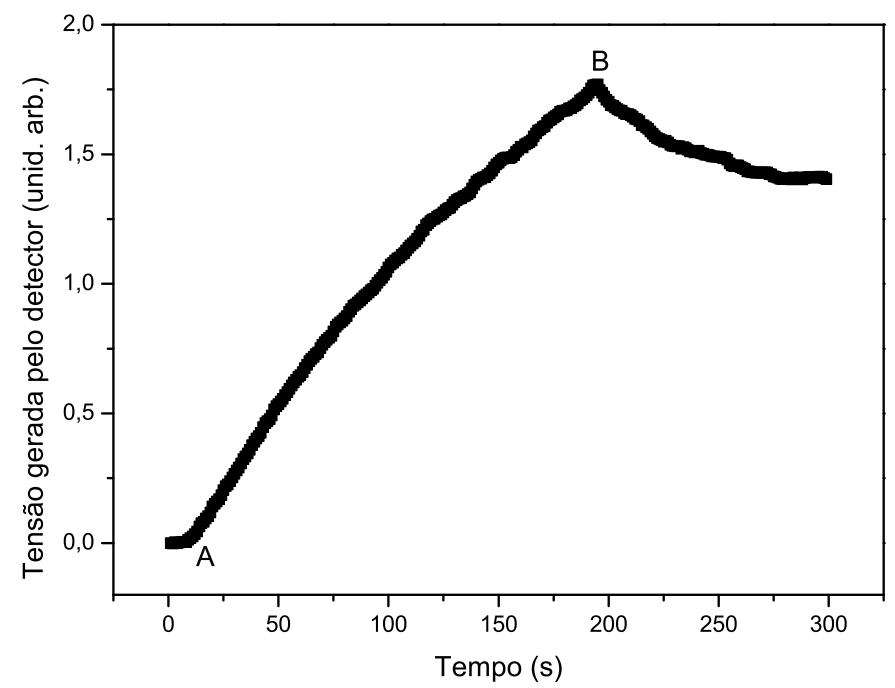

Figura 4.5: Resultado ilustrativo obtido em uma medida de birrefringência induzida via absorção de dois fótons em filme polimérico de PMMA contendo moléculas de DR13.

\subsubsection{Resultados das medidas de birrefrigência}

A Fig. 4.6 apresenta os resultados das birrefringência induzida no filme polimérico de PMMA com DR13 para seis intensidades médias de luz.

Para calcular a birrefringência a partir dos sinais gerados pelo detector utiliza-se a seguinte relação:

$$
\Delta n=\frac{\lambda}{\pi d} \operatorname{sen}^{-1} \sqrt{T}
$$

onde $\lambda$ é o comprimento de onda do laser de leitura $(632,8 \mathrm{~nm}), d$ é a espessura da amostra, $T$ é a razão entre a intensidade da luz do laser de leitura que é transmitida através da amostra e a intensidade da luz que incide na amostra, a transmitância $T=I / I_{0}$. A intensidade da luz de leitura é reduzida para um valor em torno de $10 \mu W$. O valor de tensão correspondente a $I_{0}$ é muito alto para ser medido pelo detector e foi necessário a utilização de filtros de transmitância conhecida para determinar esse valor.

Os resultados apresentados na Fig. 4.6 tem com principal objetivo demonstrar a possibilidade de armazenamento óptico via absorção de dois fótons. Observa-se o crescimento da birrefringência induzida pelos pulsos de luz de comprimento de onda de $775 \mathrm{~nm}$, portanto fora da banda de absorção linear da amostra, como pôde ser visto na Fig. 4.3 


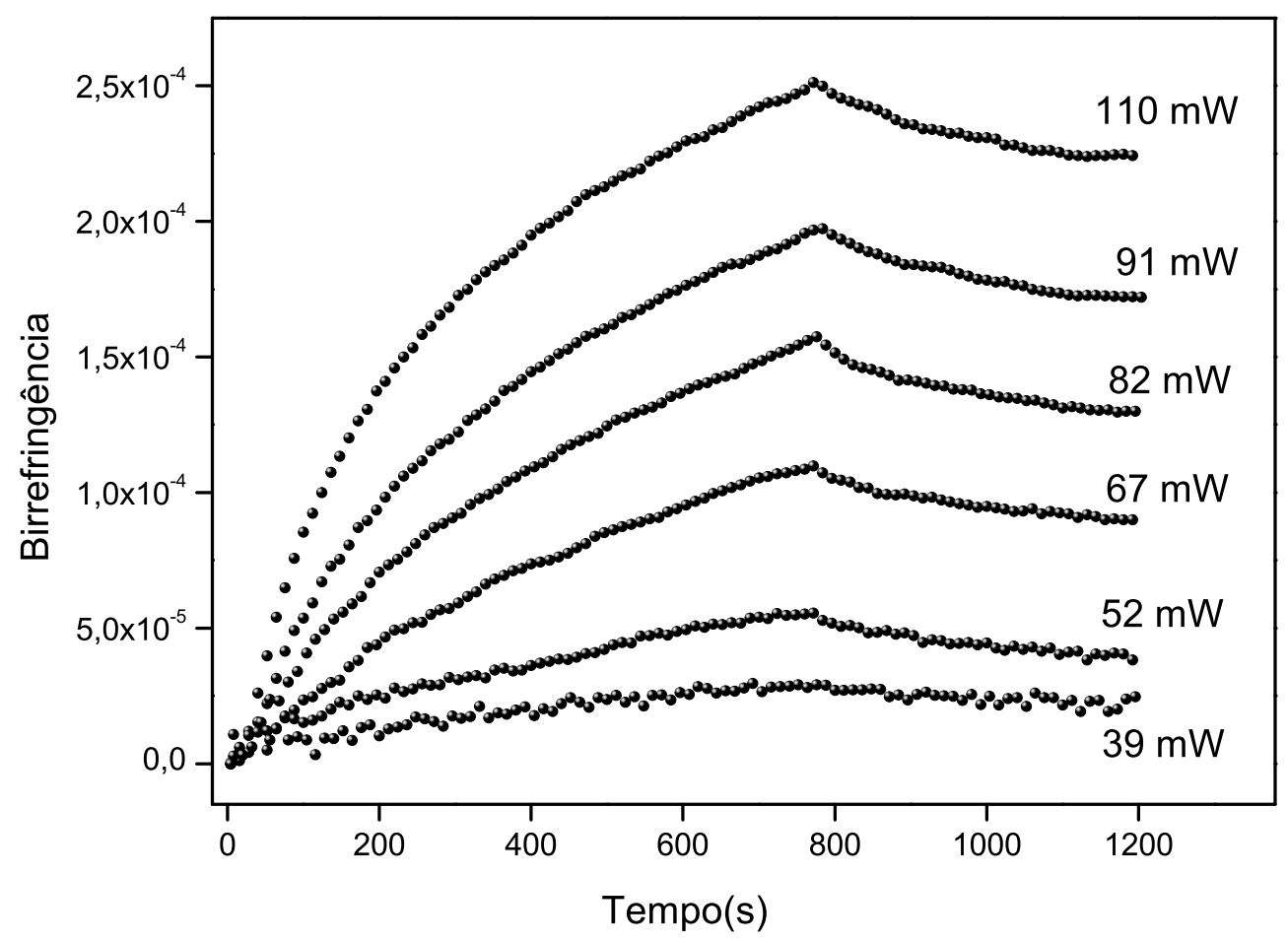

Figura 4.6: Resultado das medidas de birrefringência induzida por dois fótons em filme de PMMA contendo moléculas azo-aromáticas DR13. A figura mostra sei potências médias diferentes do laser de escrita.

É interessante notar que a birrefringência cresce de maneira aproximadamente análoga aos experimentos que utilizam luz de comprimento de onda dentro da banda de absorção linear da amostra [55, 8]. Nota-se também que, apesar do tempo relativamente longo de incidência, 800 s, não se observa saturação da birrefringência, fato que ocorre em poucos segundos quando se trabalha com luz de comprimento de onda dentro da banda de absorção linear do material. Esse fato deve-se a baixa eficiência do processo de absorção de dois fótons em relação ao processo de absorção de dois fótons [67]. Para ilustrar esse fato, apresentamos na Fig. 4.7 curvas da evolução temporal do sinal devido à birrefringência induzidas por um e por dois fótons. Outra observação importante é quanto à relaxação, que é mais rápida para a excitação por um fóton. A Fig. 4.7 mostra que para o mesmo intervalo de tempo de relaxação, o sinal produzido por absorção linear cai para $5 \%$ do valor inicial, enquanto que o sinal produzido devido a interação não linear cai para $20 \%$ 
do valor inicial.

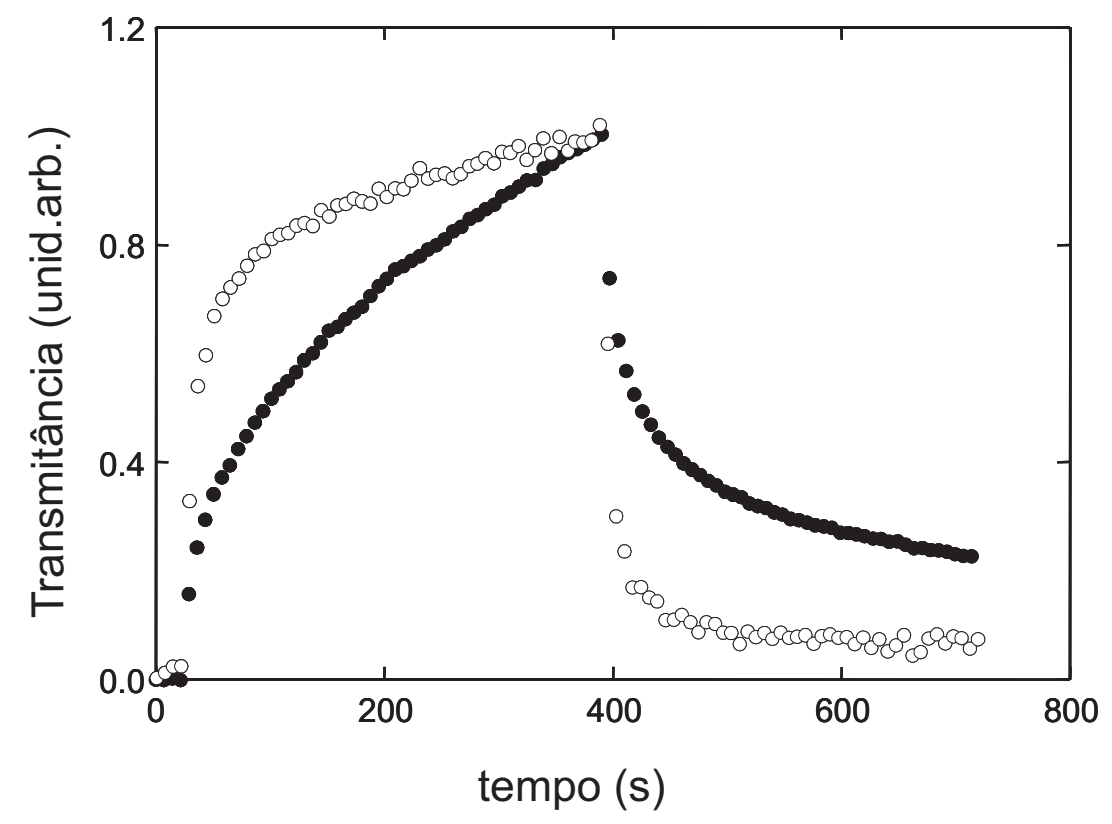

Figura 4.7: Os circulos brancos são devido a birrefringência gerada por luz laser verde $(\lambda=532 \mathrm{~nm}$ ) linearmente ressonante com o material (filme polimérico contendo azomoléculas). Os círculos escuros são devido a radiação fora da ressonância linear $(\lambda=775 \mathrm{~nm})$. A figura mostra que o efeito de memória gravada por 1 fóton cai com taxa maior que a birrefringência gravada por dois fótons.

A Fig. 4.8 mostra em escala logarítmica, o gráfico do logaritmo da birrefringência em função da intensidade no instante de 700 s após o início da gravação. O coeficiente angular próximo de 2 fortalece a hipótese de o efeito ser devido à absorção de dois fótons, já que a absorção de dois fótons cresce com o quadrado da intensidade da radiação.

\subsection{Uma aplicação de armazenamento óptico tridimen- sional}

O objetivo principal dos nossos estudos sobre armazenamento óptico por dois fótons é tomar proveito da possibilidade de localização espacial que é possível conseguir com esse tipo de excitação. A Fig. 2.1 mostra claramente esse efeito de localização do efeito da produção de fluorescência. Utilizando uma lente, podemos focalizar a luz numa região diminuta do espaço e gravar a birrefringência apenas nessa região. A incidência de radiação circularmente polarizada também permite apagar essa informação. Dessa forma, 


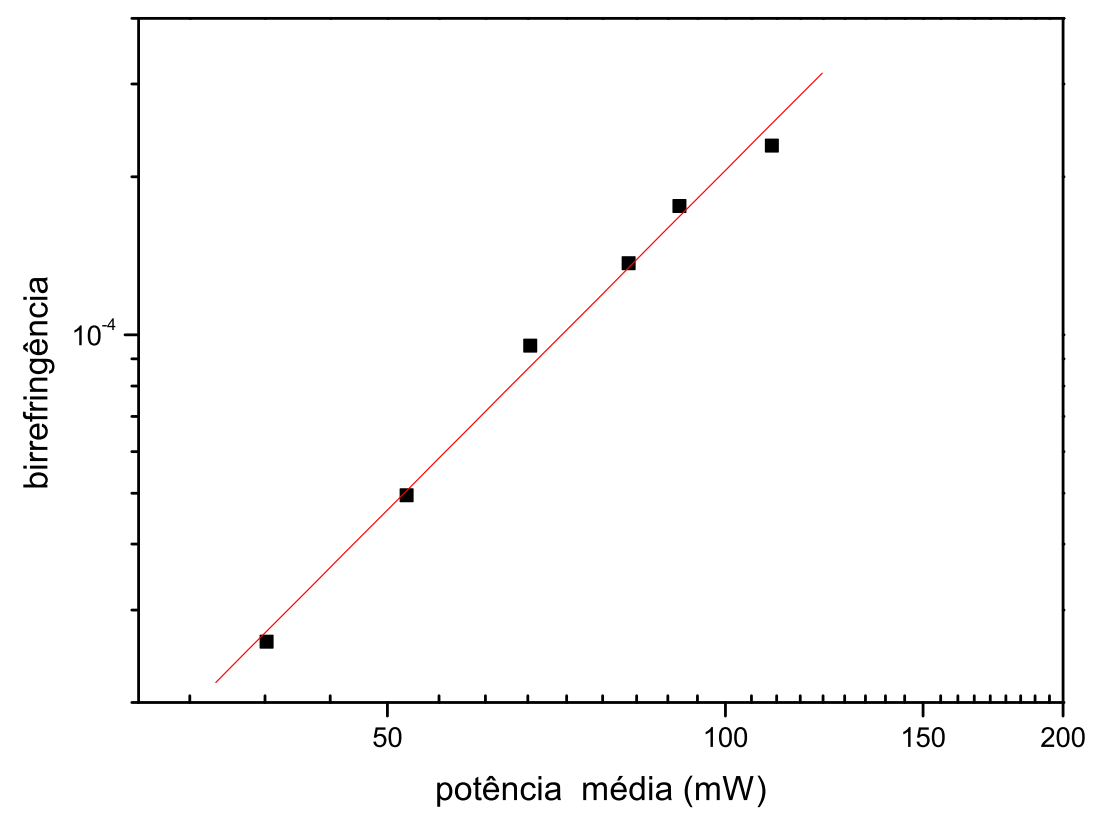

Figura 4.8: Birrefringência em função da potência média. O coeficiente angular da reta é de aproximadamente 2,1 .

a informação poderia ser gravada no interior do material, aumentando enormemente a capacidade de armazenamento de informação. Com esse objetivo, foi preparado um bloco de polímero contendo moléculas azo-aromáticas.

\subsubsection{A produção do bloco de polímero}

O bloco de polímero foi confeccionado no grupo de polímeros do Instituto de Física de São Carlos, pelos pesquisadores D.S. dos Santos Jr. e F.J. Pavinatto, que se basearam na seguinte referência [65. Foi utilizado o reagente de nome [4'[[2-(Meth-acryloyloxy)ethyl]ethylamino]-2-chloro-4-nitroazobenzeno metacrilato], abreviadamente DR13Ma (aldrich). A polimerização foi realizada em uma ampola de vidro contendo 18,72 g (0,187 moles) de metil-metacrilato (MMA), 0,021 g (5,04.10-6 moles) de DR13Ma e 0,0032 g de 2,2-azobisisobutyronitrile (AIBN). A ampola foi resfriada em nitrogênio líquido e colocada em vácuo e então selada. A temperatura foi elevada até a temperatura ambiente e depois aquecida até $60^{\circ} \mathrm{C}$ por duas horas. Após esse procedimento, se obtém o polímero desejado. A ampola foi quebrada e o material foi cortado em forma de paralelepípedo de dimensões 
$1 \times 2 \times 0,5 \mathrm{~cm}$, e cuidadosamente polido.

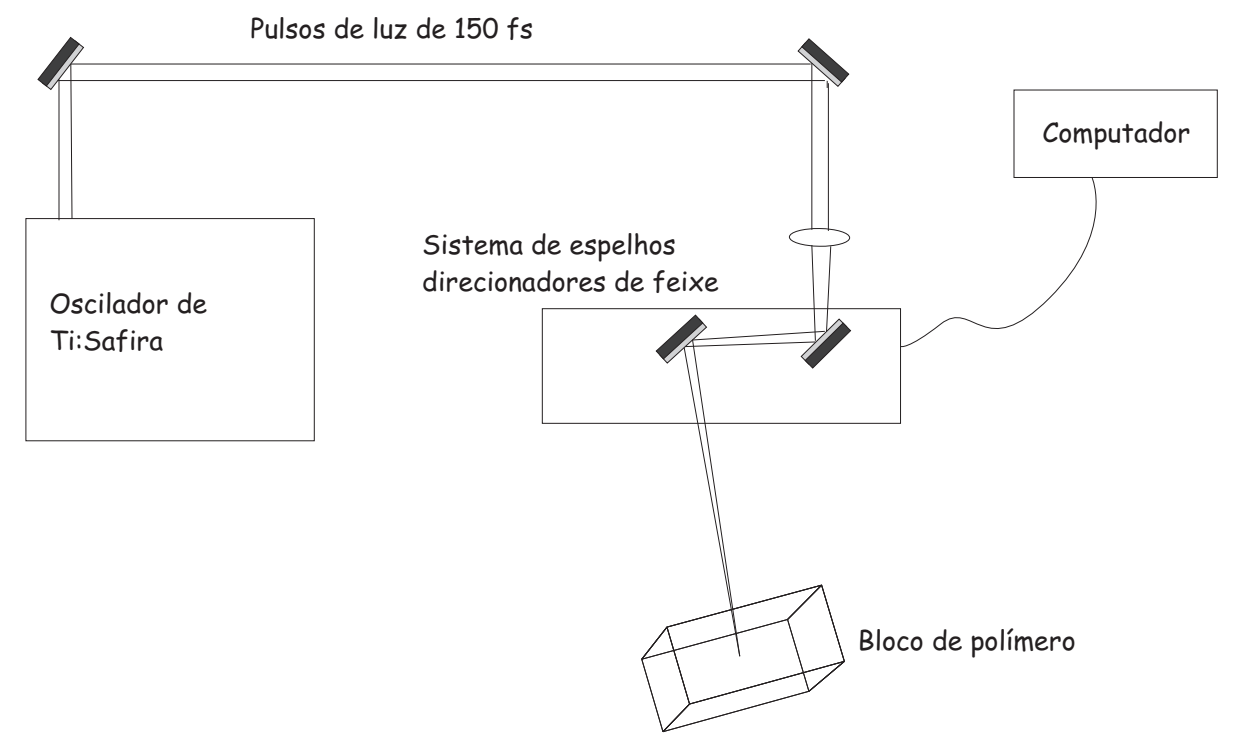

Figura 4.9: O sistema é capaz de focalizar a luz no interior do bloco. A distância focal da lente e o perfil espacial e temporal do pulso, determinam o tamanho da região onde a luz é focalizada.

\subsubsection{Gravação da informação no interior do bloco}

Para realizar a gravação foi desenvolvido um dispositivo mecânico, controlado por computador, que permite a movimentação do feixe laser focalizado no interior do bloco. A distância focal da lente, o tipo de pulso e o comprimento de onda determinam o tamanho da região focal. Um esquema deste dispositivo de gravação é mostrado na Fig. 4.9.

A Fig. 4.10 apresenta o anagrama USP, escrito via birrefringência induzida por absorção de dois fótons no bloco de polímero. A imagem é visível apenas quando observada com o auxílio de dois polarizadores cruzados (i). A observação do bloco a olho nu não permite a observação das letras no interior do bloco (ii).

\subsection{Armazenamento óptico em filmes de Salen em PMMA}

As moléculas de Salen com e sem metais, descritas no Capítulo 3, contém dois grupos azo-aromáticos em sua constituição. Dessa forma, esperamos observar efeitos de birrefrin- 


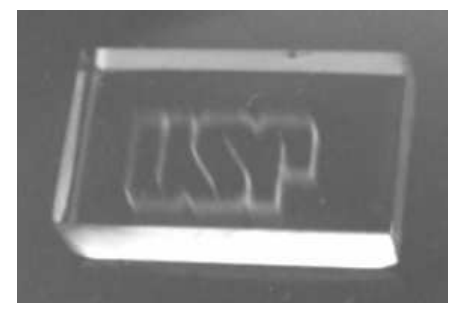

(i)

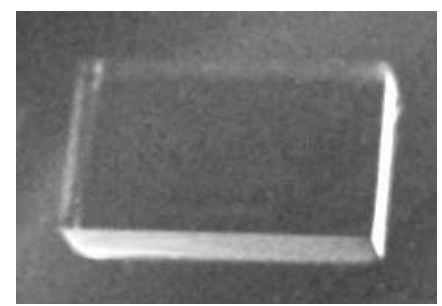

(ii)

Figura 4.10: Fotografias do bloco de polímero onde foi gravado o anagrama da Universidade de São Paulo, USP. A imagem (i) foi obtida com a colocação do bloco entre dois polarizadores cruzados. A imagem (ii) foi obtida sem os polarizadores. As imagens estão estáveis há mais de três anos.

gência foto-induzida nessas moléculas. Essa seção descreve experimentos que tem como objetivo testar esses compostos para aplicações em armazenamento óptico utilizando excitações via um e dois fótons. Foram preparados filmes dos compostos de Salen em matriz de PMMA. Os filmes foram produzidos pelo método casting, de modo semelhante ao descrito na preparação do filme de DR13 com PMMA. Os detalhes sobre a preparação dos filmes podem ser vistos na referência [67]. A Fig. 4.11 apresenta resultados de armazenamento óptico via absorção de um fóton (excitação em $532 \mathrm{~nm}$ ) nos filmes de Salen Dye, enquanto que a Fig. 4.12 apresenta o experimento para as mesmas amostras, mas agora utilizando o efeito de absorção de dois fótons (excitação em $775 \mathrm{~nm}$ ).

As medidas mostram que as moléculas de Salen podem ser utilizadas em experimentos de armazenamento óptico e que presença dos metais não tem importância significativa na propriedade de armazenamento óptico dos filmes. Além dessas observações, outras duas observações podem ser feitas. A primeira é com relação às magnitudes das birrefringências. A birrefringência produzida com a luz de comprimento de onda dentro da banda de absorção linear (532 nm) do material é uma ordem de grandeza maior do que a birrefringência obtida via o efeito de absorção de dois fótons $(775 \mathrm{~nm})$. A segunda observação é com respeito à evolução temporal da birrefringência. Nota-se que para excitação por um fóton, à birrefringência cresce rapidamente e em poucos segundos atinge um valor próximo da saturação. Para a excitação via absorção de dois fótons nota-se que, mesmo após um intervalo de 20 minutos de excitação, a birrefringência continua a crescer. 


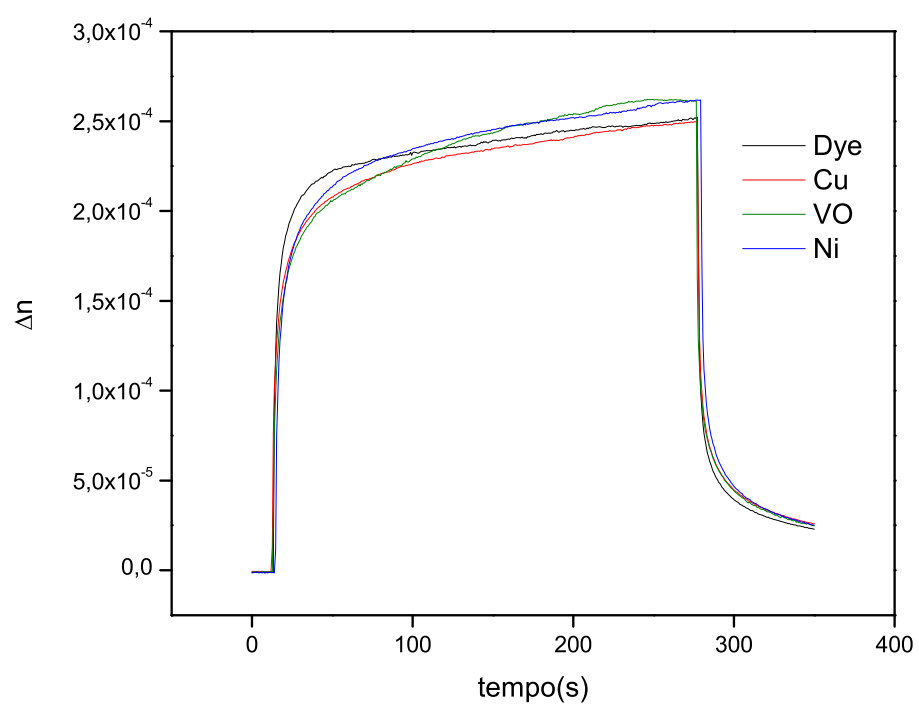

Figura 4.11: Armazenamento óptico em filmes de Salen via absorção de um fóton. A potência média utilizada foi a mesma para todas as amostras ( $8 \mathrm{~mW}$ ).

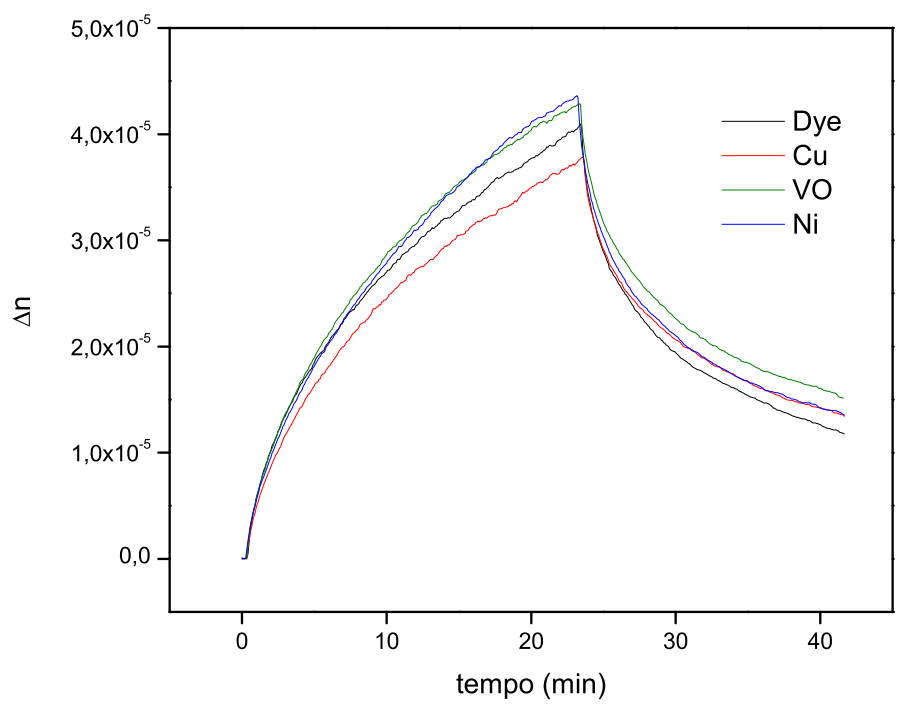

Figura 4.12: Armazenamento óptico em filmes de Salen via absorção de dois fótons. A intensidade média utilizada foi a mesma para todas as amostras $\left(4 \mathrm{GW} / \mathrm{cm}^{2}\right)$. 


\subsection{Modelo simples para a dinâmica da criação da ani- sotropia óptica induzida por luz}

A ligação entre as propriedades macroscópicas e o mecanismo físico em escala molecular é um assunto de grande interesse em ciência. Estudos nesse sentido para a orientação fotoinduzida em azo-polímero têm sido feitos e levam a um melhor entendimento do efeito macroscópico da criação da birrefringência por luz. Sekkat et al. propuseram um modelo para a dinâmica da criação da anisotropia induzida por luz [4]. O desenvolvimento de Sekkat não é de fácil entendimento, devido ao fato de considerar todas as possibilidades de orientação espacial dos dipolos moleculares. O modelo simplificado que propomos é baseado num artigo de Hore, Natansohn e Rochon [68]. Esse modelo é muito simples e considera aproximações muito drásticas. Mas, mesmo assim, o modelo mostrou ser eficiente para nosso objetivo que é apenas estudar qualitativamente o processo da formação da birrefringência em termos da reorientação dos dipolos moleculares provocada pela absorção de luz.

Vamos considerar que inicialmente todas as moléculas de cromóforos, dipolos moleculares, distribuem-se igualmente no volume do filme nas direções $x, y$ e $z$, e estão todos na configuração isomérica trans (configuração isomérica mais estável). Admitimos então que a luz de excitação está polarizada na direção $x$. Dessa forma, apenas as moléculas cujos dipolos possuem orientação $x$ poderão absorver luz. A absorção de luz levam as moléculas para a configuração instável cis. As moléculas em cis podem retornar para trans absorvendo luz ou por efeito da temperatura, como representado na Fig. 2.2

A primeira aproximação que vamos fazer é quanto à população cis. A quantidade de moléculas no estado excitado, cis, corresponde a uma fração muito pequena de moléculas relativamente às populações no estado trans. Além disso, o tempo de vida das moléculas em cis é muito pequeno devido aos efeitos da luz e da temperatura [3]. Dessa forma, vamos desprezar a população cis. As moléculas orientadas na direção $x, P(x)$, e somente elas, absorvem a luz. As moléculas orientadas nas direções $y$, denominada $P(y)$, e $z$, denominada $P(z)$, não absorvem luz por possuírem momento de dipolo perpendicular à polarização do laser. A Fig. 4.13 apresenta esquematicamente essas possibilidades. 


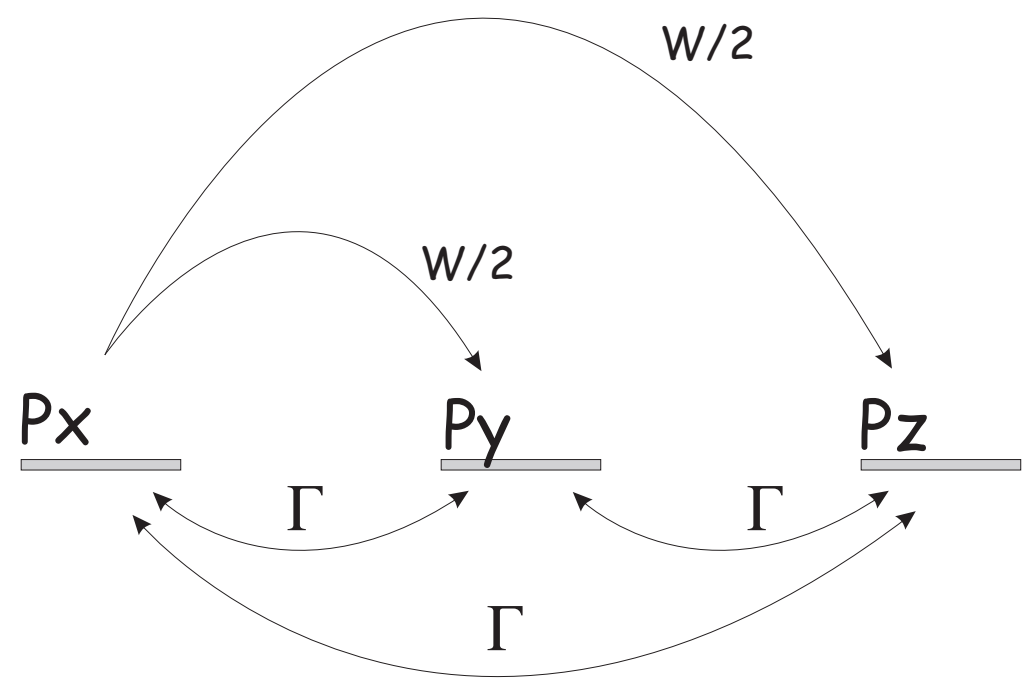

Figura 4.13: Possiveis orientações para os dipolos moleculares.

A taxa com que as moléculas em $P_{x}$ absorvem luz é $W$. Dessa forma, $P_{x}$ transfere sua população para $P_{y}$ e $P_{z}$ numa taxa de $W / 2$. A taxa $\Gamma$ é introduzida para considerar a possibilidade de mudança de orientação molecular devido à temperatura. Nesse trabalho, não analisamos a dependência desta taxa com a temperatura, dessa forma $\Gamma$ é constante. Esse sistema leva ao seguinte conjunto de equações para as populações:

$$
\begin{gathered}
\frac{d P_{x}(t)}{d t}=-2\left(\frac{W}{2}\right) P_{x}(t)-2 \Gamma P_{x}(t)+\Gamma P_{y}(t)+\Gamma P_{z}(t) \\
\frac{d P_{y}(t)}{d t}=+\frac{W}{2} P_{x}(t)+\Gamma P_{x}(t)+\Gamma P_{z}(t)-2 \Gamma P_{y}(t) \\
\frac{d P_{z}(t)}{d t}=+\frac{W}{2} P_{x}(t)+\Gamma P_{x}(t)+\Gamma P_{y}(t)-2 \Gamma P_{z}(t)
\end{gathered}
$$

A equação para a população $P_{z}$ é idêntica à população $P_{y}$, pois possuem taxas idênticas de aumento e diminuição da temperatura. Assim temos que

$$
P_{y}(t)=P_{z}(t)
$$

Em nossa dedução vamos precisar de $P_{x}$ e $P_{y}$, então vamos reescrever as equações para essas grandezas utilizando, $P_{y}(t)=P_{z}(t)$ : 


$$
\begin{gathered}
\frac{d P_{x}(t)}{d t}=-W P_{x}(t)-2 \Gamma P_{x}(t)+2 \Gamma P_{y}(t) \\
\frac{d P_{y}(t)}{d t}=+\frac{W}{2} P_{x}(t)+\Gamma P_{x}(t)-\Gamma P_{y}(t)
\end{gathered}
$$

Vamos utilizar o fato de que a soma das populações das moléculas nas orientações $x$, $y$ e $z$ é constante, $P_{T}$, para desacoplar as equações

$$
P_{x}(t)+P_{y}(t)+P_{z}(t)=P_{T}
$$

ou ainda, usando 4.5

$$
P_{y}=\frac{1}{2}\left[P_{T}-P_{x}(t)\right]
$$

Assim, as Eq4.6 torna-se

$$
\frac{d P_{x}(t)}{d t}+(W+3 \Gamma) P_{x}(t)=\Gamma P_{T}
$$

Uma equação ordinária de primeira ordem com coeficientes constantes. A solução dessa equação é:

$$
P_{x}(t)=\frac{\Gamma P_{T}}{(W+3 \Gamma)}+c e^{-(W+3 \Gamma) t}
$$

onde $c$ é uma constante. Para determinar o valor dessa constante impomos a condição de que no início as moléculas estão igualmente distribuídas nas três orientações possíveis:

$$
P_{x}(t=0)=P_{y}(t=0)=P_{z}(t=0)=P_{T} / 3
$$

Essa imposição mostra que a constante $c$ vale

$$
c=\frac{P_{T}}{3}-\frac{\Gamma P T}{(W+3 \Gamma)}
$$

e finalmente, a população $P_{x}$ evolue no tempo segundo:

$$
P_{x}(t)=\frac{\Gamma P_{T}}{(W+3 \Gamma)}+\left\{\frac{P_{T}}{3}-\frac{\Gamma P_{T}}{(W+3 \Gamma)}\right\} e^{-(W+3 \Gamma) t}
$$


Para obter a população $P_{y}$ em função do tempo, não precisamos resolver a Eq. 4.7 Basta novamente usar o fato da população total ser constante, Eq. 4.9 A equação para $P_{y}(t)$ fica:

$$
P_{y}(t)=\frac{P_{T}}{2}-\frac{1}{2}\left[\frac{\Gamma P_{T}}{(W+3 \Gamma)}+\left\{\frac{P_{T}}{3}-\frac{\Gamma P_{T}}{(W+3 \Gamma)}\right\} e^{-(W+3 \Gamma) t}\right]
$$

Dessa forma a diferença entre as populações orientadas nas direções $y$ e na direção $x$, evoluem da seguinte forma

$$
P_{y}(t)-P_{x}(t)=\frac{P_{T}}{2}-\frac{3}{2} \frac{\Gamma P_{T}}{(W+3 \Gamma)}+\left\{\frac{3}{2} \frac{\Gamma P_{T}}{(W+3 \Gamma)}-\frac{P_{T}}{2}\right\} e^{-(W+3 \Gamma) t}
$$

Nesse ponto, levantamos nossa hipótese. Consideramos que a birrefringência produzida é proporcional à diferença entre as populações $P_{y}$ e $P_{x}$. Dessa forma a birrefringência é expressa do seguinte modo:

$$
\Delta n \propto c_{1}+c_{2} e^{-(W+3 \Gamma) t}
$$

onde abreviamos os termos constantes da Eq. 4.16 por $c_{1}$ e $c_{2}$.

A primeira observação que pode ser feita é quanto à dependência exponencial com que cresce a diferença entre as populações. Esse comportamento é observado nas medidas de birrefringência, como pode ser visto nas Figs. 4.6 e 4.7 A Fig. 4.14 mostra a evolução no tempo das populações $P_{x}$ e $P_{y}$, bem como a diferença entre essas populações.

Observa-se que a população $P_{x}$ começa com o valor inicial de $1 / 3$ e decresce, enquanto a população $P_{y}$ parte da mesma população inicial e cresce (consideramos $P_{T}=1, W=10$ e $\Gamma=0,1$ para construir o gráfico). Esse comportamento para $P_{x}$ e $P_{y}$ já era esperado, uma vez que apenas as moléculas alinhadas na direção $x$ são excitadas. Dessa forma, a população $P_{x}$ deve ter seu valor máximo no início do processo. Nota-se também que a função para a diferença ente as populações cresce e tende à saturação, como ocorre nas medidas experimentais de birrefringência.

Outra observação importante que chegamos com esse modelo é quanto à dependência da birrefringência com a intensidade. Para isso, tomemos um tempo fixo, $t=\tau$, na Eq. 


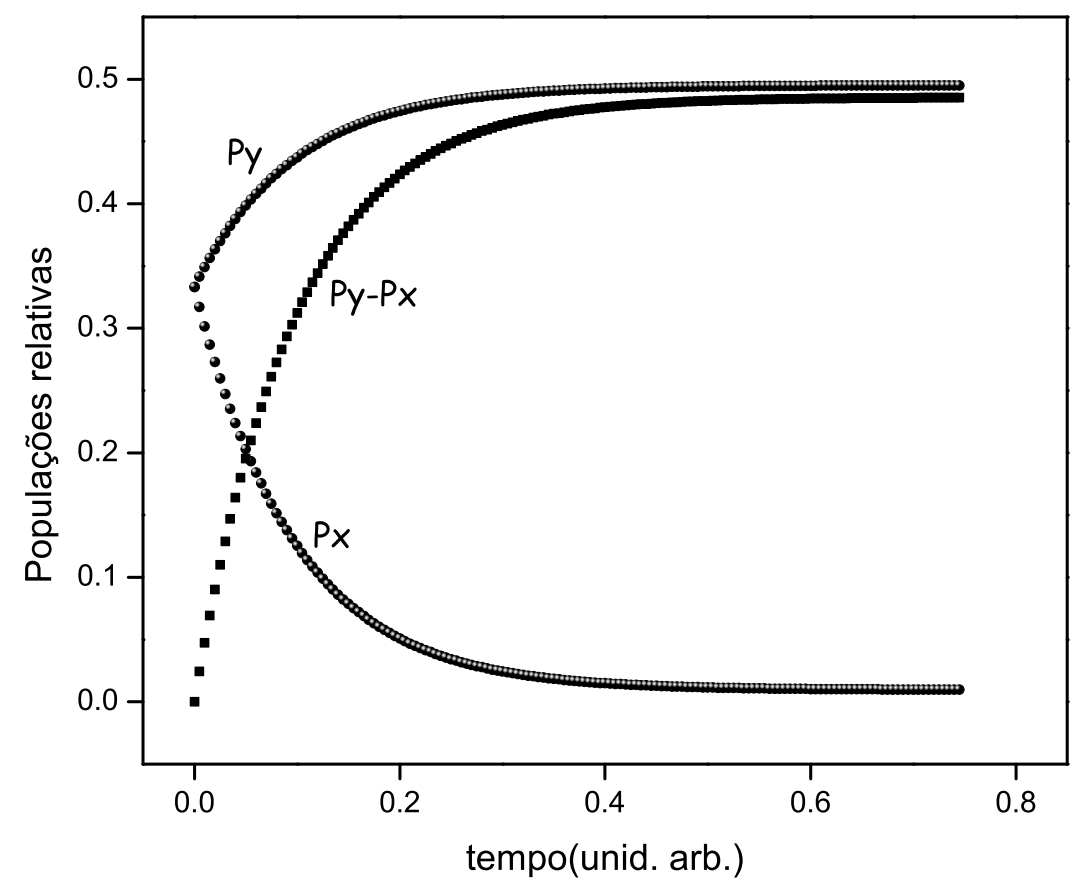

Figura 4.14: Resultado da simulação para a evolução temporal da birrefringência.

4.17 e expandimos para pequenos valores de $W \tau$. Assim $\left(e^{-W t} \approx 1-W t\right)$ e a Eq. 4.17 mostra que a magnitude da birrefringência gerada é proporcional a taxa de excitação $W$ :

$$
\Delta n \propto W
$$

Para efeitos lineares

$$
W=\frac{\sigma I}{h \nu}
$$

onde $I$ é a intensidade da luz. Assim, a diferença de população e, pela nossa hipótese, a birrefringência variam linearmente com a intensidade da luz.

$$
\Delta n \propto I
$$

Para o caso da excitação por dois fótons, a taxa de excitação segue a seguinte equação:

$$
W=\frac{\delta I^{2}}{(h \nu)^{2}}
$$


Assim, a birrefringência varia com o quadrado da intensidade da luz.

$$
\Delta n \propto I^{2}
$$

Esses fatos concordam com as observações experimentais apresentadas na Fig. 4.8 [60, 67].

\subsection{Conclusões}

Demonstramos a viabilidade da utilização da excitação por dois fótons para aplicações de armazenamento óptico utilizando compostos azo-aromáticos. Verificamos que apesar da magnitude do sinal da birrefringência induzido por dois fótons ser menor que a magnitude produzida utilizando excitação na região da ressonância linear do material, a birrefringência residual é maior no processo via dois fótons. Isto é, a birrefringência demora mais para se perder quando é gravada via absorção de dois fótons. Além disso, o objetivo principal do estudo foi atingido quando gravamos a birrefringência no interior do bloco de polímero. Essa técnica pode permitir a produção de dispositivos volumétricos de alta capacidade de armazenamento óptico de informação. O modelo para evolução temporal da birrefringência permitiu um entendimento qualitativo do processo de geração da birrefringência, em termos da reorganização orientacional produzida no fenômeno da foto-isomerização. 


\section{Capítulo 5}

\section{Controle coerente da taxa de foto-isomerização}

O objetivo desse capítulo é introduzir o leitor ao tema controle coerente, e apresentar o estudo que realizamos sobre controle coerente da taxa de foto-isomerização de moléculas azo-aromáticas. O método utilizado para induzir a birrefringência nos filmes poliméricos contendo as moléculas azo-aromáticas é a incidência de pulsos ultracurtos de luz laser polarizados sobre esses filmes. Através de um dispositivo de modelamento de pulsos que tem como componente principal um espelho deformável, foi possível alterar as fases das componentes espectrais do pulso ultracurto, e medir o efeito que essa manipulação produz na birrefringência induzida.

\subsection{Introdução ao controle coerente}

A preparação, evolução controlada e medida de um estado quântico específico são atividades fundamentais em Física. O estudo de novos estados da matéria e as perspectivas em Física quântica sobre o processamento de informações são exemplos importantes que requerem um bom entendimento do controle de sistemas quânticos. Desde o advento do laser, muitos cientistas têm estudado a capacidade de manipular seletivamente as transformações moleculares, através do controle do modo como a energia é transferida para o sistema.

O controle quântico pode ser utilizado para redirecionar uma determinada reação quí- 
mica ao longo de um determinado caminho [69, 70], ou operar precisamente uma operação lógica quântica [71]. Além disso, a técnica fornece um meio importante de investigar o comportamento dos sistemas quânticos.

Átomos simples, moléculas ou sistemas com graus de liberdade coletivos como sólidos, são exemplos de sistemas passíveis de controle quântico coerente. A ferramenta mais comum para realizar esse controle são os lasers. Pulsos ultracurtos de luz laser são muito versáteis para essa finalidade, pois possuem amplitudes e fases dependentes do tempo, passíveis de sintonização com as múltiplas freqüências eletrônicas e vibrações de átomos, moléculas e sólidos [72].

É possível controlar os graus de liberdade de um sistema direta ou indiretamente. Quando pulsos laser são utilizados para o controle de uma molécula, os campos eletromagnéticos podem causar excitações eletrônicas em um determinado sentido. Dependendo do acoplamento entre os elétrons e os núcleos, essas excitações podem ser transferidas para movimentos de vibração molecular ou de spin eletrônico ou nuclear. Lasers podem agir também diretamente controlando outros graus de liberdade, como vibrações moleculares de moléculas e de cristais, através de uma escolha apropriada do comprimento de onda. Muitos sistemas quânticos possuem uma rica estrutura espectral, e o estado que se procura atingir através do controle coerente tipicamente consta de uma superposição de muitos auto-estados. Dessa forma, campos ópticos de espectros largos freqüentemente são bem úteis. As diferentes componentes espectrais devem ser coerentes, pois a coerência da luz é mapeada na coerência quântica do sistema sobre controle. Progressos significativos na tecnologia de lasers alcançados na última década permitem a modelação de pulsos em nível de femtosegundo, com larga flexibilidade de comprimentos de onda.

Aplicando técnicas de manipulação de pulso é possível ajustar as fases e amplitudes das componentes espectrais de um pulso de luz com grande precisão. De um modo geral, o que se faz é decompor espacialmente o pulso em suas componentes espectrais através de uma rede de difração. As componentes, decompostas e separadas no espaço, atravessam um dispositivo que pode atuar sobre a luz, modificando sua fase e até mesmo a intensidade, dependendo do dispositivo utilizado.

Os dispositivos mais comuns para o ajuste das amplitudes e fases das componentes 
espectrais utilizam um conjunto de células de cristais líquidos controláveis [73]. Existem também os moduladores acusto-óptico e os "formatadores"por espelhos deformáveis. Em nosso trabalho, utilizamos um espelho deformável para modificar as fases das componentes espectrais dos pulsos. Com esse tipo de equipamento não é possível atuar nas amplitudes espectrais, pois não temos controle sobre o poder reflexivo do espelho.

\subsection{Controle coerente da absorção de dois fótons}

Para introduzir o conceito de controle coerente da absorção de dois fótons, vamos considerar parte do trabalho feito por Silberberg e Meshulach [74]. Considere a interação devida a absorção de dois fótons proveniente de um pulso luminoso ultracurto por átomos de Césio, Fig. 5.1. Podemos considerar o sistema como composto por dois níveis. Se a interação não é ressonante, isto é, não há transições reais em níveis intermediários, a probabilidade de esse pulso induzir a transição para um estado excitado, denominada $S_{2}$, é proporcional a:

$$
S_{2}=\left|E\left(\omega_{0}+\Omega\right) E\left(\omega_{0}-\Omega\right) d \Omega\right|^{2}
$$

ou ainda

$$
S_{2}=\left|\int A\left(\omega_{0}+\Omega\right) A\left(\omega_{0}-\Omega\right) e^{i\left[\Phi\left(\omega_{0}+\Omega\right)+\Phi\left(\omega_{0}-\Omega\right)\right]}\right|^{2} d \Omega
$$

onde $E(\omega)=A(\omega) e^{i \phi(\omega)}$ é a transformada de Fourier do campo $\mathcal{E}(t), A(\omega)$ é a função que indica as amplitudes de cada frequiência da luz e $\Phi(\omega)$ a fase de cada componente. Essa equação leva em conta todos os pares de fótons de freqüências $\omega_{1}$ e $\omega_{2}$ que possuem energia suficiente para promoverem a excitação, ou seja, $\omega_{1}+\omega_{2}=2 \omega_{0}$, com $\omega_{1}$ e $\omega_{2}$ pertencentes ao espectro dos pulsos incidentes, como ilustrado na Fig. [5.1] [74].

Desse modo, como todas as componentes de freqüência do pulso contribuem para a probabilidade de transição, podemos controlar a probabilidade de transição, esta pode ser controlada pela manipulação das componentes espectrais do pulso. 


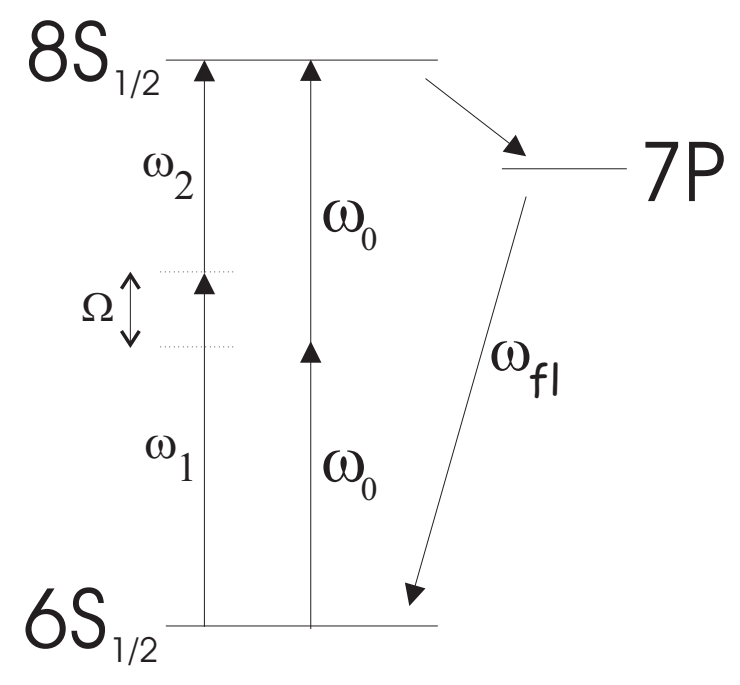

Figura 5.1: Transições dos átomos de Césio entre os níveis $6 S_{1 / 2}$ e $8 S_{1 / 2}$ devido à absorção de dois fótons. As transições ocorrem para todos os pares de fótons cujas freqüências $\omega_{1}$ e $\omega_{2}$ satisfaçam: $\omega_{1}+\omega_{2}=2 \omega_{0}$.

Para uma dada distribuição de amplitudes $A(\omega)$, temos que a probabilidade de absorção de dois fótons pelo sistema atômico, $S_{2}$, é maximizado para pulsos no limite de transformada, ou seja, pulsos que possuam o menor tempo de duração com $\Phi(\omega)=0$. Para pulsos com o mesmo espectro mas tendo uma distribuição de fase anti-simétrica em torno da freqüência da transição atômica $\omega_{0}$, isto é, $\Phi\left(\omega_{0}+\Omega\right)=-\Phi\left(\omega_{0}-\Omega\right)$, a probabilidade da transição por dois fótons independe das fases espectrais e é idêntica a de um pulso no limite de transformada. Isso é facilmente visto na Eq. 5.2

Uma maneira de demonstrar o controle coerente da transição por dois fótons é através da medida da fluorescência produzida pelo sistema atômico ao absorver radiação, que é uma medida direta da probabilidade de absorção de dois fótons, para diversas configurações de fase das componentes espectrais do pulso. As fases das componentes espectrais foram manipuladas, no trabalho de Silberberg et al., através de um modulador de cristal líquido. Os pulsos são separados espacialmente em suas componentes espectrais por uma grade de difração. Diferentes componentes espectrais incidem em diferentes posições do modulador de cristal líquido. Pequenas diferenças de índice de refração permitem defasar as componentes espectrais entre si. Após atravessar o modulador, os pulsos são reconstituídos por uma segunda rede de difração antes de serem direcionados para o experimento. 
Pela introdução de uma máscara de fase senoidal dada por $\Theta(\Omega)=\alpha \cos (\beta \Omega+\varphi)$, onde $\alpha$ e $\beta$ são respectivamente a amplitude e a freqüência da modulação, pode-se demostrar que uma distribuição espectral de fases anti-simétrica em torno da freqüência de transição $\omega_{0}$, isto é $\phi\left(\omega_{0}+\Omega\right)=-\phi\left(\omega_{0}-\Omega\right)$, produz uma probabilidade de transição independe da fase espectral, sendo idêntica a probabilidade produzida por pulsos no limite de transformada. Através da manipulação conveniente das amplitudes e freqüência da modulação introduzida ao pulso, foram produzidos os denominados pulsos escuros, pulsos que atravessam o sistema sem que ocorra interação com a matéria. Situações intermediárias entre a maximização e a minimização da interação entre os pulsos e o sistema atômico revelam a influência das fases e amplitudes espectrais na interação da luz com a matéria [75].

O experimento que propomos, assim como no experimento de Silberberg, tem como objetivo controlar a interação da luz com a matéria. O sistema estudado constitui-se de moléculas azo-aromáticas imersas em um filme polimérico que tem o poli-metil metacrilato (PMMA) como matriz. Em vez da fluorescência, usamos a medida da birrefringência para medir a probabilidade de isomerização provocada pela luz via absorção de dois fótons, cujas componentes espectrais foram manipuladas pela utilização de um espelho deformável. Os detalhes desse experimento são descritos a seguir.

\subsection{O sistema de produção e manipulação dos pulsos de luz}

O sistema gerador de pulsos ultracurtos (oscilador) é bombeado por um laser contínuo (5 W), operando no comprimento de onda $532 \mathrm{~nm}$. A Fig. 5.2 ilustra a disposição dos elementos ópticos no oscilador Kerr Lenns Modelocked, baseado num cristal de Ti:Safira.

O sistema pode operar produzindo luz laser contínua ou em forma de pulsos da ordem de 20 fs centrado em $800 \mathrm{~nm}$, com até $5 \mathrm{~nJ}$ de energia. A mudança entre esses dois modos de operação é realizada através de uma pequena perturbação no sistema que pode ser conseguida pela movimentação em um dos prismas. O cristal de Ti:Safira, além de atuar como meio de ganho, tem importância fundamental na produção dos pulsos pois 


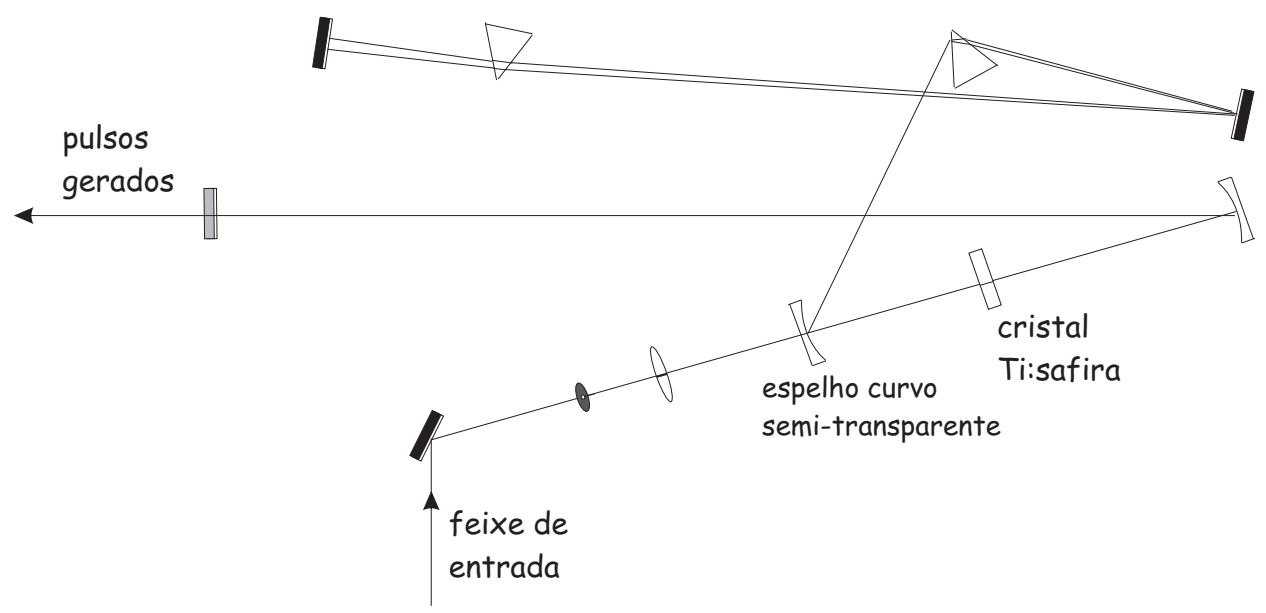

Figura 5.2: Diagrama do oscilador de Ti:Safira. O sistema de prismas tema função de compensar a dispersão causada pelos elementos ópticos e pelo ar.

atua como modulador de fases e de ganho/perda. Os prismas têm a função de compensar a dispersão das velocidades de grupo dos pulsos luminosos. A Fig. 5.3 mostra o espectro de emissão desse sistema operando em modo contínuo, CW, que emite banda espectral estreita, e o espectro no regime pulsado que apresenta uma banda espectral com largura com meia altura de aproximadamente $50 \mathrm{~nm}$, produzido quando o sistema opera em travamento de modos (modelocking-ML).

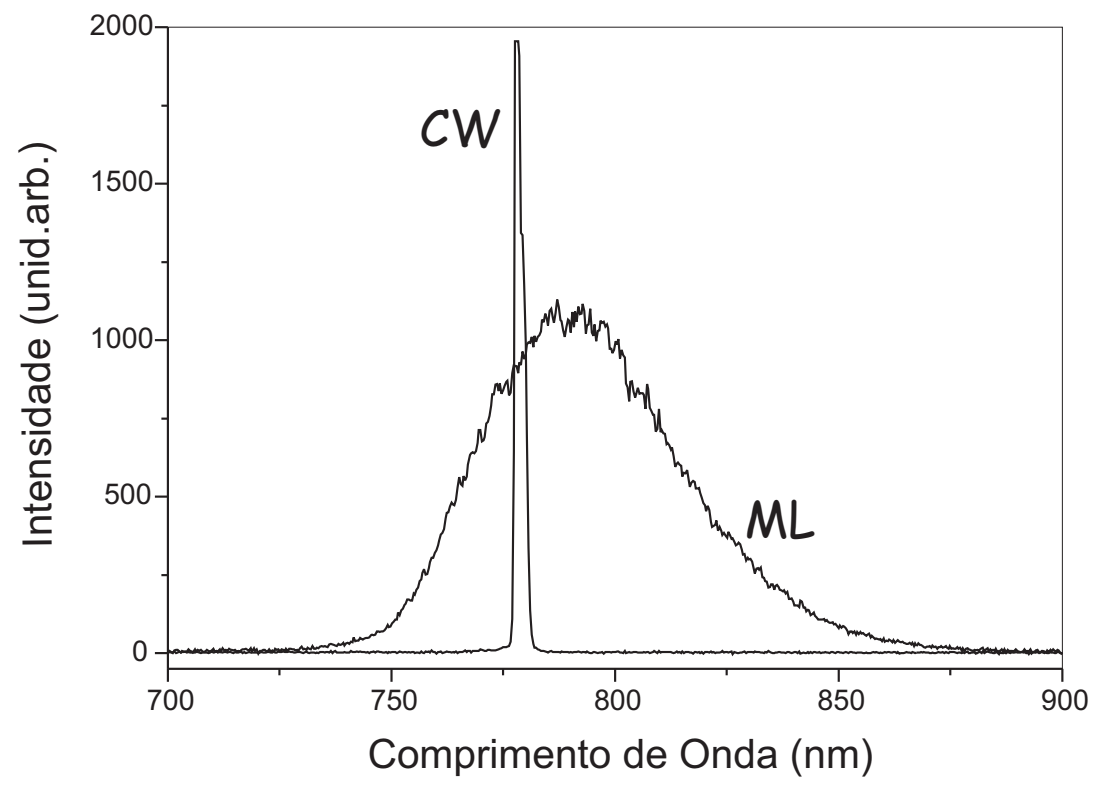

Figura 5.3: Oscilador de Ti:Safira operando em situação de acoplamento de modos, ML, que produz espectro largo e operando com luz contínua, $C W$, espectro estreito. 
O principal dispositivo no nosso sistema de formatação de pulsos é o espelho deformável. Esse espelho consiste de uma fina superfície refletora de ouro sobre um substrato de nitreto de Silício, que pode ser deformada pela ação de 19 atuadores localizados na parte posterior da superfície espelhada (OKO technologies). A Fig. 5.4 ilustra o sistema de formatação de pulsos. Um programa de computador permite controlar a forma imposta à superfície do espelho deformável através dos atuadores elétricos. As freqüências dos pulsos ultracurtos (provenientes do oscilador) são separadas pela rede de difração (600 linhas/mm) e seguem em direção a um espelho curvo que tem a função de focalizar as componentes espectrais do pulso na superfície do espelho deformável. A superfície do espelho altera as fases das componentes do espectro dos pulsos, introduzindo diferenças relativas nos caminhos ópticos das ondas luminosas. Em seguida, as componentes são refletidas novamente para o espelho curvo que as refletem para a mesma rede de difração para serem novamente compactadas, de forma a reconstituir o pulso.

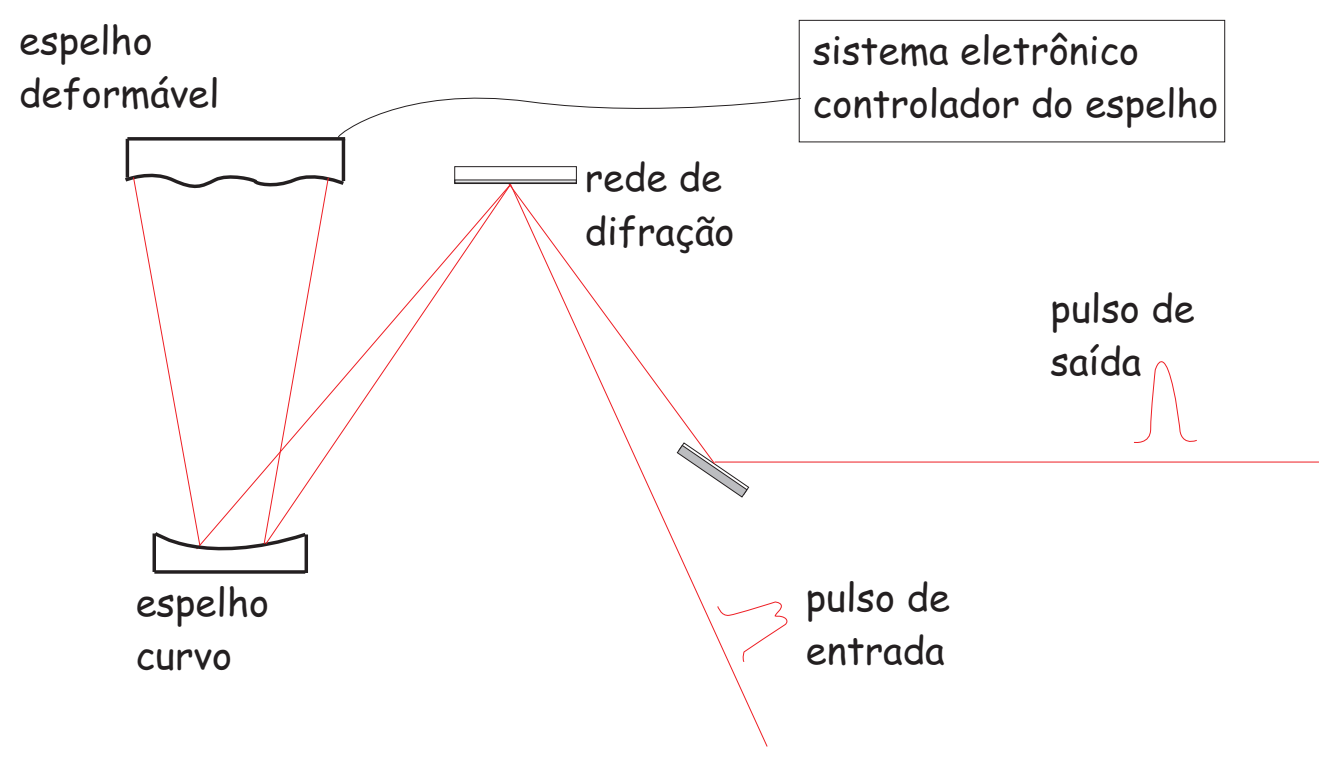

Figura 5.4: Sistema utilizado para manipulação das fases das componentes espectrais dos pulsos de luz. 


\section{$5.4 \quad \mathrm{O}$ experimento de controle}

Nesta seção, descrevemos o experimento de controle coerente da taxa de foto-isomerização. O método utilizado para a detecção dessa taxa de foto-isomerização consiste na produção e medida da birrefringência em um filme polimérico de PMMA contendo moléculas do azo-corante.

Antes de realizar o experimento de produção da birrefringência no filme polimérico, realizamos um experimento utilizando um cristal de KDP de $500 \mu m$, que produz intensa geração de segundo harmônico. Esse experimento tem a função de nos fornecer informação sobre a forma espectral dos pulsos de escrita.

\subsubsection{O experimento de controle coerente da produção de se- gundo harmônico}

Os pulsos criados no oscilador de Ti:Safira são manipulados no sistema com o espelho deformável, e incidem no cristal de KDP. Pulsos com o dobro da freqüência são produzidos nesse cristal, os quais são detectados por um foto-detector de silício. A Fig. 5.5 apresenta um diagrama esquemático do arranjo experimental.

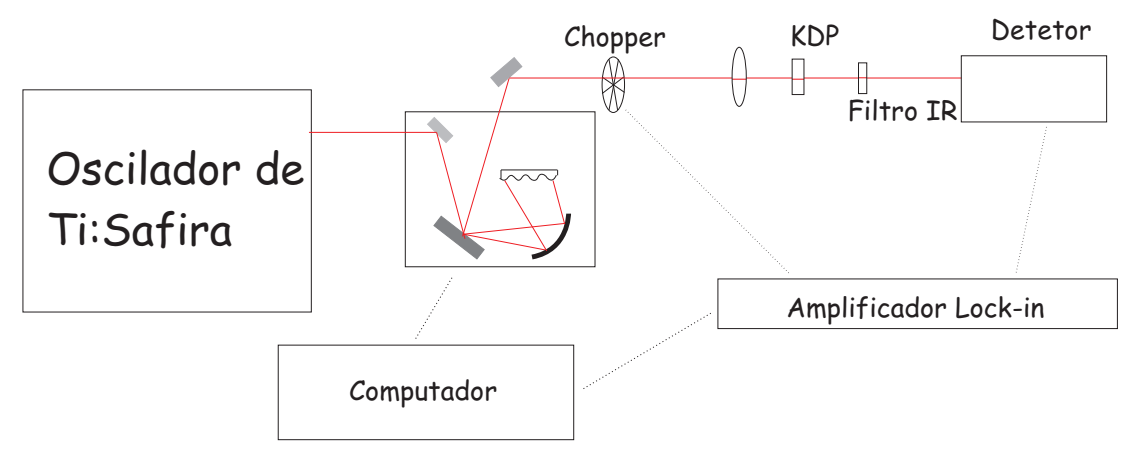

Figura 5.5: Esquema do aparato experimental utilizado para monitorar o efeito da forma espectral do pulso na geração de segundo harmônico.

Vamos utilizar a mesma equação apresentada na seção 5.2 para sistemas atômicos para descrever esse experimento com o cristal de KDP e com o sistema polimérico, a saber:

$$
S_{2}\left(2 \omega_{0}\right)=\left|E\left(\omega_{0}+\Omega\right) E\left(\omega_{0}-\Omega\right) d \Omega\right|^{2}
$$


A Eq. 5.1leva em conta todos os pares de fótons, com freqüências tal que $\omega_{1}+\omega_{2}=2 \omega_{0}$. Nessa equação, o campo elétrico tem a seguinte forma $E(\Omega)=A(\Omega) e^{[i \Phi(\Omega)]}$. Vamos assumir que a amplitude do campo seja proporcional a seguinte Gaussiana $A(\omega)=e^{(\Omega / \Delta \omega)^{2}}$, onde $\Delta \omega$ é a largura espectral do laser e $\Phi(\Omega)$ descreve a fase de cada componente espectral. Nesse experimento, vamos aplicar um padrão cossenoidal de tensão nos atuadores do espelho deformável, através de um sistema eletrônico controlado por computador, enquanto variamos a fase $\Phi(\Omega)$.

Resta ainda considerar o efeito da dispersão dos pulsos de luz que ocorre quando a luz atravessa qualquer meio. Para levar em consideração esse importante efeito, foi necessário introduzir o termo (1/2) $\beta \Omega^{2}$ na equação das componentes espectrais (chirp linear) [76]. Assim, a equação final para as fases das componentes espectrais fica:

$$
\Phi(\Omega)=\alpha \cos (\gamma \Omega-\phi)+\frac{1}{2} \beta \Omega^{2}
$$

onde $\alpha$ é a amplitude da modulação e depende da tensão aplicada aos atuadores do espelho, $\gamma=2 \pi N / \Delta \omega$ é o período da deformação e $\phi$ relaciona-se à posição da função cossenoidal imposta ao espelho. O chirp pode ser ajustado alterando-se a distância entre o espelho curvo e o espelho deformável. A equação final para descrever o processo torna-se

$$
S_{2}\left(2 \omega_{0}\right) \propto\left|\int_{-\infty}^{\infty} e^{-2(\Omega / \Delta \omega)^{2}+2 i \alpha \cos (\gamma \Omega) \cos \phi+\beta \Omega^{2}} d \Omega\right|^{2}
$$

Para $\beta=0$, a Eq. 5.5 prediz que variando $\delta$ entre 0 e $4 \pi$, quatro picos de mesma intensidade e igualmente espaçados devem ser observados. Na Fig. 5.6(h) apresentamos o gráfico obtido para a geração de segundo harmônico nesta condição.

Para realizar esse teste, inicialmente o espelho deformável foi colocado na posição plana. Para isto basta não aplicar nenhuma tensão nos atuadores do espelho. A seguir, ajustou-se a compressão do pulso através do ajuste da distância entre o espelho curvo e o espelho deformável, de forma a obter a máxima produção de segundo harmônico (400 nm). Esse procedimento tem como objetivo eliminar o efeito da dispersão do pulso, 
levando-o para uma situação próxima ao seu limite de transformada. O próximo passo é aplicar o padrão cossenoidal ao espelho, $\alpha \cos (\gamma \Omega-\phi)$. Essa tensão curva o espelho e modifica a configuração das fases do espectro dos pulsos afastando-os da situação de limite de transformada. Em seguida, reajustou-se levemente a compressão do pulso para novamente maximizar a produção de segundo harmônico. A tensão foi colocada em 100 $\mathrm{V}$, que corresponde a amplitude de $\alpha=0.6 \pi$. O período da modulação foi ajustado para $\gamma=40 f s$. Por fim, basta variar a posição do padrão cossenoidal aplicada à superfície do espelho variando a fase $\phi$, de 0 até $4 \pi$. Os gráficos de (a) a (e) na Fig. 5.6 mostram os sinais de intensidade de segundo harmônico obtidos nessa varredura de $\phi$, para duas posições onde o espelho curvo foi aproximado do espelho deformável (a e b), e para duas posições onde ele foi afastado do espelho deformável (d e e). Os gráficos de (f) a (g) na Fig. 5.6 mostram os resultados obtidos da simulação, Eq. 5.5 usando os seguintes valores para os parâmetros: $\alpha=1, \gamma=40$ e $\beta=-2200 f s^{2},-2000 f s^{2}, 0 f s^{2}, 2000 f s^{2}$ e $2200 f s^{2}$, respectivamente para as figuras de (f) a (j).
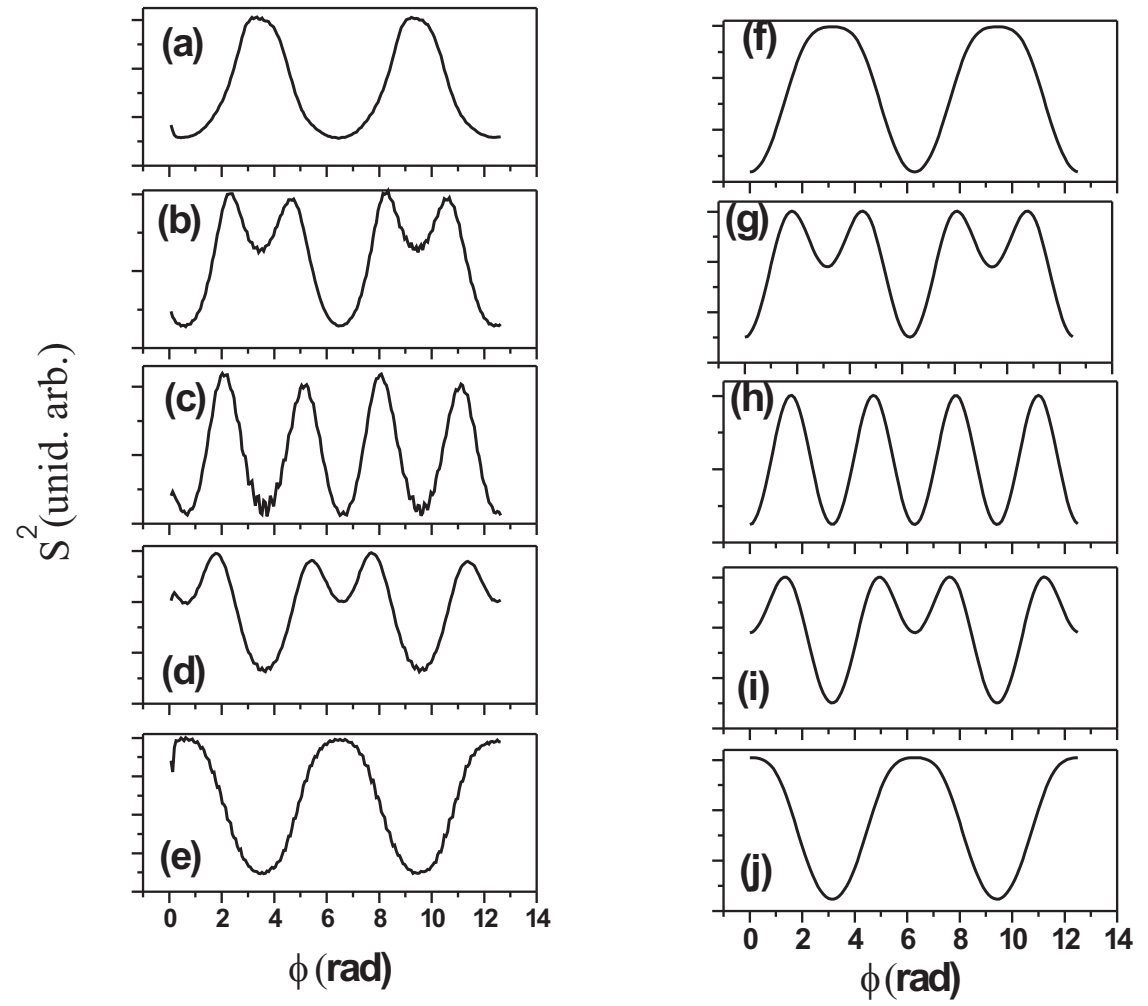

Figura 5.6: Sinal produzido pela geração de segundo harmônico pelo cristal de KDP em função das defasagens para vários valores de chirp. 


\subsubsection{O experimento de controle coerente da taxa de foto-isome- rização}

O método utilizado para produzir e medir a birrefringência nesse experimento é o mesmo utilizado e descrito no Capítulo 4. A amostra de filme polimérico utilizado nesse estudo também é a mesma utilizada no estudo da birrefringência via absorção de dois fótons, descrita naquele capítulo e constitui-se de um filme polimérico de PMMA contendo moléculas do cromóforo DR13. Os pulsos de luz, cujas componentes espectrais podem ser manipuladas pelo nosso sistema formatador de pulsos, constituem a luz de escrita, que tem a função de produzir a birrefringência. Um feixe fraco de luz vermelha proveniente de um laser He-Ne (632 nm) é utilizada para monitorar a birrefringência induzida no filme. O esquema ilustrando o aparato experimental é exposto na Fig. 5.7. É importante observar que o feixe de escrita é linearmente polarizado, e possui comprimento de onda em torno de $790 \mathrm{~nm}$. Assim o processo de indução da birrefringência ocorre via absorção de dois fótons.

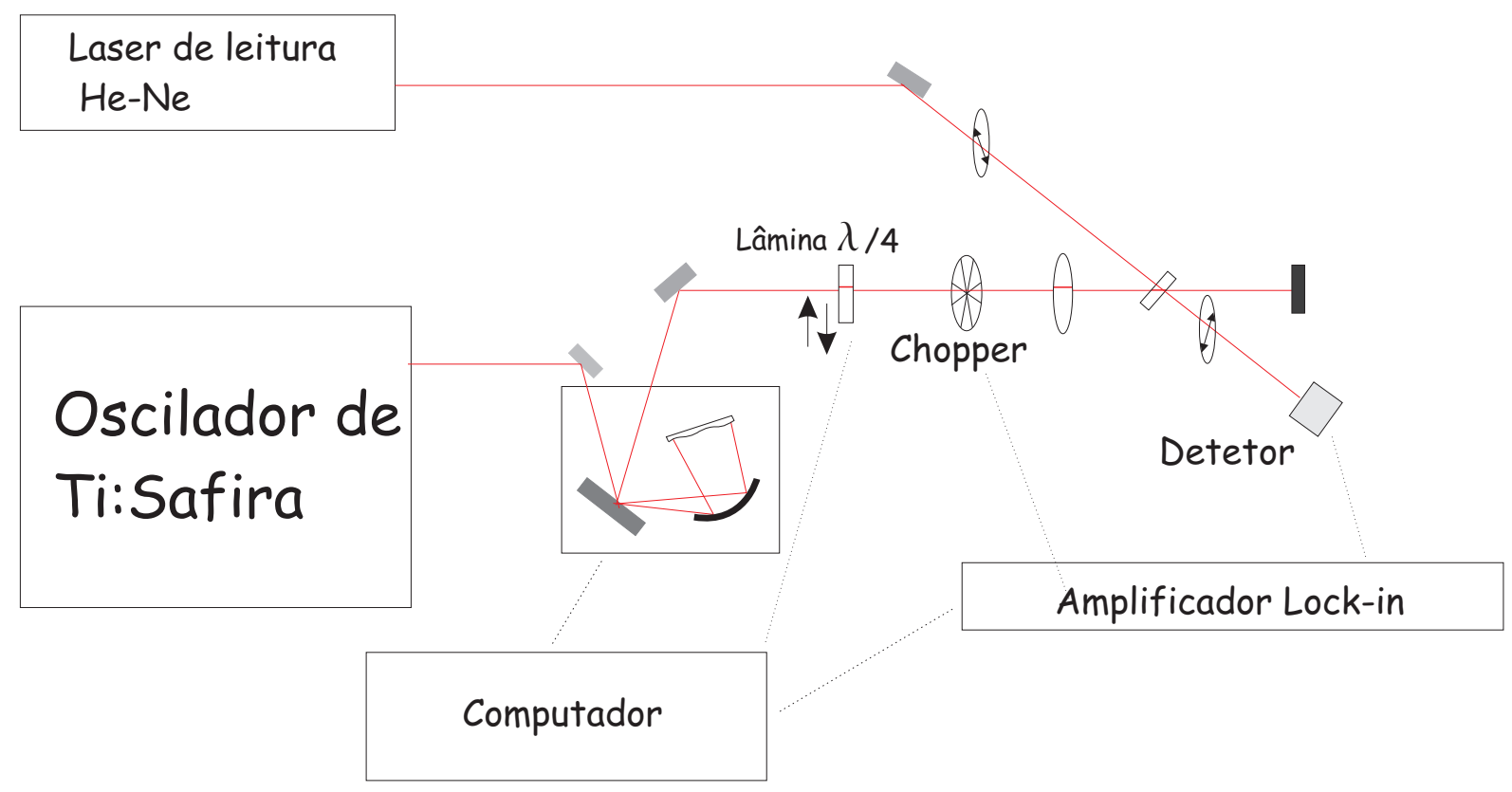

Figura 5.7: Esquema do aparato experimental para realizar o controle coerente da taxa de foto-isomerização.

Um programa de computador foi escrito para permitir que as seguintes tarefas sejam 
automaticamente executadas: aquisição do sinal proveniente do detector, movimentação da lâmina de quarto de onda para introduzi-la e retira-la da direção do laser de escrita e produção e deslocamento da função cosseno na superfície do espelho deformável. A seqüência das ações para a obtenção de uma medida é a seguinte:

Uma função cosseno é impressa no espelho deformável, e em seguida o laser de escrita é libertado para incidir na amostra durante 18 segundos. O sistema de detecção coleta o valor da tensão produzida pelo detector ao final desse intervalo de tempo. Em seguida, com a finalidade de apagar a birrefringência, a lâmina de quarto de onda é introduzida na frente do feixe de escrita, alterando sua polarização de linear para circular. A luz circularmente polarizada incide durante 2 minutos no filme, na mesma posição onde foi criada a anisotropia pelos pulsos de luz linearmente polarizados. Constatamos que esse intervalo de tempo é suficiente para eliminar toda birrefringência induzida. Após essa ação, a função no espelho é deslocada de $\pi / 10$ e todo o processo de criação da birrefringência, coleta do sinal e destruição da birrefringência é repetido.

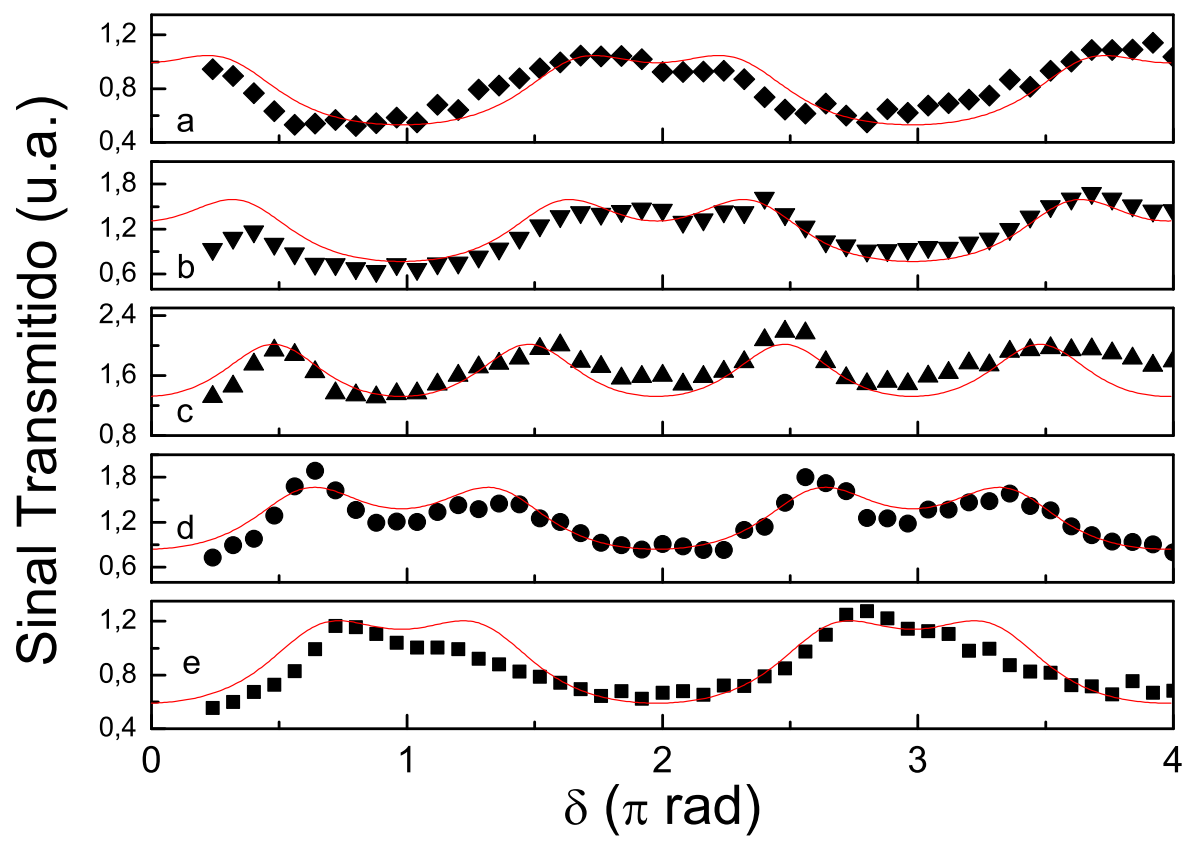

Figura 5.8: Controle do sinal de birrefrigência em função da fase para cinco posições diferentes do parâmetro $\beta$. a: $-2200 f s^{2}, b:-2000 f s^{2}, c: 0 f s^{2}, d: 2000 f s^{2}, e: 2200 f s^{2}$.

A Fig. 5.8 apresenta os resultados obtidos com a amostra de polímero contendo moléculas de DR13. As figuras apresentam os resultados dos experimentos para diferentes 
formas espectrais dos pulsos. Essas diferentes formas foram produzidas pela mudança da distância entre o espelho curvo e o espelho deformável (diferentes chirps). Como explicado no experimento com o KDP, a alteração de posição relativa entre esses espelhos alteram o chirp do pulso devido ao efeito da dispersão. Como pode ser visto, o sinal de armazenamento óptico apresenta múltiplos picos de diferentes formatos, dependendo do valor de $\beta$ que é o parâmetro associado ao chirp. Vamos utilizar novamente o termo devido ao chirp linear $\beta \Omega^{2}$ para levar em consideração o efeito de dispersão. A equação para as defasagens das componentes do espectro dos pulsos fica:

$$
\phi(\Omega)=\alpha \cos (\gamma \Omega+\delta)+\frac{1}{2} \beta \Omega^{2}
$$

onde $\alpha$ e a amplitude de fase, $\gamma$ é a modulação no domínio da frequência $\left[2 \pi N /\left(\Omega_{\max }-\right.\right.$ $\left.\Omega_{\min }\right)$ ] com período $N$ e $\delta$ é a posição do padrão cossenoidal imposto ao espelho em relação à posição inicial do padrão. Introduzindo essa função $\phi(\Omega)$ na Eq. [5.2, que fornece a probabilidade de excitação por dois fótons:

$$
S_{2}\left(2 \omega_{0}\right) \propto\left|\int_{-\infty}^{\infty} e^{-2(\Omega / \Delta \omega)^{2}+2 i \alpha \cos (\gamma \Omega) \cos \phi+\beta \Omega^{2}} d \Omega\right|^{2}
$$

Variando $\phi$ e considerando $\beta=0$, a Eq. 5.7 produz um gráfico com quatro picos simetricamente posicionados, representado pela linha contínua na Fig. 5.8 (c). Observa-se que esta simulação concorda com os dados experimentais que são representados pelos pontos na mesma figura. Os outros gráficos apresentados na Fig. 5.8 apresentam os dados experimentais (pontos) e os gráficos obtidos da integração da Eq. 5.5 para diferentes valores de chirp. Nota-se uma boa concordância entre os resultados experimentais e as simulações, além de uma boa semelhança com os resultados apresentados para o KDP, mostrados na Fig. [5.6 Esse fato reforça nossa interpretação para o experimento.

A Fig. 5.9 mostra um resultado típico de um experimento de armazenamento óptico induzido por dois fótons. As configurações escolhidas para esses ensaios foram de $\beta=0$ (chirp nulo) e defasagens $\delta: 5 \pi / 10$ que corresponde ao máximo de sinal gravado, $\pi$ mínimo e $7 \pi / 10$ para um nível se sinal intermediário. Antes de incidir o laser de escrita, não há 
transmissão da luz do laser de leitura (He-Ne) devido a orientação aleatória dos cromóforos no filme polimérico. Quando os pulsos de luz incidem no filme, Fig. 5.9, a luz do laser de leitura é detectada, e cresce rapidamente durante os 600 segundos subseqüentes. No instante $\mathrm{t}=600 \mathrm{~s}$, os pulsos de excitação (escrita) são bloqueados, e o sinal produzido pela birrefringência cai devido à desorientação espontânea que ocorre devido a temperatura. Após 1000 segundos, ainda temos cerca de $20 \%$ por cento do sinal chegando ao detector. O nível de birrefringência remanescente depende do tipo do material utilizado bem como do método de preparação. Em algumas aplicações, deseja-se que o nível de birrefringência residual permaneça alto após muito tempo (armazenamento óptico de informação).

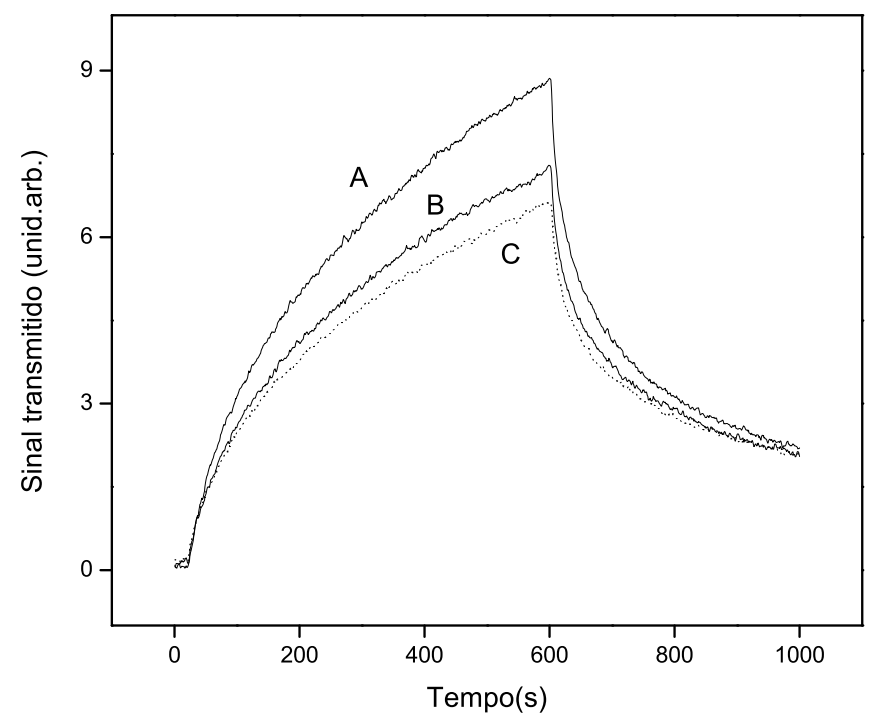

Figura 5.9: Curvas de armazenamento óptico de informação em filme de PMMA com DR13 para três valores distintos de $\delta: A: 5 \pi / 10, B: 7 \pi / 10$ e $C: \pi$.

Esses resultados mostram claramente que a manipulação das fases do espectro dos pulsos pode-se controlar as taxas de foto-isomerização que produzem a birrefringência em compostos azo-aromáticos.

\subsection{Conclusões}

Esses experimentos demonstram, pela primeira vez, o controle coerente da orientação molecular macroscópica de um cromóforo azo-aromático em uma matriz polimérica. A 
capacidade de manipulação das fases espectrais dos pulsos nos permite aumentar ou reduzir a birrefringência induzida, em concordância com os resultados teóricos. Esses resultados sugerem que o controle coerente pode ser importante para estudos sobre armazenamento óptico de informação. Temos, por exemplo, a possibilidade de realizar a gravação de diferentes níveis de birrefringência apenas através do controle das fases dos pulsos de luz. 


\section{Capítulo 6}

\section{Conclusões Gerais e Perspectivas}

Iniciemos as conclusões gerais acerca dos estudos dos processos não-lineares absorcivos em compostos azoaromáticos pelo Capítulo 3. Nesse capítulo, o principal resultado foi à demonstração experimental, através das medidas com método da varredura $Z$, do espectro de absorção de dois fótons. Os resultados mostraram que o espectro de absorção de dois fótons das moléculas de Salen com os metais é idêntico, dentro do erro experimental, ao espectro da molécula de Salen sem metal. Além disso, mostramos que esses espectros são idênticos ao espectro de absorção de dois fótons do azo-cromóforo DR1 (vermelho disperso 1). As moléculas de Salen possuem grupos idênticos ao DR1 em sua estrutura, e nossos experimentos não deixam dúvidas que os efeitos absorcivos lineares e não lineares devemse apenas a essa parte (DR1)da estrutura molecular das moléculas de Salen. Um outro ponto importante estudado nesse capítulo foi a interpretação dos resultados pela utilização do modelo de soma de estados (SOS) [21, 19, 23]. A aplicação desse modelo nos permitiu extrair dos resultados experimentais valores de momentos de dipolos de transição, os quais concordaram com valores obtidos por simulação computacional. Uma perspectiva que temos desse estudo é a possibilidade de aplicar os resultados da teoria SOS para explicar mecanismos de absorção de luz por moléculas de interesse para a fotônica. Esse entendimento também permitirá sugerir possíveis estruturas moleculares que maximizem os efeitos absorcivos do material.

O Capítulo 4 refere-se a estudos de armazenamento óptico de informação em material polimérico contendo moléculas azo-aromáticas via absorção de dois fótons. Nossos resul- 
tados demonstraram a possibilidade da utilização desse tipo de excitação para produção de birrefringência nesse tipo de material. Além disso, tivemos sucesso no processo de produção da birrefringência no interior de um bloco de material feito com moléculas azoaromáticas e polímero. Esse processo pode aumentar significativamente a capacidade de armazenamento de informação de um dispositivo óptico do tipo estudado. A informação pode ser gravada no volume do dispositivo em vez da tradicional gravação superficial. A parte final do capítulo descreve um modelo fenomenológico simples que propomos, com o intuito de ganhar um maior entendimento sobre a dinâmica de formação da birrefringência em termos dos movimentos moleculares oriundos do processo de foto-isomerização induzido por dois fótons. Esse modelo resultou em uma equação exponencial para a formação da birrefringência em função do tempo, em acordo com resultados encontrados na literatura e obtidos em nosso laboratório. No entanto, certos resultados exigem uma equação composta de duas exponenciais diferentes, caso não previsto e nosso modelo simplificado. Outro fato estudado com o modelo foi à dependência linear da birrefringência com a intensidade para excitações lineares, e a dependência quadrática para excitações não lineares com a intensidade quando a excitação é via absorção de dois fótons. Esses resultados concordam com os experimentos descritos nessa tese.

No Capítulo 5 é descrito o experimento de controle coerente da taxa de foto-isomerização. O ponto principal desse experimento é a demonstração da possibilidade de modificar a taxa de interação entre as moléculas azo-aromáticas e pulsos de luz de mesma intensidade, mas diferentes distribuições para as fases de suas componentes espectrais. Esse experimento demonstra que técnicas de controle coerente podem ser utilizadas para aplicações de armazenamento óptico, sendo possível maximizar a interação entre a luz e as moléculas azo-aromáticas apenas atuando sobre as fases das componentes do espectro dos pulsos. Na interpretação dos resultados tivemos sucesso na aplicação do modelo baseado no modelo do Silberberg [74], que foi desenvolvido para o caso de controle coerente da absorção de luz por sistemas atômicos. Através da inclusão de um termo que leva em consideração o chirp do pulso ultracurto no modelo [76], fomos capazes de obter uma equação teórica que produz resultados bem próximos dos obtidos no experimento. 


\section{Referências Bibliográficas}

[1] P. A. Franken, G. Weinreich, C. W. Peters, and A. E. Hill. Generation of optical harmonics. Physical Review Letters, 7(4):118-119, 1961.

[2] Paras N. Prasad and David J. Introduction to nonlinear optical effects in molecules and polymers. John wiley \& Sons, Inc., 1991.

[3] H. Rau. Azo compounds in Photochromism Molecules and Systems. H. Durr and H. Bouas-Laurent, eds., 1990.

[4] Z. Sekkat, J. Wood, and W. Knoll. Reorientation mechanism of azobenzenes within the trans-double-right-arrow-cis photoisomerization. Journal Of Physical Chemistry, 99(47):17226-17234, November 1995.

[5] W. Knoll Z. Sekkat. Photoreactive Organic Thin Films. Academic Press, USA, 2002.

[6] S. Xie, A. Natansohn, and P. Rochon. Recent developments in aromatic azo polymers research. Chemistry Of Materials, 5(4):403-411, April 1993.

[7] A. Dhanabalan, D. S. Dos Santos, C. R. Mendonca, L. Misoguti, D. T. Balogh, J. A. Giacometti, S. C. Zilio, and O. N. Oliveira. Optical storage in mixed langmuirblodgett (lb) films of disperse red-19 isophorone polyurethane and cadmium stearate. Langmuir, 15(13):4560-4564, June 1999.

[8] Ubaldo Martins das Neves; David Sotero dos Santos Junior; José Alberto Giacometti; Sergio Carlos Zílio; Lino Misoguti; Débora Terezia Balogh; Osvaldo Novais de Oliveira Junior; Cleber Renato Mendonça. Optical storage properties in cast films of an azopolymer. Materials Research, vol.6, no.3:p.409-414, 2003.

[9] Y. L. Wu, A. Natansohn, and P. Rochon. Photoinduced birefringence and surface relief gratings in polyurethane elastomers with azobenzene chromophore in the hard segment. Macromolecules, 37(16):6090-6095, August 2004.

[10] F. Lagugne-Labarthet, T. Buffeteau, and C. Sourisseau. Inscription of holographic gratings using circularly polarized light: influence of the optical set-up on the birefringence and surface relief grating properties. Applied Physics B-Lasers And Optics, 74(2):129-137, February 2002. 
[11] J. Borghetti, V. Derycke, S. Lenfant, P. Chenevier, A. Filoramo, M. Goffman, D. Vuillaume, and J. P. Bourgoin. Optoelectronic switch and memory devices based on polymer-functionalized carbon nanotube transistors. Advanced Materials, 18(19):2535-2540, October 2006.

[12] Walter David Jackson. Classical eletrodynamics, Second Edition. John Wiley \& Sons, New York, Chichester, Brisbane and Singapore, 1975.

[13] M. Göppert-Mayer. Elementray actions with two quantum leaps. Ann. Physik, 9:273, 1931.

[14] W. Kaiser and C. G. B. Garrett. 2-photon excitation in caf2 - eu2+. Physical Review Letters, 7(6):229-231, 1961.

[15] E. M. Evleth and W. L. Peticolas. 2-photon capture cross sections of pyrene + benzpyrene from scf-mo calculations. Journal Of Chemical Physics, 41(5):1400-1407, 1964.

[16] Peticola.WL. Multiphoton spectroscopy. Annual Review Of Physical Chemistry, 18:233-260, 1967.

[17] H. P. Trommsdorff B. Dick, R. M. Hochstrasser. Ressonante molecular optics Nonlinear Optical Properties of Organic Molecules and Crystals, Vol. 2, D. S. Chemla and J. Zyss, Eds.,. New York: Academic, 1987.

[18] E. Zojer, D. Beljonne, T. Kogej, H. Vogel, S. R. Marder, J. W. Perry, and J. L. Bredas. Tuning the two-photon absorption response of quadrupolar organic molecules. Journal Of Chemical Physics, 116(9):3646-3658, March 2002.

[19] B. J. Orr and J. F. Ward. Perturbation theory of non-linear optical polarization of an isolated system. Molecular Physics, 20(3):513-526, 1971.

[20] S. Mukamel and H. X. Wang. Nonlinear optical-response of conjugated polymers - electron-hole anharmonic-oscillator picture. Physical Review Letters, 69(1):65-68, July 1992.

[21] J. F. Ward. Calculation of nonlinear optical susceptibilities using diagrammatic perturbation theory. Reviews Of Modern Physics, 37(1):1-18, 1965.

[22] C. W. Dirk, L. T. Cheng, and M. G. Kuzyk. A simplified 3-level model describing the molecular 3rd-order nonlinear optical susceptibility. International Journal Of Quantum Chemistry, 43(1):27-36, July 1992.

[23] R. R. Birge and B. M. Pierce. Theoretical-analysis of the 2-photon properties of linear polyenes and the visual chromophores. Journal Of Chemical Physics, 70(1):165-178, 1979. 
[24] T. Kogej, D. Beljonne, F. Meyers, J. W. Perry, S. R. Marder, and J. L. Bredas. Mechanisms for enhancement of two-photon absorption in donor-acceptor conjugated chromophores. Chemical Physics Letters, 298(1-3):1-6, December 1998.

[25] K. Kamada, K. Ohta, I. Yoichiro, and K. Kondo. Two-photon absorption properties of symmetric substituted diacetylene: drastic enhancement of the cross section near the one-photon absorption peak. Chemical Physics Letters, 372(3-4):386-393, April 2003.

[26] L. De Boni, D. L. Silva, U. M. Neves, K. Feng, M. Meador, X. R. Bu, L. Misoguti, and C. R. Mendonca. Two- and three-photon excited fluorescence in y-shaped molecules. Chemical Physics Letters, 402(4-6):474-478, February 2005.

[27] J. D. Bhawalkar, G. S. He, and P. N. Prasad. Nonlinear multiphoton processes in organic and polymeric materials. Reports On Progress In Physics, 59(9):1041-1070, September 1996.

[28] P. D. Maker and R. W. Terhune. Study of optical effects due to an induced polarization third order in electric field strength. Physical Review, 137(3A):A801-A818, 1965.

[29] H. Rau, G. Greiner, G. Gauglitz, and H. Meier. Photochemical quantum yields in the a ( + h-upsilon)-reversible $\mathrm{b}(+\mathrm{h}$-upsilon,delta) system when only the spectrum of a is known. Journal Of Physical Chemistry, 94(17):6523-6524, August 1990.

[30] Z. Sekkat and W. Knoll. Creation of second-order nonlinear-optical effects by photoisomerization of polar azo dyes in polymeric films - theoretical-study of steady-state and transient properties. Journal Of The Optical Society Of America B-Optical Physics, 12(10):1855-1867, October 1995.

[31] L. De Boni, L. Misoguti, S. C. Zilio, and C. R. Mendonca. Degenerate two-photon absorption spectra in azoaromatic compounds. Chemphyschem, 6(6):1121-1125, June 2005.

[32] W. Denk, J. H. Strickler, and W. W. Webb. 2-photon laser scanning fluorescence microscopy. Science, 248(4951):73-76, April 1990.

[33] K. S. Samkoe and D. T. Cramb. Application of an ex ovo chicken chorioallantoic membrane model for two-photon excitation photodynamic therapy of age-related macular degeneration. Journal Of Biomedical Optics, 8(3):410-417, July 2003.

[34] M. Drobizhev, N. S. Makarov, Y. Stepanenko, and A. Rebane. Near-infrared twophoton absorption in phthalocyanines: Enhancement of lowest gerade-gerade transition by symmetrical electron-accepting substitution. Journal Of Chemical Physics, 124(22):224701, June 2006. 
[35] B. J. Coe, M. Samoc, A. Samoc, L. Y. Zhu, Y. P. Yi, and Z. G. Shuai. Two-photon absorption properties of iron(ii) and ruthenium(ii) trischelate complexes of 2,2 ': 4,4 ": 4 ',4 "'-quaterpyridinium ligands. Journal Of Physical Chemistry A, 111(3):472478, January 2007.

[36] A. M. McDonagh, M. G. Humphrey, M. Samoc, and B. Luther-Davies. Organometallic complexes for nonlinear optics. 17. synthesis, third-order optical nonlinearities and two-photon absorption cross section of an alkynylruthenium dendrimer. Organometallics, 18(25):5195-5197, December 1999.

[37] S. K. Hurst, M. P. Cifuentes, and M. G. Humphrey. A rapid convergent approach to organometallic dendrimers: Sterically controlled dendron synthesis. Organometallics, 21(12):2353-2355, June 2002.

[38] A. A. Andrade, N. M. B. Neto, L. Misoguti, L. De Boni, S. C. Zilio, and C. R. Mendonca. Two-photon absorption investigation in reduced and oxidized cytochrome c solutions. Chemical Physics Letters, 390(4-6):506-510, June 2004.

[39] F. E. Hernandez, A. Marcano, Y. Alvarado, A. Biondi, and H. Maillotte. Measurement of nonlinear refraction index and two-photon absorption in a novel organometallic compound. Optics Communications, 152(1-3):77-82, June 1998.

[40] L. Dyers, S. Y. Que, D. VanDerveer, and X. R. Bu. Synthesis and structures of new salen complexes with bulky groups. Inorganica Chimica Acta, 359(1):197-203, January 2006.

[41] A. A. Said, M. Sheikbahae, D. J. Hagan, T. H. Wei, J. Wang, J. Young, and E. W. Vanstryland. Determination of bound-electronic and free-carrier nonlinearities in znse, gaas, cdte, and znte. Journal Of The Optical Society Of America B-Optical Physics, 9(3):405-414, March 1992.

[42] T. D. Krauss and F. W. Wise. Femtosecond measurement of nonlinear absorption and refraction in cds, znse, and zns. Applied Physics Letters, 65(14):1739-1741, October 1994.

[43] H. Ma, A. S. L. Gomes, and C. B. Dearaujo. Trapping-states contributions to the optical nonlinearity of cd(s,se)-doped glasses. Journal Of The Optical Society Of America B-Optical Physics, 9(12):2230-2233, December 1992.

[44] R. Rangelrojo, T. Kosa, E. Hajto, P. J. S. Ewen, A. E. Owen, A. K. Kar, and B. S. Wherrett. Near-infrared optical nonlinearities in amorphous chalcogenides. Optics Communications, 109(1-2):145-150, June 1994.

[45] A. A. Said, C. Wamsley, D. J. Hagan, E. W. Vanstryland, B. A. Reinhardt, P. Roderer, and A. G. Dillard. 3rd-order and 5th-order optical nonlinearities in organic materials. Chemical Physics Letters, 228(6):646-650, October 1994. 
[46] T. H. Wei, D. J. Hagan, M. J. Sence, E. W. Vanstryland, J. W. Perry, and D. R. Coulter. Direct measurements of nonlinear absorption and refraction in solutions of phthalocyanines. Applied Physics B-Photophysics And Laser Chemistry, 54(1):46-51, January 1992.

[47] M. Sheikbahae, A. A. Said, and E. W. Vanstryland. High-sensitivity, single-beam n2 measurements. Optics Letters, 14(17):955-957, September 1989.

[48] M. Sheikbahae, A. A. Said, T. H. Wei, D. J. Hagan, and E. W. Vanstryland. Sensitive measurement of optical nonlinearities using a single beam. Ieee Journal Of Quantum Electronics, 26(4):760-769, April 1990.

[49] K. Kamada, K. Matsunaga, A. Yoshino, and K. Ohta. Two-photon-absorptioninduced accumulated thermal effect on femtosecond z-scan experiments studied with time-resolved thermal-lens spectrometry and its simulation. Journal Of The Optical Society Of America B-Optical Physics, 20(3):529-537, March 2003.

[50] P. Audebert, K. Kamada, K. Matsunaga, and K. Ohta. The third-order nlo properties of d-pi-a molecules with changing a primary amino group into pyrrole. Chemical Physics Letters, 367(1-2):62-71, January 2003.

[51] R.L. Sutherland. Handbook of Nonlinear Optics. 1996.

[52] P. N. Day, K. A. Nguyen, and R. Pachter. Tddft study of one- and two-photon absorption properties: Donor-pi-acceptor chromophores. Journal Of Physical Chemistry B, 109(5):1803-1814, February 2005.

[53] HyperChem Professional Release 5.1, A Molecular Visualization and Simulation Software Package. Hypercube Inc., Gainesville, Florida, 2000.

[54] Ira N. Levine. Quantum Chemistry. Prentice Hall, New Jersey, 1991.

[55] A. Natansohn, P. Rochon, J. Gosselin, and S. Xie. Azo polymers for reversible optical storage .1. poly[4'-[[2-(acryloyloxy)ethyl]ethylamino]-4-nitroazobenzene]. Macromolecules, 25(8):2268-2273, April 1992.

[56] A. Natansohn and P. Rochon. Photoinduced motions in azo-containing polymers. Chemical Reviews, 102(11):4139-4175, November 2002.

[57] Y. Enami, C. T. Derose, D. Mathine, C. Loychik, C. Greenlee, R. A. Norwood, T. D. Kim, J. Luo, Y. Tian, A. K. Y. Jen, and N. Peyghambarian. Hybrid polymer/solgel waveguide modulators with exceptionally large electro-optic coefficients. Nature Photonics, 1(3):180-185, March 2007.

[58] F. Weigert. Verh.Phys. Ges., 21:485, 1919. 
[59] F. F. Dall'Agnol, O. N. Oliveira, and J. A. Giacometti. Influence from the free volume on the photoinduced birefringence in azocompound-containing polymers. Macromolecules, 39(14):4914-4919, July 2006.

[60] S. W. Magennis, F. S. Mackay, A. C. Jones, K. M. Tait, and P. J. Sadler. Two-photoninduced photoisomerization of an azo dye. Chemistry Of Materials, 17(8):2059-2062, April 2005.

[61] Z. Sekkat, H. Ishitobi, and S. Kawata. Two-photon isomerization and orientation of photoisomers in thin films of polymer. Optics Communications, 222(1-6):269-276, July 2003.

[62] Z. Sekkat. Isomeric orientation by two-photon excitation: a theoretical study. Optics Communications, 229(1-6):291-303, January 2004.

[63] G. Xu, J. H. Si, X. C. Liu, Q. G. Yang, P. X. Ye, Z. Li, and Y. Q. Shen. Comparison of the temperature dependence of optical poling between guest-host and side-chain polymer films. Journal Of Applied Physics, 85(2):681-685, January 1999.

[64] X. Meng, A. Natansohn, and P. Rochon. Azo polymers for reversible optical storage. 11 poly4,4'-(1-methylethylidene)bisphenylene 3-[4-(4-nitrophenylazo)Phenyl]-3aza-pentanedioate. Journal Of Polymer Science Part B-Polymer Physics, 34(8):14611466, June 1996.

[65] A. Dhanabalan, C. R. Mendonca, D. T. Balogh, L. Misoguti, C. J. L. Constantino, J. A. Giacometti, S. C. Zilio, and O. N. Oliveira. Storage studies of langmuir-blodgett (lb) films of methacrylate copolymers derivatized with disperse red-13. Macromolecules, 32(16):5277-5284, August 1999.

[66] J. H. Si, K. Kitaoka, T. Mitsuyu, P. X. Ye, and K. Hirao. Thermosetting enhancement of the light-induced polar orientation stability of molecules in polymers. Journal Of Applied Physics, 85(12):8018-8022, June 1999.

[67] M. R. Cardoso, U. M. Neves, L. Misoguti, Z. H. Ye, X. R. Bu, and C. R. Mendonca. One- and two-photon induced birefringence in salen dye cast films. Optical Materials, 28(8-9):1118-1122, June 2006.

[68] D. Hore, A. Natansohn, and P. Rochon. Irradiance and temperature dependence of photoinduced orientation in two azobenzene-based polymers. Canadian Journal Of Chemistry-Revue Canadienne De Chimie, 76(11):1648-1653, November 1998.

[69] S. A. Rice. Active control of molecular dynamics: Coherence versus chaos. Journal Of Statistical Physics, 101(1-2):187-212, October 2000.

[70] A. H. Zewail. Femtochemistry: Ultrafast dynamics of the chemical bond. Word Scientific, Singapore, 1994. 
[71] D. Psaltis. Coherent optical information systems. Science, 298(5597):1359-1363, November 2002.

[72] Marcus Motzkus Herschel Rabitz, Regina de Vivie-Riedle and Karl Kompa. Whither the future of controlling quantum phenomena? Science, 288:824-828, 2000.

[73] A. M. Weiner, D. E. Leaird, J. S. Patel, and J. R. Wullert. Programmable femtosecond pulse shaping by use of a multielement liquid-crystal phase modulator. Optics Letters, 15(6):326-328, March 1990.

[74] Y. Silberberg and D Meshulach. Coherent quantum control of two-photon transitions by a femtosecond laser pulse. Nature, 396(6708):239-242, November 1998.

[75] D. Meshulach and Y. Silberberg. Coherent quantum control of multiphoton transitions by shaped ultrashort optical pulses. Physical Review A, 60(2):1287-1292, August 1999.

[76] V. V. Lozovoy, I. Pastirk, K. A. Walowicz, and M. Dantus. Multiphoton intrapulse interference. ii. control of two- and three-photon laser induced fluorescence with shaped pulses. Journal Of Chemical Physics, 118(7):3187-3196, February 2003. 